\title{
The Cerebrospinal Fluid in Severe Pain Conditions
}

Clinical, Pharmacological and Proteomic Aspects

\section{Emmanuel Bäckryd}

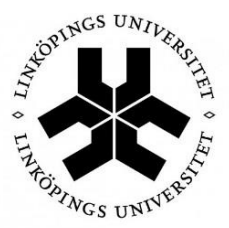

Linköping University

FACULTY OF HEALTH SCIENCES

Department of Medical and Health Sciences

Faculty of Health Sciences, Linköping University

SE-581 83 Linköping, Sweden

Linköping 2015 
The cover photo was downloaded from Pixabay - Free Images, https://pixabay.com

ISBN 978-91-7519-032-7

ISSN 0345-0082

Printed by LiU-Tryck, Linköping, Sweden, 2015

Copyright () 2015 Emmanuel Bäckryd 
TO THE MEMORY OF

VILGOT BÄCKRYD

* 2 JUNE $2012 \dagger$ 

The sciences have two extremes which meet. The first is the pure natural ignorance in which all men find themselves at birth. The other extreme is that reached by great intellects, who, having run through all that men can know, find they know nothing, and come back again to that same ignorance from which they set out. But this is a learned ignorance which is conscious of itself.

Blaise Pascal (1623-1662)

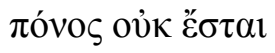

Revelation 21:4 



\section{Abstract}

The treatment of both cancer pain and non-cancer chronic pain is still suboptimal. The overall aim of this $\mathrm{PhD}$ thesis was to conduct translational pain research at the interface between clinical pain medicine and the field of human proteomics, using the practice of intrathecal analgesia at our institution as a starting point. Hence, the cerebrospinal fluid (CSF) is at the centre of the present dissertation, both as a target for infusing analgesics (Papers I and II - clinical and pharmacological aspects) and as an important biofluid for human biomarker studies (Papers III and IV - proteomic aspects). In Paper I, 28 cases of intrathecal analgesia in cancer patients were prospectively followed. Movement-evoked breakthrough pain remained a major clinical problem throughout the study month despite otherwise successful intrathecal analgesia (defined as good control of spontaneous resting pain paralleled by a marked decrease of concomitant systemic opioid doses). This study therefore illustrates the importance of considering not only spontaneous resting pain but also movement-evoked breakthrough pain.

In Paper II, an expert-based algorithm for trialing the intrathecal analgesic ziconotide by bolus injections was evaluated in an open-label study of 23 patients with chronic neuropathic pain. We found few responders $(13 \%)$ according to the strict criteria of the algorithm, but ziconotide bolus injection trialing seems feasible. The predictive power of ziconotide bolus trialing remains unclear, and the pharmacological profile of ziconotide (with very slow tissue penetration due to high hydrophilicity) calls the rationale for ziconotide bolus trialing into question.

In Paper III, we found low levels of beta-endorphin in the CSF of chronic neuropathic pain patients $(n=15)$ compared to healthy controls $(n=19)$. We speculate that this might indicate dysfunctional top-down control of nociception. Substance P levels in the CSF did not differ by univariate statistics. In Paper IV, the CSF proteome of 11 patients with chronic neuropathic pain and 11 healthy controls was exploratively studied, combining gel-based proteomics with multivariate data analysis. After eliminating four proteins associated with age, 32 proteins were found to highly discriminate between groups. Among these, the seven proteins having the highest discriminatory power between patients and controls were: one isoform of angiotensinogen, two isoforms of alpha-1-antitrypsin, three isoforms of haptoglobin, and one isoform of pigment epithelium-derived factor. 
In conclusion, this $\mathrm{PhD}$ thesis demonstrates the fruitfulness of studying the CSF, both as a target for infusing analgesics and as a potential mirror of the neurobiological processes involved in pathological pain conditions. The thesis points to the need for more research into the mechanisms of different pain conditions, in order to hopefully achieve the vision of mechanism-based pain diagnoses.

Keywords: beta-endorphin; biomarkers; breakthrough pain; cancer pain; cerebrospinal fluid; intrathecal analgesia; multivariate data analysis; neuropathic pain; pain; proteomics; substance $\mathrm{P}$; ziconotide 


\section{List of Abbreviations}

$\mathrm{AE}$

AMPA

ANOVA

ATP

BBB

$\mathrm{BCB}$

BDNF

$\mathrm{BE}$

BTP

CGRP

CNS

CNTF

CSF

CPM

DAMP

DBP

DNIC

DRt

GABA

GCP

GDNF

GFAP
Adverse Event

$\alpha$-Amino-3-hydroxy-5-Methyl-4-isoxazolepropionic Acid

Analysis Of Variance

Adenosine Triphosphate

Blood-Brain Barrier

Blood-CSF Barrier

Brain-Derived Neurotrophic Factor

Beta-Endorphin

Breakthrough Pain

Calcitonin Gene-Related Peptide

Central Nervous System

Ciliary Neurotrophic Factor

Cerebrospinal Fluid

Conditioned Pain Modulation

Damage-Associated Molecular Patterns

Diastolic Blood Pressure

Diffuse Noxious Inhibitory Controls

Dorsal Reticular nucleus

$\gamma$-Aminobutyric Acid

Good Clinical Practice

Glial cell line-Derived Neurotrophic Factor

Glial Fibrillary Acidic Protein 
IASP International Association for the Study of Pain

ICD International Classification of Diseases

IT Intrathecal

ITA Intrathecal Analgesia

LTP Long Term Potentiation

MAP Mean Arterial Pressure

MEPI Movement-Evoked Pain Intensity

MVDA Multivariate Data Analysis

NFL Neurofilament protein Light subunit

NGF Nerve Growth Factor

NK1 Neurokinin 1

NMDA N-Methyl-D-Aspartate

NRS Numerical Rating Scale

NSE Neuron-Specific Enolase

OPLS-(DA) Orthogonal PLS - (Discriminant Analysis)

PAG Periaqueductal Grey

PC Principal Component

PCA Principal Component Analysis

PEDF Pigment Epithelium-Derived Factor

PGDS Prostaglandin-H2 D-isomerase

PGIC Patient Global Impression of Change

PLS Partial Least Squares projections to latent structures

POMC Pro-Opiomelanocortin

PPR Percentage Pain Reduction

PTM Post-Translational Modification

RAS Renin-Angiotensin System

RCT Randomized Controlled Trial

RVM Rostral Ventromedial Medulla

SAE Serious Adverse Event 
SBP

SCS

SOD

$\mathrm{SP}$

SPC

SRD

SRPI

SUSAR

VASPI

VIP

WHO
Systolic Blood Pressure

Spinal Cord Stimulation

Spot Optical Density

Substance P

Summary of Product Characteristics

Subnucleus Reticularis Dorsalis

Spontaneous Resting Pain Intensity

Suspected Unexpected Serious Adverse Reaction

Visual Analogue Scale Pain Intensity

Variable Influence on Projection

World Health Organization 


\section{List of Papers}

This thesis is based on the following studies, which will be referred to in the text by their Roman numerals:

Paper I: Bäckryd E, Larsson B. Movement-evoked breakthrough cancer pain despite intrathecal analgesia: a prospective series. Acta Anaesthesiol Scand 2011; 55:1139-46

Paper II: Bäckryd E, Sörensen J, Gerdle B. Ziconotide trialing by intrathecal bolus injections: an open-label non-randomized clinical trial in postoperative/posttraumatic neuropathic pain patients refractory to conventional treatment. Neuromodulation 2015; 18:404-413

Paper III: Bäckryd E, Ghafouri B, Larsson B, Gerdle B. Do low levels of beta-endorphin in the cerebrospinal fluid indicate defective top-down inhibition in patients with chronic neuropathic pain? A cross-sectional, comparative study. Pain Med 2014; 15:111-9

Paper IV: Bäckryd E, Ghafouri B, Carlsson AK, Olausson P, Gerdle B. Multivariate proteomic analysis of the cerebrospinal fluid of patients with peripheral neuropathic pain and healthy controls: a hypothesis-generating pilot study. J Pain Res 2015; 8:321-333

The papers have been reprinted with the permission of the copyright holders. 


\section{Contents}

$\begin{array}{lll}\text { Abstract } & \text { vii }\end{array}$

List of Abbreviations $\quad$ ix

List of Papers $\quad$ xiii

$\begin{array}{lll}\text { Contents } & \text { Xv }\end{array}$

Part I: Comprehensive Thesis Summary 1

1. Background 3

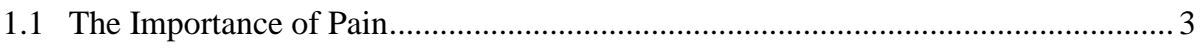

1.1.1 Pain is a Basic Human Experience …............................................................ 3

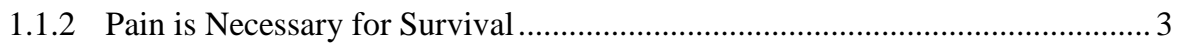

1.1.3 Pain is a Public Health Challenge ....................................................................... 4

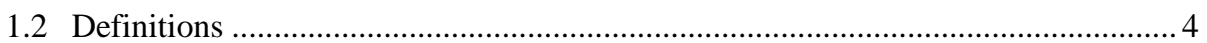

1.2.1 The Complexity of Pain Taxonomy …............................................................. 4

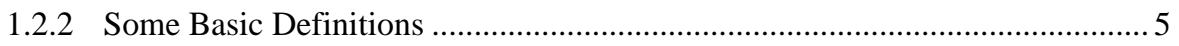

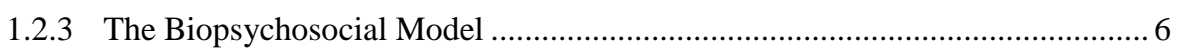

1.3 Spinal and Brainstem Mechanisms of Pathological Pain ........................................ 6

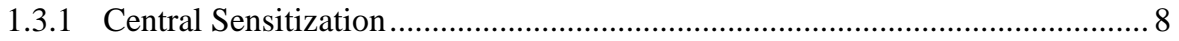

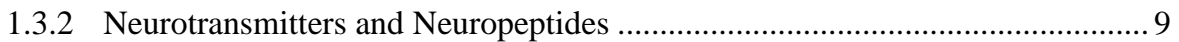

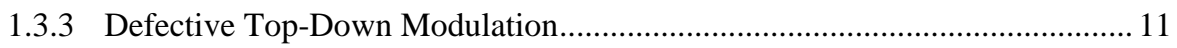

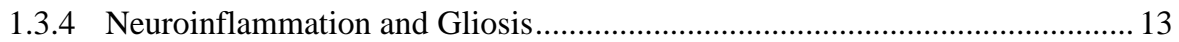

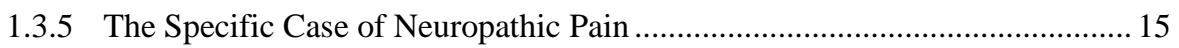

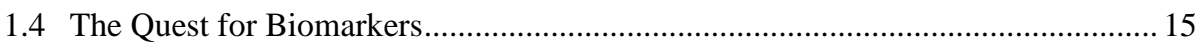

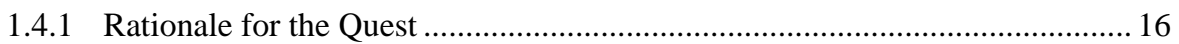

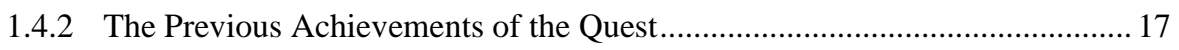

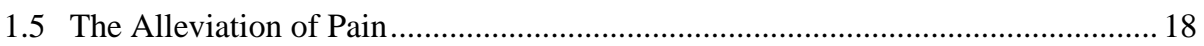

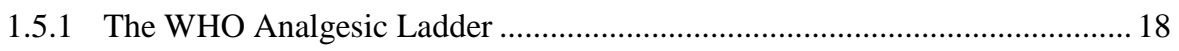




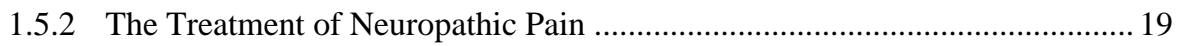

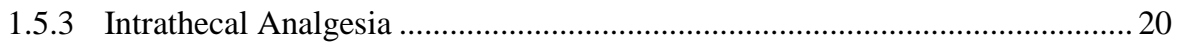

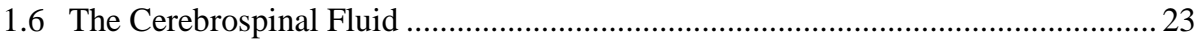

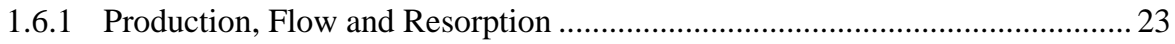

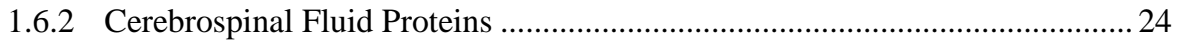

2. Aims 27

3. Methods 29

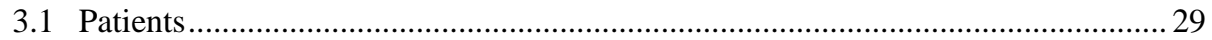

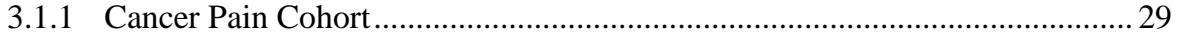

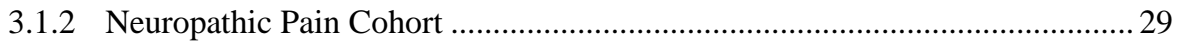

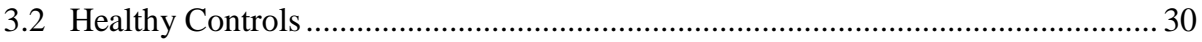

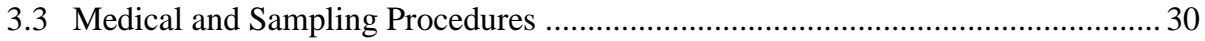

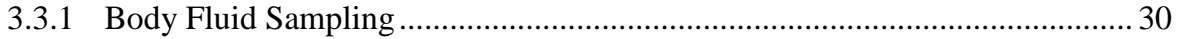

3.3.2 Ziconotide Trialing Procedure .......................................................................... 31

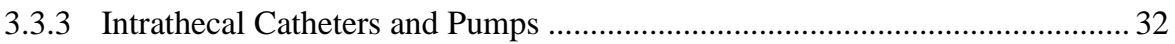

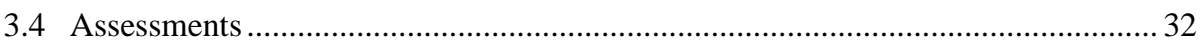

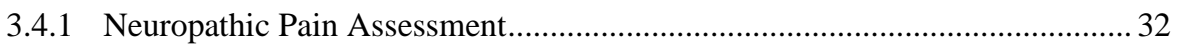

3.4.2 Numerical Rating Scale and Global Level of Satisfaction ............................. 33

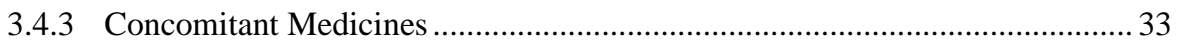

3.4.4 VASPI, Percentage Pain Reduction, and PGIC ............................................... 33

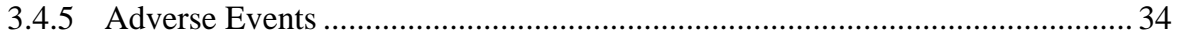

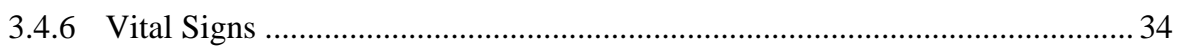

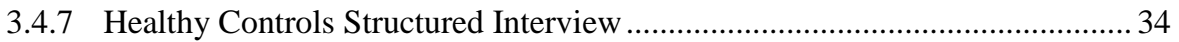

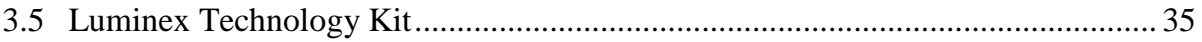

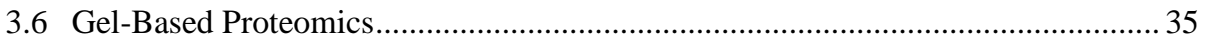

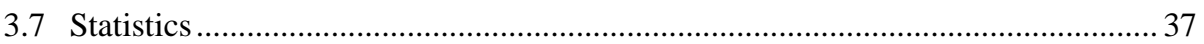

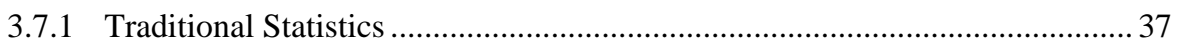

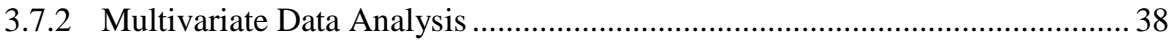

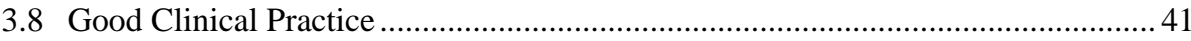

4. Results 43

4.1 Movement-Evoked Pain despite Intrathecal Analgesia ....................................... 43

4.2 Ziconotide Bolus Trialing Seems Feasible ............................................................. 44

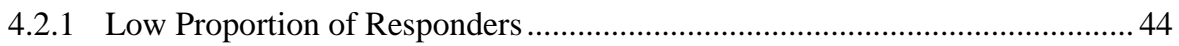

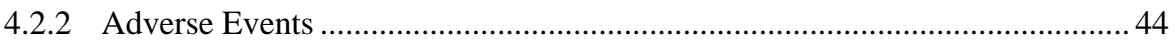

4.3 Low CSF Beta-Endorphins in Neuropathic Pain ................................................. 45 
4.4 A Neuropathic Pain Proteomic Fingerprint? .......................................................... 46

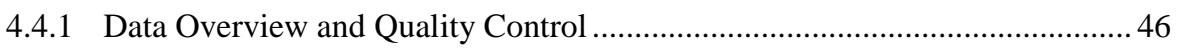

4.4.2 Regression of Class Discriminating Proteins .................................................... 47

4.4.3 The Seven Most Discriminating Proteins ............................................................. 48

4.4.4 Final Statistical Model Based on the Seven Proteins ....................................... 50

4.4.5 Pain Networks Interaction Analysis ................................................................ 50

5. Discussion 53

5.1 Improving the Treatment of Cancer Breakthrough Pain ....................................... 54

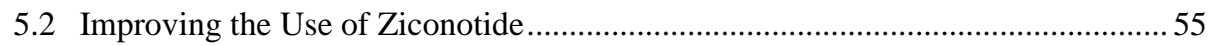

5.3 Improving the Understanding of Top-Down Control ...........................................57

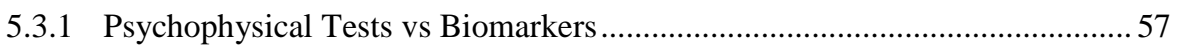

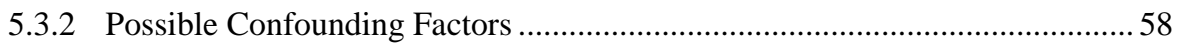

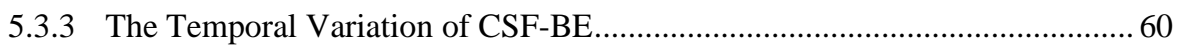

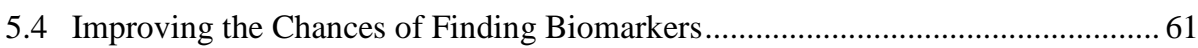

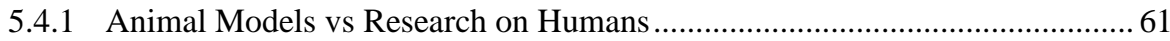

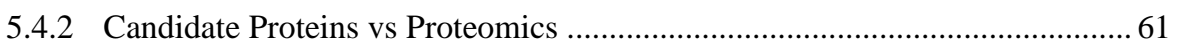

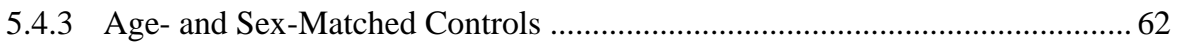

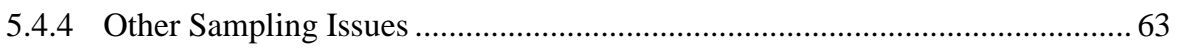

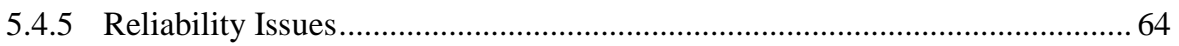

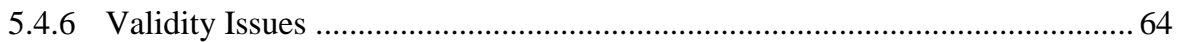

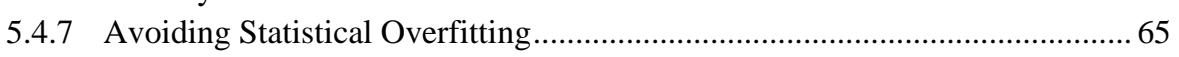

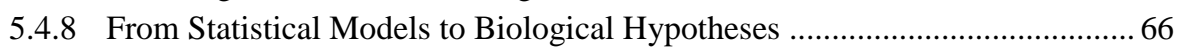

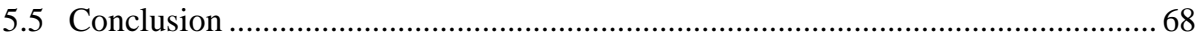

6. Future Prospects 69

$\begin{array}{ll}\text { 7. Summary in Swedish } & 71\end{array}$

$\begin{array}{ll}\text { 8. Acknowledgements } & 73\end{array}$

$\begin{array}{ll}\text { References } & 75\end{array}$

Part II: Appended Papers I-IV 95 



\section{Part I}

\section{Comprehensive Thesis Summary}





\title{
Background
}

\author{
I DEVOTED MYSELF TO STUDY
}

ECCLESIASTES 1:13

\subsection{The Importance of Pain}

\subsubsection{Pain is a Basic Human Experience}

The inescapability of pain is expressed in one of the oldest poems of world literature, the Book of Job: "Yet if I speak, my pain is not relieved; and if I refrain, it does not go away" (Job 16:6). Pain is one of the most basic experiences of human existence, and it is therefore of central importance in religions (e.g., Christianity and Buddhism) and philosophical systems of various sorts (e.g., hedonistic utilitarism and stoicism). The experience of pain is also intrinsically linked to the so-called "hard problem" of consciousness [42]: how can a network of $\sim 100$ billion neurons (amounting to $>10^{14}$ synapses) give rise to consciousness and subjective experience?

\subsubsection{Pain is Necessary for Survival}

The unpleasantness of pain must not make us forget its survival value. Congenital insensitivity to pain is a genetic disorder characterized by a substantial lack of nociceptive nerve fibres [111]. The deleterious consequences of such painlessness have been well described [160]. Likewise, a condition like leprosy (Hansen's disease) illustrates what leprosy specialist Paul Brand called the "nightmares of painlessness" [26]. Not being able to feel pain is a threat to the integrity and survival of the organism. Indeed, pain has been described as a homeostatic emotion [56], homeostasis being the process of maintaining an optimal balance in the physiological status of the body. Different interoceptive homeostatic systems monitor the state of the body and give rise to different "feelings", e.g. thirst, hunger, and temperature [55]. According to this view, pain is one of many homeostatic emotions and, as such, is necessary for survival. 


\subsubsection{Pain is a Public Health Challenge}

Almost three decades ago, the World Health Organization (WHO) three-step analgesic ladder for the treatment of cancer pain was presented [262,274]. Notwithstanding the claim that in about $90 \%$ of cases adequate analgesia can be achieved by following these WHO guidelines [97,216,274], the treatment of cancer pain remains suboptimal even in developed European countries [27]. Globally, the World Palliative Care Alliance has deemed that the lack of access to pain treatment is a public health emergency in many countries worldwide [14].

The prevalence of pain in hospitalized patients is high, varying between $44 \%$ and $78 \%$ in different studies [243]. In the general population, a large European epidemiological survey in 2006 concluded that $19 \%$ of adult Europeans have at least moderate chronic pain [28]. This finding concurs with other epidemiological studies, and chronic pain is therefore associated with very high socio-economic costs [90,102,114,221]. Hence, both acute, chronic and cancer pain are major health issues.

\subsection{Definitions}

\subsubsection{The Complexity of Pain Taxonomy}

The need of a pain classification system has long been recognized [22], and it has been argued that defective and inconsistent pain taxonomies hamper the development of pain research [241]. In an ideal classification system, as for instance the periodic table in chemistry, the different categories are mutually exclusive and exhaustive [156]. Although this ideal will barely ever be achievable in pain medicine, the International Association for the Study of Pain (IASP) has issued an extensive, expert-based multidimensional classification system with five axes: region of the body; organ system involved; temporal characteristics; intensity and time since onset; etiology [156]. This results in a five-digit code, reflecting the complexity and heterogeneity of pain conditions. In clinical practice, pain diagnoses according to the current version of the International Classification of Diseases (ICD-10) are often based on anatomical location, duration, and/or etiology. The need for a more mechanism-based classification system has long been recognized [267,269].

ICD-10 is currently being revised, and a task force from IASP has recently proposed a new and pragmatic classification of chronic pain for the upcoming ICD-11 [240]. The new ICD category "Chronic Pain" divides into seven groups: 1) chronic primary pain (including e.g. fibromyalgia and irritable bowel syndrome), 2) chronic cancer pain, 3) chronic postsurgical and posttraumatic pain, 4) chronic neuropathic pain, 5) chronic headache and orofacial pain, 6) chronic visceral pain, 7) chronic musculoskeletal pain. The authors acknowledge that this 
is not "a perfect solution", but it is nonetheless "the first systematic approach to implementing a classification of chronic pain in the ICD" [240].

\subsubsection{Some Basic Definitions}

IASP has defined pain as an unpleasant sensory and emotional experience associated with actual or potential tissue damage, or described in terms of such damage [241]. For the purpose of this thesis, the following definitions are important to keep in mind.

Chronic pain is arbitrarily defined as pain for more than three (or six) months [241]. Moreover, it is often stated that chronic pain is pain that extends beyond the expected period of healing, and that the pain is without purpose and a disease in its own right [173]. In this context, some authors use concepts like pathological pain, or maladaptive pain, or maldynia (Greek for "bad pain") [71,96]. It is sometimes stated that the vital importance of acute pain might be an important background to why pain can become chronic. According to this view, because the organism cannot afford missing potential life-threatening damage, the nervous system is heavily biased in favour of pain sensitivity [33].

Neuropathic pain is caused by a lesion or disease of the somatosensory nervous system [116]. It is often contrasted to nociceptive pain, which designates pain arising from actual or threatened damage to non-neural tissue. The prevalence of chronic pain with neuropathic characteristics in the general population has been estimated to $7 \%$ [25]. Both nociceptive and neuropathic pain are very heterogeneous categories. Inflammatory pain is often seen as a subtype of nociceptive pain [141] (nociceptors being sensitized by the process of inflammation), but some authors view inflammatory pain as a distinct subtype (see e.g. Wolf [267]; in that case, nociceptive pain is defined as an early warning mechanism that aims at protecting the organism from tissue damage.)

Future mechanism-based classifications will probably build on but also transcend the simple dichotomy between nociceptive and neuropathic pain. For instance, a group of pain physicians at the Swedish Quality Registry for Pain Rehabilitation has recently proposed that chronic widespread pain (also known as generalized pain) should be viewed as a specific pain type, with a postulated (presently to a large degree unknown) core pathophysiological mechanism [233]. When the pain is caused by a severe psychiatric disease, it is called psychogenic (this should be clearly differentiated from the psychological co-morbidities commonly associated with chronic pain) [233]. Sometimes, the mechanism underlying the pain of an individual patient remains idiopathic. Hence, five pain types emerge: nociceptive (including inflammatory), neuropathic, widespread, psychogenic, and idiopathic.

Cancer-related pain is a mixed entity, encompassing varying degrees of nociceptive and neuropathic pain [165,197]. The pain is caused either by the disease itself (cancer pain proper), or by its treatment [85]. Examples of the latter are persistent post-surgery pain, 
radiation-induced mucositis, and painful post-chemotherapy polyneuropathy. Tumour invasion into or compression of neural structures can cause neuropathic cancer pain [165]. In patients with cancer-related pain, a systematic review from 2012 found a prevalence of neuropathic pain of almost $40 \%$ (when patients with mixed pain were included) [18].

Breakthrough pain (BTP) was defined more than 20 years ago as "a transitory exacerbation of pain that occurs on a background of otherwise stable pain in a patient receiving chronic opioid therapy" [191]. However, there is still no unequivocal definition of BTP [106]. Often BTP is categorized into spontaneous BTP, end-of-dose failure, and incident pain (of which movement-evoked pain is a subtype) [85].

\subsubsection{The Biopsychosocial Model}

In a widely influential paper published in Science in 1977, psychiatrist George L. Engel introduced the biopsychosocial model of health and disease [23,78]. This model has had a great impact on pain medicine [88]. Engel argued that the prevailing biomedical model, with its reductive physicalism and mind-body dualism, had come to a dead end. Engel was not denying the overwhelming advances of modern medicine, but he contended that there was a need for a more holistic reframing of medical science. In his own words, the doctor "must weigh the relative contributions of social and psychological as well as of biological factors implicated in the patient's dysphoria and dysfunction as well as in his decision to accept or not accept patienthood and with it the responsibility to cooperate in his own health care".

Pain is not equivalent to nociception. Nociception is the neural process of encoding noxious stimuli; pain is a subjective experience. This experience is often described as having three different aspects: a sensory-discriminative aspect, an affective-motivational aspect, and a cognitive-evaluative aspect [153]. The biopsychosocial model fits well with such a multifaceted view of pain. For instance, it is widely recognized that affective factors like fear [264] and depression [140] are important to assess in pain patients, although the causal relationships are complex and difficult to disentangle [140,263]. The biopsychosocial model is consistent with the view of the brain as an active system that filters, selects and, through descending neural pathways, modulates nociceptive input from the periphery $[153,154,179,231]$. The biopsychosocial model is also consistent with the fact that pain is not just about an "inner" experience; pain is associated with behavioural changes, e.g. fearrelated avoidance of physical activity [264]. Basic knowledge in behavioural medicine [93] is therefore arguably of paramount importance for pain practitioners.

\subsection{Spinal and Brainstem Mechanisms of Pathological Pain}

While acknowledging the importance of a broad biopsychosocial perspective, this thesis focuses on the neurobiological and sensory-discriminative aspects of the pain experience, 


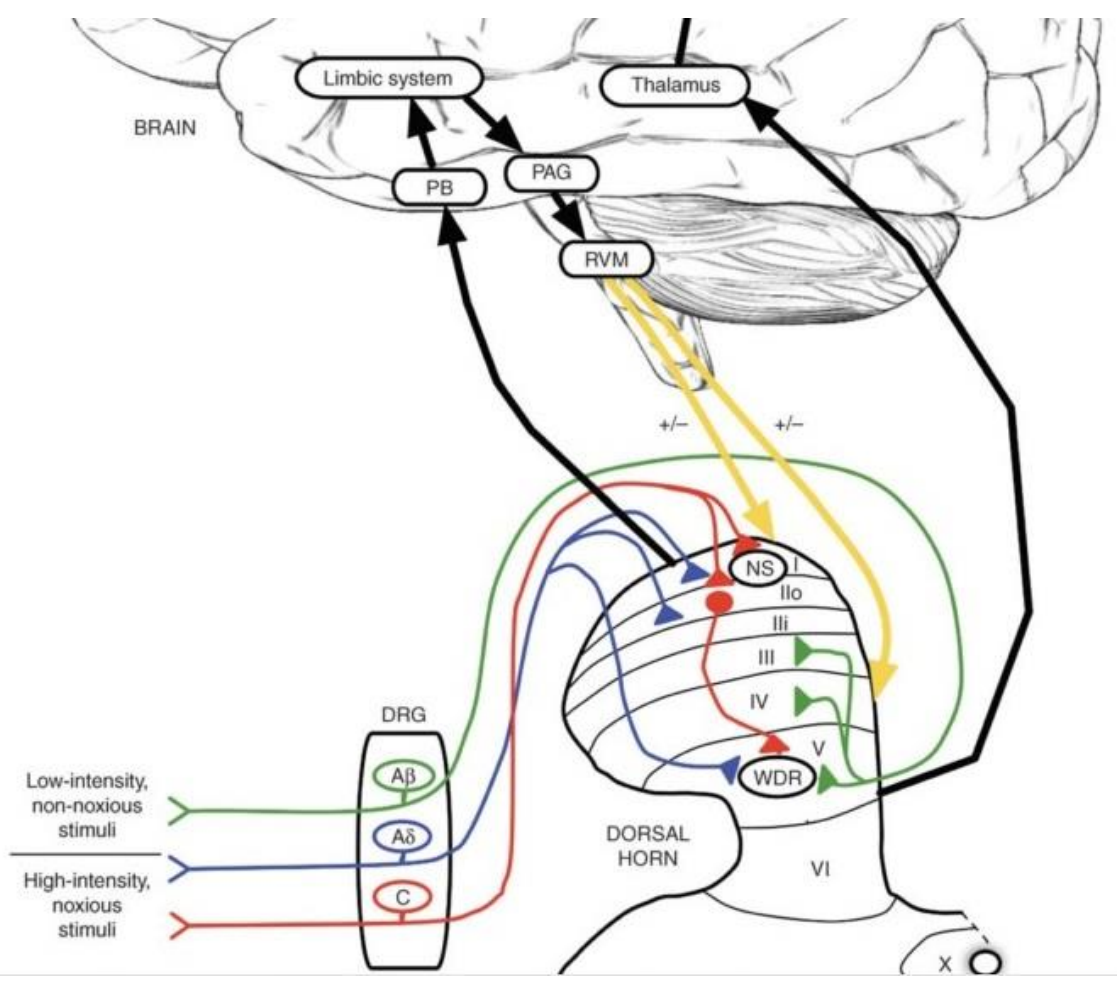

Figure 1 Basic pain-related neuroanatomy, with a focus on the spinal cord and brainstem. The figure is reproduced from [60] with permission. Nociceptive primary afferents (A $\delta$ and C fibres) synapse with second order neurons in Rexed lamina I, lamina II (=substantia gelatinosa), and (in the case of A $\delta$ fibres) lamina V. Nociceptive specific (NS) second order neurons are mainly found in the superficial dorsal horn (laminae I-II), whereas most wide dynamic range neurons (WDRs) are located deeper (lamina V). Second order neurons from the superficial dorsal horn innervate brainstem areas such as the parabrachial area (PB) and the periaqueductal grey (PAG), as well as medial nuclei of the thalamus (not shown); the interaction with the "limbic system" is symbolically depicted (the affective-motivational aspect of the pain experience). Lamina $\mathrm{V}$ second order neurones mainly project to the thalamus, and from there the somatosensory cortex is activated (the sensory-discriminative aspect). Descending pathways are depicted by downward arrows - see section 1.3.3 and Figure 3. 
with a special emphasis on the spinal cord and the cerebrospinal fluid (CSF). In the following, I will therefore review some key concepts concerning the neurobiological mechanisms of pathological pain at the spinal and brainstem level, with special reference to neuropathic pain. Basic knowledge of peripheral processes is assumed, the nociceptive input from primary afferents being transmitted to second order neurons in the dorsal horn of the spinal cord [60]. See Figure 1 for a schematic depiction of pain-related spinal and brainstem neuroanatomy.

\subsubsection{Central Sensitization}

Pioneering work of Clifford J. Woolf [266] led to the concept of central sensitization. Until the 1980s, pain processing was largely seen to work much like a telephone wire [268]. Today central sensitization, defined as a nociception-driven amplification of neural signalling within the central nervous system (CNS) leading to pain hypersensitivity, is generally acknowledged to be of physiological importance in chronic pain conditions [268]. Clinically, as seen in Figure 2, central sensitization is inferred indirectly from allodynia (pain due to a stimulus that does not normally provoke pain) or hyperalgesia (increased pain from a stimulus that normally provokes pain).

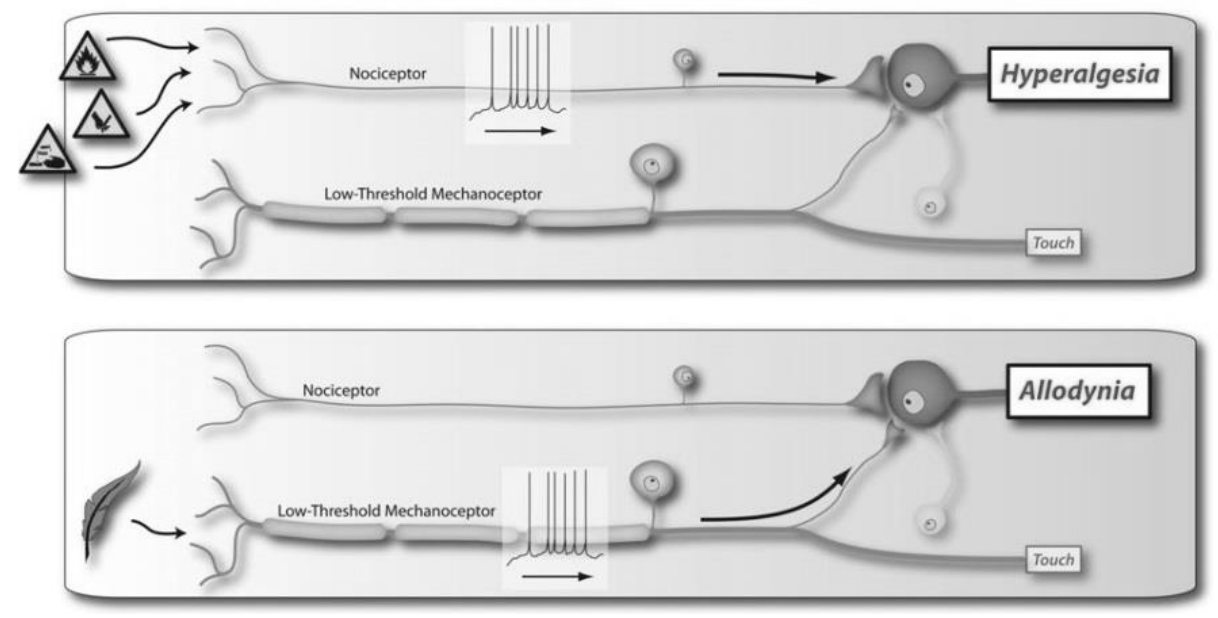

Figure 2 With the induction of central sensitization in somatosensory pathways, a central amplification occurs enhancing the pain response to noxious stimuli in amplitude, duration and spatial extent (resulting in hyperalgesia). Strengthening of normally ineffective synapses recruits subliminal inputs such that inputs in low threshold sensory inputs can now activate the pain circuit (resulting in allodynia). Reproduced from [268] with permission. 
Synaptic plasticity, described as long term potentiation (LTP), is an important general neurobiological principle underlying learning and memory [32]. In the pain setting, LTP is best seen as a particular component of central sensitization [211,268]. Moreover, central sensitization differs from the older concept of windup in that the former entails an amplification that outlasts the end of the conditioning stimuli, whereas the latter represents an increasing output during the course of a train of identical stimuli [268]. Windup does not in itself have any long-term consequences, but in conjunction with central sensitization it can greatly enhance the nociceptive output of the dorsal horn [211].

Central sensitization has been divided into an acute and a late phase. The acute phase is dependent on nociceptor input to the spinal cord (activity dependent), whereas the late phase entails transcriptional changes (transcription dependent) [267].

The term central sensitization seems to be increasingly used in clinical pain medicine [104], and it has been invoked in a wide range of different pain conditions: complex regional pain syndrome, fibromyalgia, miscellaneous musculoskeletal disorders, neuropathic pain, osteoarthritis, post-surgical pain, rheumatoid arthritis, temporomandibular disorders, tension-type headache, visceral pain hypersensitivity syndromes [268]. Given the broadness of the concept, it has been claimed that central sensitization should probably not be viewed as a specific pain type [233]. Moreover, it is important to remember that it is a neurophysiological term which can only be applied when both neural input and output are known [104]. Hence, strictly speaking, the concept of central sensitization should be restricted to the preclinical neurophysiological setting. Nonetheless, some authors use concepts like "central sensitivity syndromes" or "centralized pain" to characterize some of the clinical pain conditions listed above in this paragraph [48,231].

\subsubsection{Neurotransmitters and Neuropeptides}

Some of the key neurotransmitters and neuropeptides involved in nociception and central sensitization will now be briefly reviewed. However, it is important to acknowledge that there are also other classes of molecules involved in the modulation of nociception, e.g. the neuromodulatory lipids of the endocannabinoid system [100]; these will not be discussed in the present thesis.

Classical neurotransmitters are small molecules such as amino acids or monoamines. Glutamate (an amino acid) is the most common excitatory neurotransmitter in the CNS and, by activating e.g. N-Methyl-D-Aspartate (NMDA) receptors, plays a role in LTP [32]. Glutamate-induced activation of NMDA receptors in the spinal cord by continuous nociceptive afferent input is believed to be a very important factor in the initiation of central sensitization [211]. Suppressed inhibitory effects by amino acid neurotransmitters $\gamma$ Aminobutyric Acid (GABA) and glycine are also important for the development of central amplification of nociceptive input to the spinal cord [211]. Other classical neurotransmitters 
that are important in the pain setting include the monoamines serotonin and norepinephrine; these will be briefly mentioned below when describing top-down modulation.

Neuropeptides are different from classical neurotransmitters in many ways: they require high-frequency firing to be released; their receptors are found mainly outside the synapses; they have prolonged neuromodulatory effects; their receptors are normally not ionotropic; they have diverse effects (on gene expression, glial cells, blood flow, and synaptogenesis) [230]. In the dorsal horn, neuropeptides such as Substance P (SP) or Calcitonin GeneRelated Peptide (CGRP) are co-localized with glutamate in a subpopulation of primary nociceptive C-fibres [32,230], and intensive nociceptive input results in their co-release with glutamate, promoting NMDA receptor activation [33,211].

$\mathrm{SP}$ is an 11-amino-acid neuropeptide, with Neurokinin 1 (NK1) as its receptor [230]. Although it has been said that dorsal horn Lamina I neurons expressing the NK1 receptor are necessary for the development of central sensitization [126], and despite promising preclinical studies, several clinical trials in humans (in diverse pain states such as painful diabetic neuropathy, post-herpetic neuralgia, migraine, visceral pain, osteoarthritis, and fibromyalgia) have failed to demonstrate any analgesic effects of NK1 receptor antagonists $[139,230]$. Although several lines of evidence suggest a central role for SP and the NK1 receptor in nociception, it is possible that other types of signalling by these neurons may be more important than those involving the NK1 receptor itself [237]. The release of SP from primary nociceptive afferents is lessened by opioids [15].

There are three classes of classical endogenous opioids: endorphins, enkephalins, and dynorphins. The respective precursors to these important pain-modulating neuropeptides are pro-opiomelanocortin (POMC), pro-enkephalin, and pro-dynorphin, respectively [181]. Moreover, so-called endomorphins have also been identified; they have the highest affinity for the $\mu$ opioid receptor [129]. However, the status of endomorphins as endogenous ligands remains controversial [149]. In addition to the classical three opioid receptors $\delta, \kappa$, and $\mu$ associated with the above-mentioned endogenous opioids, a fourth opioid receptor has been described: the nociceptin receptor (also named NOP, or orphanin FQ, or $\mathrm{OP}_{4}$, or opioid-like receptor 1) [149,181]. Currently, cebranopadol, which is both a nociceptin receptor agonist and a $\mu$ receptor agonist, is being tested in several clinical trials [133].

Exogenous opioids are well-known as analgesics. Because opioid receptors are widely distributed in the CNS, and because of differences in types of exogenous opioids and routes of administration, the exact location of opioid-mediated analgesia is somewhat difficult to determine [149]. The dorsal horn of the spinal cord contains all types of opioid receptors, notably $\mu$ opioid receptors in lamina II (substantia gelatinosa) interneurons (with axons projecting to lamina I or III-V) [149]. Moreover, the periaqueductal grey (PAG), the locus ceruleus, and the rostral ventral medulla show high concentrations of opioid receptors, the activation of $\mu$ opioid receptors in these structures leading to top-down inhibition of nociception through descending pathways (see below) [181]. 
Endogenous opioids are released in the dorsal horn of the spinal cord upon activation of topdown inhibitory systems. It is also possible that their release is driven by purely intraspinal circuits (i.e., not involving top-down control) following nociceptive input from the periphery, although it seems clear they are not secreted directly by primary afferents or second-order neurons. Hence, the main sources of endogenous opioids in the dorsal horn are interneurons and supraspinal axons. Furthermore, it is unlikely that endogenous opioids in the spinal cord act in a classic synaptic manner; instead, they act by volume transmission [149]. (Volume transmission means that they act like local hormones on all nearby receptors having the proper specificity, usually within a few micrometers from the release site [32].) Of the three classes of classical endogenous opioids, enkephalins and dynorphins are expressed in the dorsal horn, whereas endorphins (e.g., beta-endorphins) are not [149].

The physiology of beta-endorphin (BE) has recently been reviewed [259]. For the purposes of the present thesis, the following points are noteworthy:

- $\mathrm{BE}$ is a 31 amino acids polypeptide with a molecular weight of $3465 \mathrm{Da}$, meaning that it is about 10 times "bigger" than the alkaloid morphine.

- There are probably two functionally different BE systems: one peripheral (release of BE by the pituitary into the systemic circulation) and one central (synthesis in hypothalamic POMC neurons).

- An intact blood-brain barrier (BBB) hinders free exchange of BE between plasma and CSF.

- Even though these two systems are functionally different, there still may be some bi-directional exchange of BE: from plasma to brain in small areas lacking a BBB; from brain to plasma by means of transport mechanisms across capillaries.

- Hypothalamic POMC neurons can release BE directly into the CSF of the third ventricle.

- The CSF can serve as a transport medium for BE to distant brain or spinal sites. This is called "long-distance volume transmission" and is by no means unique for BE.

\subsubsection{Defective Top-Down Modulation}

The PAG, which for obvious neuroanatomical reasons is one of the first areas exposed to $\mathrm{BE}$ released into the third ventricle (see above), is part of an intricate top-down system that modulates nociceptive inputs at the spinal level [179,231]. The best studied top-down descending pathway is the PAG-RVM system, which links the PAG to the spinal cord via the rostral ventromedial medulla (RVM) [108]. The PAG and the RVM contain a high density of opioid receptors [181]. Neurons projecting from the RVM to the spinal cord are GABA-ergic, glycinergic or serotonergic; the effect of spinal serotonin can be either inhibitory or facilitatory, depending on the receptor subtype activated [179]. Noradrenergic pathways, originating in e.g. the locus coeruleus (in the pons), are also involved in 
downward pain modulation [186], and these circuits are partially integrated into the PAGRVM system [179]. See Figure 3 for a schematic depiction.

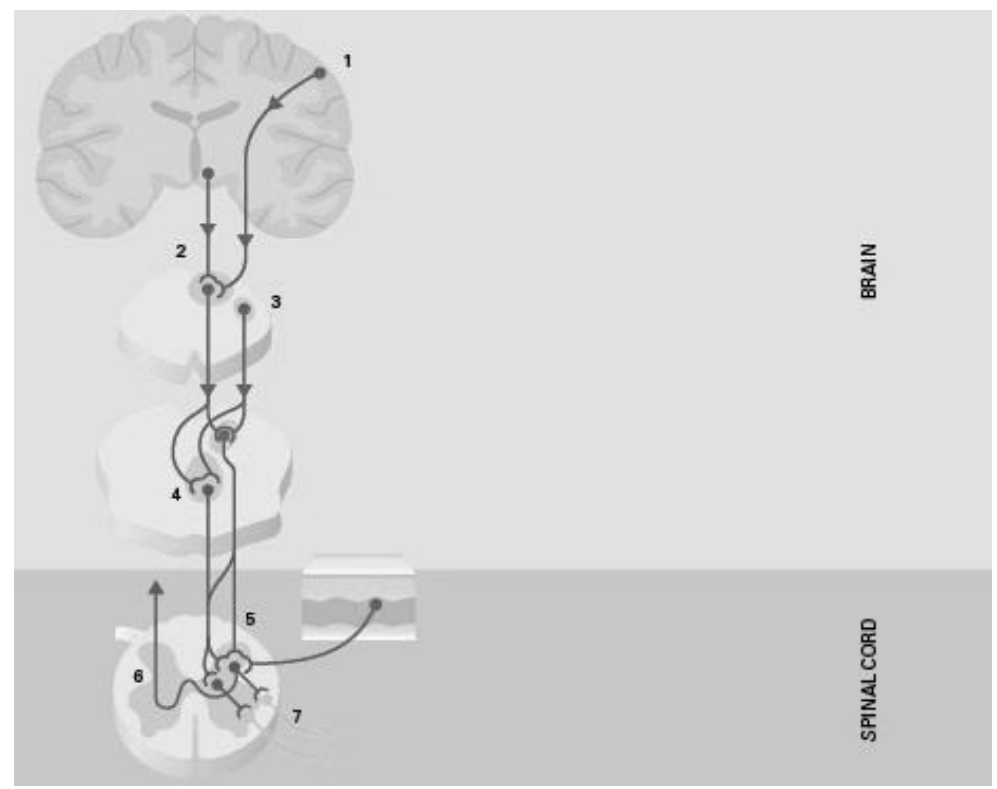

Figure 3 Schematic representation of the top-down modulation of nociception. Legend: 1) cortical/subcortical impulses; 2) periaqueductal grey (PAG) in the mesencephalon; 3) locus coeruleus in the pons (noradrenergic system); 4) raphe nucleus (serotonergic system in the $\mathrm{RVM}$ ); 5) inhibitory synapses in the dorsal horn; 6) ascending spinothalamic tract; 7) motor neuron reflex. The DNIC system is not depicted. Reproduced from [99] with permission.

Another important related concept is that of the Diffuse Noxious Inhibitory Controls (DNIC) system, also known as counter irritation. The DNIC phenomenon means that nociceptive signalling from the periphery is inhibited by applying another noxious stimulus to a remote area of the body [252]. The term "diffuse" relates to the fact that DNIC works non-somatotopically, meaning that its response is general regardless of where the noxious stimulus is applied [179]. A key relay station for this system is the medullary subnucleus reticularis dorsalis (SRD), also known as the dorsal reticular nucleus (DRt). In order to study the efficacy of the DNIC system, conditioned pain modulation (CPM) experiments can be carried out [137,272].

Hence, the concept of pain modulation at the spinal level has evolved considerably since Melzack \& Wall first presented their ground-breaking work half a century ago $[153,154]$. It is becoming increasingly clear that defective top-down modulation is an important mechanism in chronic pain conditions like fibromyalgia, temporomandibular joint disorder, 
or irritable bowel syndrome, and there seems to be considerable overlap between the concepts of central sensitization and defective top-down modulation (the latter is often viewed as part of the former) [231].

\subsubsection{Neuroinflammation and Gliosis}

Over the past two decades, non-neural immunocompetent glial cells (mainly microglia and astrocytes in the CNS but also possibly Schwann cells in the peripheral nervous system) have emerged as probable key actors in the pathophysiology of chronic pain [95]. This has been shown most convincingly concerning microglia in animal models of post-traumatic peripheral neuropathic pain [211]. Microglia are the phagocytes of the CNS (they constantly survey the local environment and respond to various stimuli), while astrocytes have a multiplicity of functions: they provide structural support, promote the formation of the BBB, regulate blood flow, contribute to synaptic transmission, provide trophic support, promote repair of neuronal system, regulate the concentration of neurotransmitters and ions in the synaptic cleft [96]. Hence, far from being passive, glial cells are key players in CNS homeostasis. The process whereby glial cells turn from maintenance and surveillance to proliferation and activation is called gliosis [96].

Microglia are activated by nociceptive input to the spinal cord (via primary afferent release of ATP, chemokines and other substances) and/or, in the case of neuropathic pain, by alarmins (also known as damage-associated molecular patterns (DAMP) molecules) released by primary afferents following nerve damage [96]. For a simplified representation, see Figure 4. However, whether microglia play a role in clinical pain remains an open question [211].

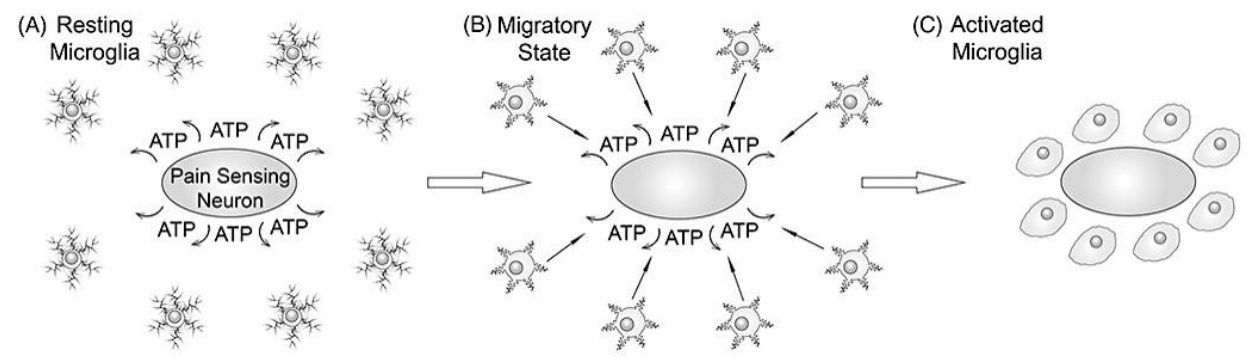

Figure 4 Principle of microgliosis. (A) Following a peripheral injury, the synaptic projection of a pain sensing neuron within the spinal cord releases e.g. ATP. (B) Nearby microglial cells within 50 to $100 \mu \mathrm{m}$ are drawn to the source of ATP and undergo morphological changes as they approach the source and become activated. (C) Fully activated microglial cells are localized around the pain sensing neuron and begin to interact with the neuron on a molecular level, releasing various neuroinflammatory agents. ATP, adenosine Triphosphate. Reproduced from [248] with permission. 
Upon activation, microglia release pro-nociceptive neurotrophic factors like brain-derived neurotrophic factor (BDNF) [17,211,230], as well as key multifunctional cytokines (TNF$\alpha$, IL-1 $\beta$, IL-6) that initiate and orchestrate the subsequent production of downstream cytokines and other proalgesic mediators [95,159,248]. This multi-faceted process is depicted in Figure 5.

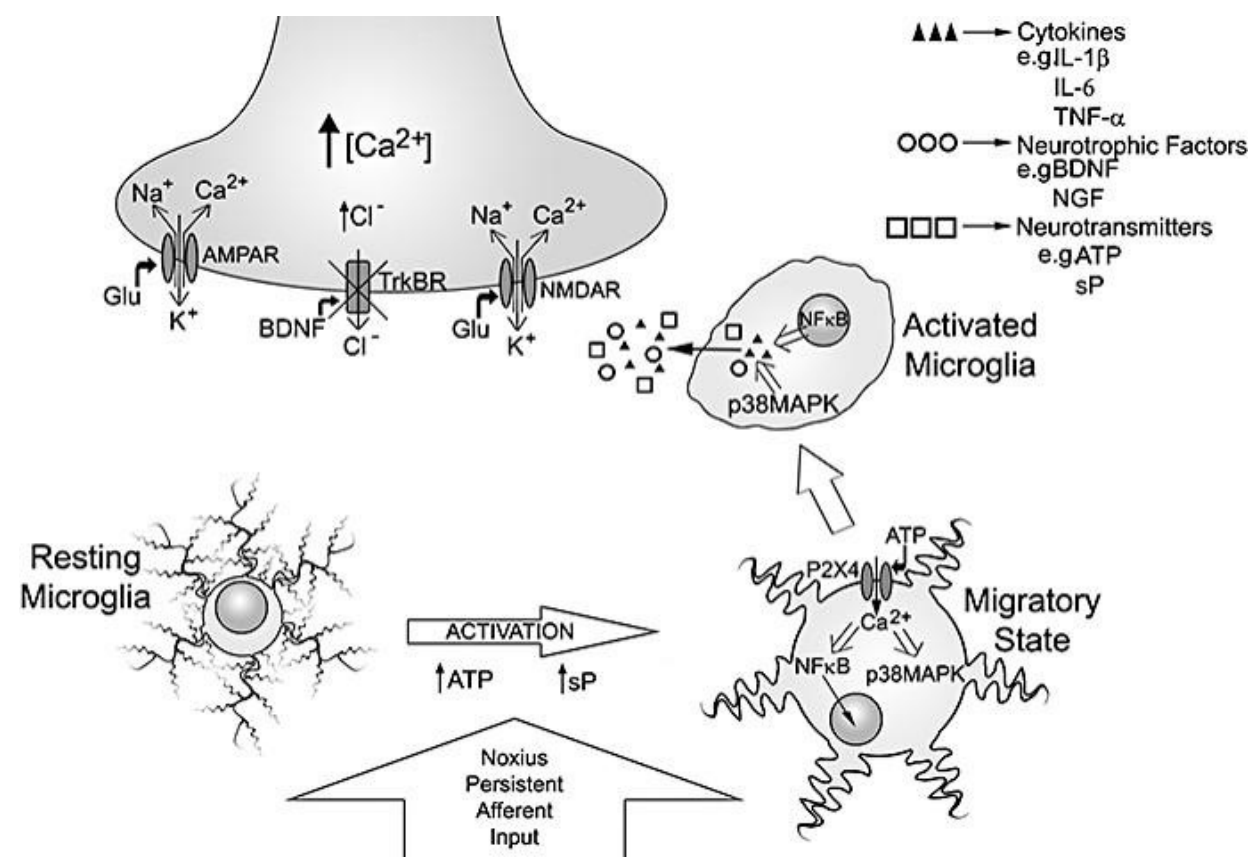

Figure 5 Noxious afferent input results in the activation of resting microglial cells that migrate to the source of ATP. Transcription of various neuroinflammatory agents including cytokines and neurotrophic factors occurs. The release of these neuroinflammatory agents into the synaptic cleft and subsequent binding to various receptors result in an increase in intracellular ions within the neuron, such as $\mathrm{Ca}^{2+}$ and $\mathrm{Cl}^{-}$, which depolarizes the cell and thereby causing sensitization. Two prominent receptors that are involved with $\mathrm{Ca}^{2+}$ influx into the neuron are AMPA and NMDA receptors. BDNF has been shown to bind to the TrkB receptor and inhibits the efflux of $\mathrm{Cl}^{-}$out of the neuron. ATP, adenosine $5^{\prime}-$ triphosphate; BDNF, brain-derived neurotrophic factor; p38MAPK, p38 mitogen activated protein kinase. Reproduced from [248] with permission.

Microglial activation leads to the activation of astrocytes, resulting in further neural sensitization [248]. Glial cell line-derived neurotrophic factor (GDNF) is secreted by astrocytes, and, in patients with chronic painful osteoarthritis, Lundborg et al found high CSF levels of GDNF, as well as an increase in pro-inflammatory cytokines [143]. Hence, evidence for neuroinflammation in human chronic pain conditions is beginning to emerge. 
Other relevant human biomarkers studies will be referred to below in the section on biomarkers (section 1.4).

\subsubsection{The Specific Case of Neuropathic Pain}

In addition to peripheral processes (e.g., ectopic nerve activity), the above-mentioned spinal and brain stem mechanisms are generally acknowledged to be important for the development of neuropathic pain. Central sensitization and NMDA receptor activation are important in neuropathic pain, as is neuroinflammation [12]. Indeed, neuropathic pain is now by some authors considered to be a neuroimmune disorder [96]. CNS microglia are thought to be important initiators of neuropathic pain, whereas astrocytes have a role in the maintainance of neuropathic pain [76]. However, there is a knowledge gap between animal models and clinical pain medicine: whereas glial changes are evident in animal models of neuropathic pain, evidence for such changes in humans are almost non-existent, and glial cells (at least astrocytes) from mice and monkeys are quite different from humans [236].

Nonetheless, based mainly on animal experiments, it is believed that glial cells in the spinal cord play an important role in the pathophysiology of neuropathic pain [248]. Glial activation is driven by neurotransmitters, ATP, chemokines, and other substances released by primary afferents under conditions of enduring nociceptive signalling [96,256], but in the specific case of neuropathic pain there is also a damage-related neuron-to-glia signal as heat shock proteins and other endogenous danger signal substances are released from the afferent terminals of injured first-order neurons and thereby activate spinal microglial cells [159]. Heat shock proteins belong to a class of molecules known as DAMP, or alarmins [96].

Defective top-down modulation seems also to be important in neuropathic pain [12]. For instance, in an animal model of neuropatic pain, tactile allodynia was precipitated in nonallodynic rats by injecting lidocaine into the RVM [64]. Also in rats, Leong and co-worker have shown that peripheral nerve injury induces death of antinociceptive RVM neurons, and this loss of RVM neurons can perhaps shift the balance of descending control from pain inhibition to pain facilitation [136]. Interestingly, the process of gliosis that is thought to be an important mechanism in the pathophysiology of post-traumatic peripheral neuropathic pain has also been demonstrated in the RVM, possibly linking the two phenomena of defective top-down inhibition and neuroinflammation [76].

\subsection{The Quest for Biomarkers}

A substantial part of the knowledge described in section 1.3 has been acquired through animal experiments. Although there are obvious similarities between species, there are also differences. This is not least the case in such a multi-faceted experience as pain, and 
translating evidence from animals to humans in this field is far from trivial [147]. It is against this background that the quest for human pain biomarkers must be understood.

\subsubsection{Rationale for the Quest}

A biomarker has been defined as a characteristic that is objectively measured and evaluated as an indicator of normal biological processes, pathogenic processes, or pharmacologic responses to a therapeutic intervention [20]. Biomarkers can help in diagnosis and prognosis, in the evaluation of treatment response and the development of drugs, and they can serve as surrogate endpoints (i.e., as substitutes for clinical endpoints) [24].

Pain medicine lacks objective biomarkers to guide diagnosis and choice of treatment [24]. This is in sharp contrast to e.g. cardiology, where chemical biomarkers (e.g., troponins) play an important role. A thorough pain analysis can often discriminate between nociceptive and neuropathic pain, but it is noteworthy that this is one of few mechanism-based distinctions (albeit a very crude one) in clinical pain medicine. Pain diagnoses are often based on anatomical location, duration and/or etiology.

As pain by definition is a subjective experience, it has been contended that biomarkers for pain is a sheer impossibility [120]. According to this view, there is a logical contradiction (and an ethical danger) in the attempts to find objective biomarkers for subjective states like pain. In the context of this debate, I have elsewhere proposed that the neologism "nocimarker" would perhaps be a better term than "pain biomarker" for denoting attempts to find objective, measurable correlates to the neurobiological processes involved in different pain conditions [9]. This proposal pertains to the philosophical distinction between the "hard" vs. "easy" problems of consciousness [42], and also to the well-known distinction between nociception and pain (nociception being the neural process of encoding noxious stimuli, see section 1.2.3). Pain is always subjective and cannot be observed "from the outside"; it is a lived reality, an "inner" experience. In contrast, the neural circuits and the biochemistry of the nociceptive pathways can be studied "from the outside" by science. In the pain setting, biomarkers should not be seen as a substitute to the patient's subjective report.

A long-term vision for pain medicine could be the possibility of basing the prescription of analgesics or even disease-modifying drugs on a mechanistic understanding of different pain types. Such a vision requires the discovery of mechanism-specific biomarkers [267]. Today, analgesics are often prescribed on a trial-and-error basis.

Biomarkers are not limited to chemical substances measured in a body fluid. Indeed, the concept of biomarker is sometimes broadened to include many different kinds of measurements in pain patients, e.g. sensory phenotyping, intraepidermal nerve fiber counts, microneurography, electrophysiological recording of noxious stimulus-evoked cortical potentials, or different kinds of functional imaging [44,58,128,187,217,232]. However, referring to psychophysical tests as biomarkers is problematic (as discussed in section 5.3). 
The cerebrospinal fluid (CSF) is an interesting target for human biomarker studies in neurological disorders [204].

\subsubsection{The Previous Achievements of the Quest}

While acknowledging that there are many different kinds of potential biomarkers described by pain researchers (see above), this section will focus on biochemical markers in the CSF. Candidates in earlier studies have included different kinds of peptides/proteins, and these will now be briefly reviewed.

\section{Neuropeptides}

Already in 1978, Almay et al reported that levels of unspecific "endorphins" were low in the CSF of patients with predominantly "neuralgic" pain, compared both to patients with what was labelled "psychogenic" pain and to healthy controls [4]. Also, in 1988, Tonelli et al found low CSF-BE in patients scheduled for Spinal Cord Stimulation (SCS), compared to historic controls [238]. As a contrast, in 1988, Vaeroy et al found normal levels of CSF$\mathrm{BE}$ in fibromyalgia syndrome patients [244]. In cancer patients, Samuelsson et al found low levels of CSF-BE; they also measured CSF-CGRP and CSF-SP, without finding any differences between patients and controls [212].

Levels of CSF-SP were elevated in two studies of fibromyalgia syndrome patients, compared with healthy controls [208,245]. Concerning neuropathic pain, two studies failed to show an elevation of CSF-SP in patients, compared to healthy controls $[3,138]$; in one of them, CSF-SP was actually lower in patients [3]. However, patients with painful osteoarthritis had high levels of CSF-SP [138]. In the acute perioperative setting, Buvanendran et al registered a sharp increase of CSF-SP during surgery, but this finding is difficult to interpret given the confounding effect of concurrent spinal anaesthesia [39]. Buvanendran et al also measured CSF-CGRP, which decreased from baseline after surgery.

Given recent reports about the analgesic potential of the nociceptin receptor and $\mu$ receptor agonist cebranopadol [133], it is of interest to note that CSF-nociceptin has also been investigated. Brooks et al did not find altered CSF-nociceptin levels in labour pain [35]. Raffaeli et al did not find any statistically significant differences between CSF-nociceptin of opioid-naïve chronic pain patients $(n=6)$ vs. controls $(n=9)$; however, chronic pain patients on continuous intrathecal morphine treatment $(n=12)$ had a significantly lower CSF-nociceptin than controls $(\mathrm{n}=9)$ [195].

\section{Neurotrophic factors}

In patients with chronic painful osteoarthritis, Lundborg et al found high levels of CSFGDNF [143]. In a study comparing three groups (chronic nociceptive low back pain, chronic neuropathic pain, and controls with normal pressure hydrocephalus), Capelle et al did not find any statistically significant differences for any of the following neurotrophic factors: GDNF, BDNF, Nerve Growth Factor (NGF), Ciliary Neurotrophic Factor (CNTF) [40]. 


\section{Cytokines}

In the study referred to above, Lundborg et al also found an increase in pro-inflammatory cytokines IL-8 and IL-1 $\beta$ in CSF [143]. In patients with disc herniation and sciatica, Brisby et al found normal levels of CSF cytokines; however, they noted a temporal pattern concerning IL-8, which was increased in patients with a shorter duration of symptoms compared to patients having a more chronic pain [30].

\section{Markers of neuronal damage}

In another study, Brisby et al studied neurofilament protein light subunit (NFL), protein S100, neuron-specific enolase (NSE), and glial fibrillary acidic protein (GFAP) in the CSF of patients with lumbar disc herniation; the main finding was that NFL and protein S-100 were higher in patients than in controls, indicating damage of axons and Schwann cells in the affected nerve root (especially in patients with short duration of symptoms) [31].

\section{Cystatin C}

In 2003, Mannes et al described Cystatin C in the CSF as a biomarker of acute labour pain in humans [146]. A year later, a larger study failed to reproduce these findings [75]. Recently, Cystatin C has been shown by Guo et al to be up-regulated in patients with painful osteoarthritis $(n=8)$ compared to controls $(n=8)$ [101].

\subsection{The Alleviation of Pain}

The need for biomarkers in pain medicine must be seen in the context of the limitations of current treatment methods: if pain relief was no longer a clinical problem, there would be no need for biomarkers. But pain remains a substantial problem, even in developed countries. The paucity of safe and effective treatments for chronic non-cancer pain is arguably an important background for the current "opioid epidemic" in the US [41,145].

The problem of opioid dependence and addiction is by no means new. In the West at the end of the $19^{\text {th }}$ century, the disastrous consequences of the then widespread use of opium had become clear; indeed, there are claims that $10 \%$ of the US population were dependent on opioids at that time [201]. This led to strict legal regulations at the beginning of the $20^{\text {th }}$ century, and to a situation of extremely restrictive use and fear of opioids (often called "opiophobia") [201]. A landmark in the gradual turn from "opiophobia" to the more liberal view prevalent today was the publication of the WHO analgesic ladder for cancer pain almost 30 years ago [262].

\subsubsection{The WHO Analgesic Ladder}

In 1986, the WHO three-step analgesic ladder for the treatment of cancer pain was published (Figure 6) [262,274]. Notwithstanding the claim that in about $90 \%$ of cases adequate 
analgesia can be achieved by following these WHO guidelines [97,216,262,274], the treatment of cancer pain remains suboptimal even in developed European countries [27]. For instance, two out of three patients with advanced cancer report pain [250].

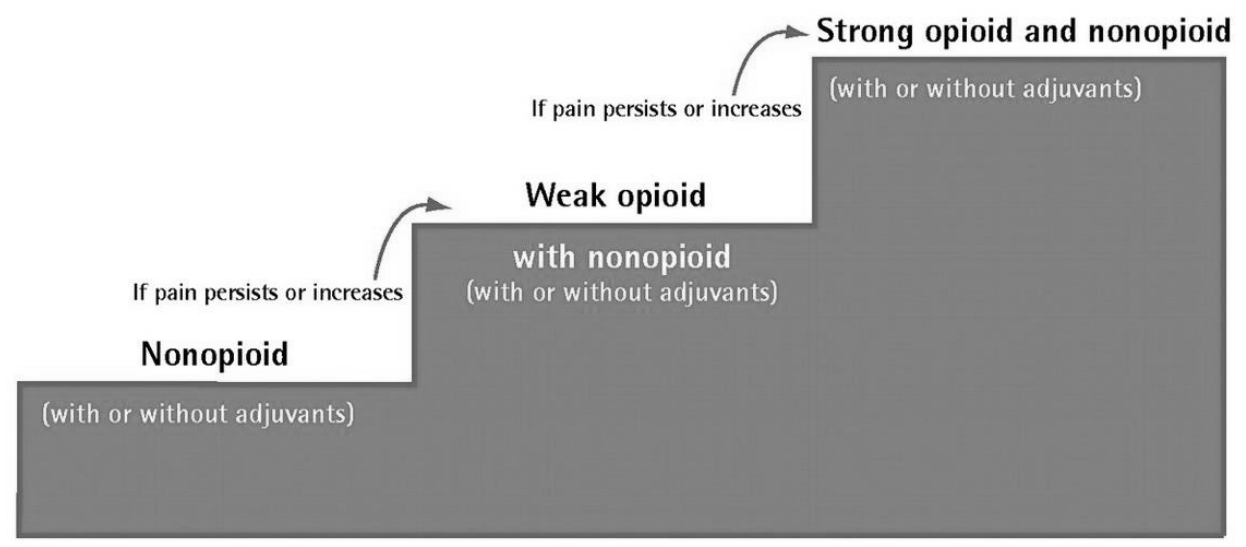

Figure 6 The WHO three-step analgesic ladder, reproduced with permission from [255]. Adjuvants pertain e.g. to the treatment of neuropathic pain. This figure is an adaptation of the original three-step ladder [262].

Nowadays, the usefulness of the second step (corresponding to the use of a weak opioid) is being debated, and in clinical practice it is often omitted [121]. Nonetheless, the three-step ladder remains an important conceptual tool for the basic treatment of cancer pain. A fourth step, consisting of advanced interventional techniques, is often described as being an essential component of modern cancer pain relief [46]. One of these advanced methods is intrathecal analgesia (ITA), which will be described below. But first, a few things need to be said about the treatment of neuropathic pain.

\subsubsection{The Treatment of Neuropathic Pain}

Neuropathic pain, defined as pain caused by a lesion or disease of the somatosensory system [116], occurs both in cancer and non-cancer pain. Clinically, the certainty of the presence of neuropathic pain can be graded by using four criteria [165]: 1) pain with a neuroanatomically plausible distribution; 2) history of a relevant lesion or disease affecting the somatosensory system; 3) confirmatory tests demonstrating presence of negative and positive sensory signs confined to innervation territory of the lesioned nervous structure; 4) further diagnostic tests confirming lesion or disease entity underlying the neuropathic pain. Criteria 1+2 entail "possible" neuropathic pain. The addition of criteria 3 or 4 entails "probable" neuropathic pain. All four criteria imply "definite" neuropathic pain. 
Evidence-based guidelines stipulate the use of antidepressants (tricyclics or duloxetine), anticonvulsants (gabapentin or pregabalin), topical lidocaine, and sometimes opioids [65]. In severe cases, SCS is a valuable option $[49,117]$. Still, many patients do not reach adequate pain control or experience troublesome side-effects $[12,65]$. Hence, neuropathic pain remains difficult to treat. Iatrogenic neuropathic pain is thought to be the major cause of chronic post-surgical pain [124,249].

\subsubsection{Intrathecal Analgesia}

Opioid receptors were identified in the spinal cord in 1973 [185]. Three years later, animal experiments by Yaksh and co-workers showed that the injection of opioids intrathecally lead to powerful and highly selective analgesia [271]. Soon, the use of intrathecal morphine injections in humans was described [253]. These ground-breaking studies were followed by others $[89,134,203]$, and in 1981 Onofrio \& Yaksh published the first case report of a continuous intrathecal infusion of morphine [177]. Hence, intrathecal analgesia (ITA) has been practised for over three decades. But what is the evidence for its effectiveness?

\section{Intrathecal Analgesia in Cancer Pain}

Since 1981, there has been a plethora of uncontrolled studies assessing the efficacy of ITA for cancer pain [11,38,51,86,91,123,176,198,219,220]. In 2010, Meyers and co-workers performed a systematic review, finding 12 randomized controlled trials (RCT) about intraspinal analgesia for cancer pain [166]. Seven out of 12 studies evaluated the effect of epidural analgesia, and hence only five were concerned with ITA. Out of five ITA-studies, one assessed the effect of the novel non-opioid analgesic ziconotide compared to placebo (see below); three compared different analgesic regimes; and one non-blinded RCT assessed the efficacy of opioid-ITA compared to what was called "comprehensive medical management". In this latter study, Smith et al showed that ITA led to improved cancer pain control and less drug toxicity after four weeks [228]. (Subsequently, this RCT rendered two additional publications [226,227]). Hence, according to the standards of evidence-based medicine, there is a paucity of high-quality studies. However, reviewers in the field seem to agree that ITA is a valuable analgesic technique in intractable cancer-related pain $[11,97,166,224]$.

In Sweden, the infusion of a combination of morphine and bupivacaine via an externalized catheter has been studied extensively by a group in Gothenburg, both for cancer pain $[172,219,220]$ and non-cancer pain $[62,171]$. Bupivacaine can also be used as the sole agent for ITA [61,67,142]. Moreover, it has been shown that the adjunction of bupivacaine to morphine leads to a diminished dose progression of morphine, suggesting a synergetic effect [251]. 


\section{Intrathecal Analgesia in Non-Cancer Pain}

Although ITA was initially developed for the treatment of cancer pain, today the majority of patients treated with ITA worldwide have non-cancer types of pain [79]. A review from 2007 concluded that in chronic non-cancer pain patients, pain seems to improve with ITA, but ITA-opioid doses increase over time and long-term effects remain unclear, due to lack of long-term follow-up (maximum of 2 years) [242]. The evidence for efficacy in noncancer pain has been called "moderate" [224] or "limited" [82]. It has to be emphasized that, with the exception of ziconotide (see below), there are no RCTs supporting the use of ITA in non-cancer pain.

\section{Ziconotide}

For many years, morphine was the gold standard for ITA. Despite the wide use of other opioids, local anaesthetics, or clonidine, the place of morphine as the first choice ITA-drug was never really challenged before the apparition of the non-opioid ziconotide (Prialt@), which in 2007 was upgraded to a first-line ITA-drug by the Polyanalgesic Consensus Conference [66,70]. Ziconotide and morphine are the only analgesics approved for ITA by the Food and Drug Administration [132].

Ziconotide is a synthetic analogue of a conopeptide found in the venom of the fish-hunting marine snail Conus magus (Figure 7) [132]. It is a polypeptide consisting of 25 amino acids, has a molecular weight of $2639 \mathrm{Da}$, and acts as a presynaptic N-type voltage-sensitive calcium channel antagonist in the Rexed lamina I and II of the spinal cord dorsal horn (Figure 8 and Figure 9) [158,189,223].

No ITA-drug has been as thoroughly investigated as ziconotide, including three pivotal RCTs [199,229,246] and many open-label studies [2,68,73,77,196,214,247,258,260]. Typical opioid adverse events (AEs) such as respiratory depression, tolerance or dependence have not been described for ziconotide [215]. However, ziconotide has a narrow therapeutic window [189,215] and several neurological AEs have been reported, e.g. dizziness, ataxia, abnormal gait, nystagmus, or nausea. Ziconotide AEs tend to occur more commonly at higher doses [213,223,257], and a slow-titration strategy is recommended $[189,257]$. Due to the risk of severe psychiatric AEs, patients with a history of psychosis should not be treated with ziconotide, and all patients have to be closely monitored for cognitive impairment, psychosis or changes in mood [174,189,213,247]. There are worrying case reports about suicidality [144]. Slow titration and close neuropsychiatric monitoring should therefore be mandatory. 


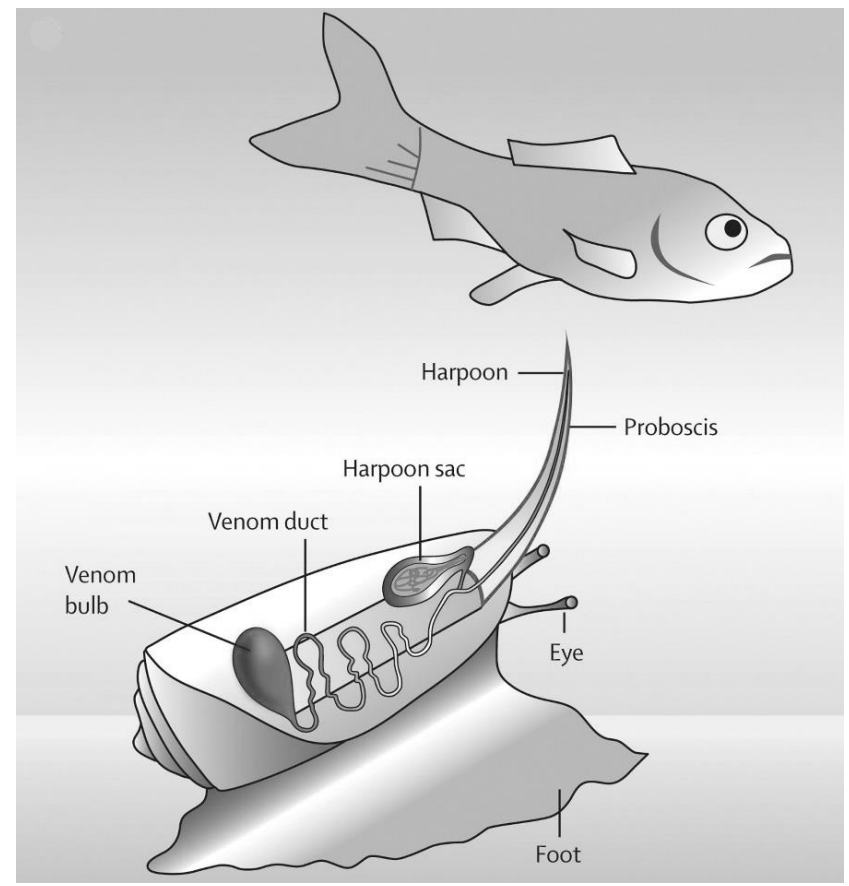

Figure 7 The fish-hunting Pacific marine snail Conus magus produces numerous venom peptides to kill its prey. The venom is injected through a "harpoon". Ziconotide is a synthetic form of one of these peptides. Reproduced from [215] with permission.

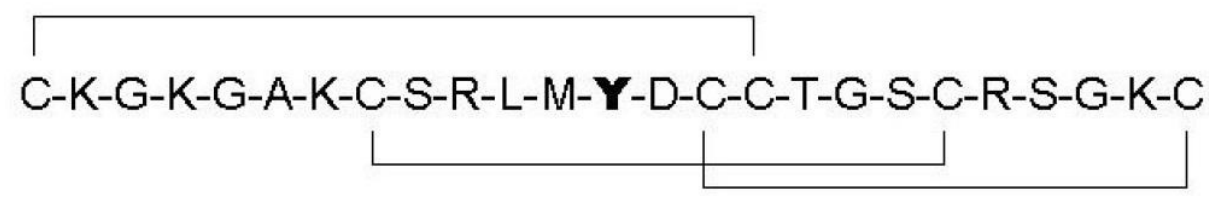

Figure 8 Amino acid sequence of ziconotide with standard one-letter amino acid abbreviations. The three stabilizing disulphide bridges are also illustrated. Reproduced from [152] with permission. 


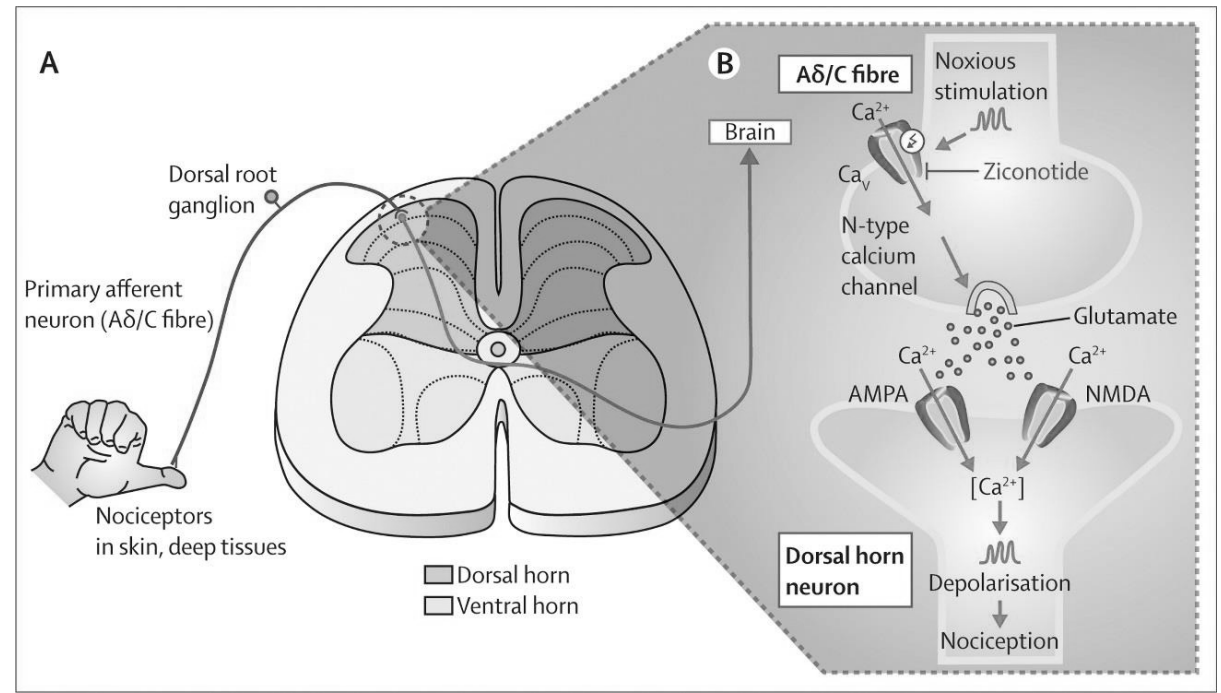

Figure 9 Ziconotide is a presynaptic N-type calcium channel blocker, thereby preventing the release of neurotransmitters like glutamate. AMPA $=\alpha$-amino-3-hydroxyl-5-methyl-4isoxazole-proprionate receptor. NMDA $=\mathrm{N}$-methyl-D-aspartic acid receptor. Reproduced from [215] with permission.

\section{Patient Selection for Intrathecal Analgesia}

Before starting long-term ITA, patients often undergo an ITA-trial in order to evaluate the efficacy and tolerability of the planned treatment [37,69]. Trial practices vary widely [1]. Ziconotide trialing can be done either by continuous intrathecal infusion via an external pump, or by bolus injections [37]. Bolus trialing is simpler and cheaper [6], but the evaluation is more difficult since the duration of the clinical effect is brief. Ziconotide has been administered by bolus injections in one study by Mohammed et al [161], as well as in small studies that have not hitherto been published in peer-reviewed journals $[98,175,207]$.

\subsection{The Cerebrospinal Fluid}

\subsubsection{Production, Flow and Resorption}

The volume of cerebrospinal fluid (CSF) is about $150 \mathrm{~mL}$ in an adult, and the rate of production is roughly $600 \mathrm{~mL}$ per day [164]. Hence, CSF turnover is roughly six hours. According to the classical teaching, CSF is produced in the choroid plexus within the ventricles, leaves the brain via the foramina of Luschka and Magendie, circulates in the subarachnoid space around the brain and spinal cord, and is resorbed into the venous sinuses 
across arachnoid villi and arachnoid granulations. However, this is too simplistic [164]. Pioneering work of Cserr et al showed that (at least in rats) there is a slow turnover from the interstitial fluid surrounding neural tissue into the CSF [59]. Hence, it is believed that $10 \%$ of the CSF comes from neural interstitial fluid [164]. Moreover, CSF resorption occurs at many locations, e.g. into spinal veins where nerve roots exit the spinal canal $[105,164]$. The driving force of CSF resorption is a pressure gradient from CSF to venous blood across arachnoid villi, hydrostatic pressure creating giant vacuoles that transport CSF unidirectionally into the blood. This transcellular (not intercellular) transport is not affected by CSF composition, as particles of different sizes pass through at the same rate [164]. Furthermore, studies suggest an important role for lymphatic drainage, as CSF is able to pass into the connective tissue surrounding the cranial nerves and spinal nerve roots (notably the olfactory nerves and cribiform plate, the CSF then reaching the nasal mucosa and eventually being drained from there into nasal lymphatic channels) [105,164,210].

Even the modified version of the classical teaching has recently been challenged. Some authors propose a completely new hypothesis, according to which CSF is permanently produced and absorbed in the whole central nervous system as a consequence of filtration and reabsorption of water through the walls of neural tissue capillaries [178]. This new hypothesis is said to be congruent with the fact that acute occlusion of the aqueduct of Sylvius does not change CSF pressure in isolated ventricles, contradicting the notion of a substantial flow of CSF out of the ventricles into the subarachnoid space [36]. Moreover, the new theory states that absorption of CSF into venous sinuses and/or lymphatics is probably of minor importance due to their minute surface area in comparison to the huge absorptive surface area of neural tissue microvessels [36]. Hence, the exact physiology of CSF production, flow and resorption remains a matter of considerable debate [164].

\subsubsection{Cerebrospinal Fluid Proteins}

In neurological conditions, the CSF is a particularly interesting body fluid for biomarker studies, as it can be hypothesized to mirror pathologies in the CNS [206]. The potential of CSF proteins as biomarkers is well illustrated by the advances made in Alzheimer's disease. In this condition, the combination of increased CSF tau protein and lowered CSF $\beta$-amyloid has a good diagnostic performance, with high specificity and high sensitivity [21,92]. Another area of intensive CSF proteomic research are CNS inflammatory and demyelinating disorders. For instance, a plethora of different biomarkers have been proposed for multiple sclerosis (markers of demyelination/remyelination, of neuroaxonal loss, of inflammation); however, none of these has yet achieved widespread clinical use [54].

The total protein concentration in CSF is about $0.5 \%$ of that in plasma $[53,113,164,204]$. Diffusion of proteins from blood to CSF is restricted directly by the Blood-CSF Barrier (BCB) located in the choroid plexus and arachnoid granulations, but also indirectly by the 
BBB which is present along almost all of the brain's capillaries (the exception being the socalled circumventricular organs of the brain) $[53,105]$. As there is no barrier separating the CNS from the CSF, the CSF is in direct contact with the extracellular space of the CNS [21,53]. Indeed, studies using highly sensitive detection methods have been able to detect thousands of CNS-unique proteins in the CSF (i.e., proteins not found in plasma) [164]. Concerning the total protein content of the CSF however, $80 \%$ is derived from plasma, albumin being the most important. Plasma-derived CSF proteins cross the BBB and the $\mathrm{BCB}$ by pinocytosis, whereas CSF proteins not derived from plasma are either synthesized in the choroid plexus or diffuse from neural interstitial fluid out into the CSF [113,204].

There is a rostral-caudal protein gradient. According to a classical study (referred to by Irani [113]), CSF in the ventricles has a protein concentration of $6-15 \mathrm{mg} / \mathrm{dl}$, the cisterna magna has $15-25 \mathrm{mg} / \mathrm{dl}$, and the lumbar region has $20-50 \mathrm{mg} / \mathrm{dl}$; recent studies show that the BCB is more permeable to proteins in these caudal locations [113].

Some of the most abundant CSF proteins will now be briefly reviewed, the word "rank" referring to the order of their abundancy in CSF, according to Irani [113]. CSF-albumin (rank 1) is not synthesized in the CNS but derives from plasma, is about 200 times less abundant in CSF than in plasma, represents $2 / 3$ of total CSF proteins, and increases to some degree with age [54,113]. The CSF albumin index, calculated as CSF-albumin / Serumalbumin, provides a simple measure of the integrity of the BBB [54].

It is incorrect to view the CSF as merely an ultrafiltrate of plasma [113]. For each protein, the CSF/plasma ratio gives an indication of whether the protein in question is likely to be synthesized in the CNS: proteins found at levels much greater than $0.5 \%$ of plasma concentrations probably undergo some local synthesis within the CNS [113]. For instance, IgG (rank 3) and Alpha-1-antitrypsin (rank 6) have a ratio of only $0.2 \%$ and $0.4 \%$, respectively, whereas Prostaglandin-H2 D-isomerase (PGDS, previously known as betatrace) (rank 2) and Cystatin C (rank 8) have a ratio of $3400 \%$ and 500\%, respectively [113]. Hence, PGDS and Cystatin C are enriched in CSF, whereas IgG and Alpha-1-antitrypsin are not. CSF-enriched proteins can sometimes be synthesized in a very precise location of the CNS, as exemplified by CSF-transthyretin (prealbumin) (rank 5) which is produced in the choroid plexus. Another CSF-enriched protein is Apolipoprotein E (rank 7); by contrast, Apolipoprotein A-I and A-II are predominantly derived from plasma [113].

Many CSF proteins can be classified into groups, e.g. into 1) structural proteins of various neural cells (NFL, GFAP, protein S-100), 2) hormones and neuropeptides (some of them using the CSF as a pathway for dissemination throughout the CNS), 3) enzymes and enzyme inhibitors, 4) immune and inflammatory mediators (not least cytokines and chemokines). As a final note of physiological and homeostatic interest, it is worth mentioning that enzyme inhibitors (including Cystatin C and Alpha-1-antitrypsin) are the second most abundant protein type in CSF (after albumin) [113]. 


\section{Aims}

\section{WISDOM BRIGHTENS A MAN'S FACE.}

\section{ECCLESIASTES 8:1}

Translational research is research that aims to bridge the gap between basic and clinical science $[125,147]$. Using the practice of ITA at our clinical department as a starting point, the overall aim of this thesis was to conduct translational pain research at the interface between clinical pain medicine and the growing field of human proteomics. More specifically, this thesis project had four concrete aims, corresponding to four papers, succinctly summarized in Figure 10.

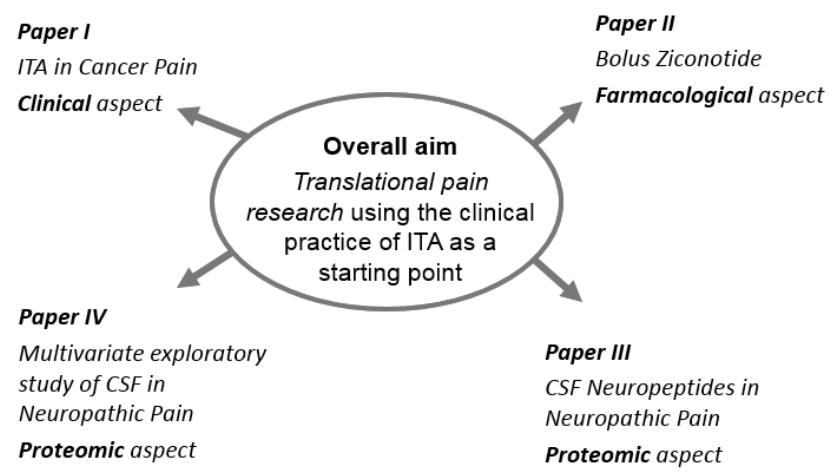

Figure 10 Overall and specific aims of the thesis. 
To be more precise, the four aims were:

1. In patients with severe cancer pain, to evaluate the effects of ITA not only on Spontaneous Resting Pain Intensity (SRPI) and non-ITA opioid doses but also specifically on Movement-Evoked Pain Intensity (MEPI). Hence, we wanted to investigate the issue of BTP in the ITA setting. Our hypothesis was that continuous ITA, with the possibility of extra patient-controlled bolus doses, would lead to substantial relief of both spontaneous resting pain and movement-evoked pain after one week and that this effect would remain for one month. Paper I.

2. To conduct a phase II, open-label, clinical trial investigating the feasibility of trialing the IT analgesic ziconotide by high dose bolus injections. Paper II.

3. In a cross-sectional study, to investigate the concentrations of the classical neuropeptides SP and BE in the CSF of patients with chronic neuropathic pain, compared to healthy controls. We also wanted to relate the levels of CSF-SP and CSF$\mathrm{BE}$ to one another, as a possible indicator of the balance between pro- and antinociceptive factors. Paper III.

4. In an explorative, hypothesis-generating study, to search for CSF biomarkers reflecting the pathophysiological mechanisms of chronic neuropathic pain. To this end, gel-based proteomic technology was combined with Multivariate Data Analysis (MVDA). Paper IV.

Hence, the logic of the project was to move "from the clinic to proteomics". 


\section{3}

\section{Methods}

\section{UNDERTOOK GREAT PROJECTS.}

\section{ECCLESIASTES 2:4}

\subsection{Patients}

The thesis is based on two cohorts of patients.

\subsubsection{Cancer Pain Cohort}

The first cohort, corresponding to Paper I, consists of 28 ITAs performed on patients with severe cancer-related pain. The patients were referred to the Pain Unit of the Pain and Rehabilitation Centre at Linköping University Hospital. The median (range) age was 59 (27-83) years and 14 out of 28 cases were women. Because of an infection in one patient and catheter dysfunction in another, the catheter was replaced in two patients. Hence, Paper I was based on 28 consecutive cases of ITA in 26 individuals.

The most frequent cancer types were lung $(n=5)$ and breast $(n=5)$ cancer. Notably, this study included four cases of vulvar cancer. Twenty cases were clinically assessed as having a neuropathic pain component (see section 3.4.1 for a description of how this was assessed). For detailed characteristics of the patients, see Table 1 in appended Paper $\mathbf{I}$.

\subsubsection{Neuropathic Pain Cohort}

The second cohort of patients participated in a clinical trial of intrathecal bolus injections of the analgesic ziconotide (Paper II), enabling CSF sampling for Paper III and IV.

Inclusion criteria for the clinical trial were 1) patient, at least 18 years of age, suffering from chronic ( $\geq 6$ months) pain, who had failed on conventional pharmacological treatment; only patients with peripheral neuropathic pain due to trauma or surgery were included; 2) Visual Analogue Scale Pain Intensity during week before inclusion $\geq 40 \mathrm{~mm}$ (VASPI-inclusion); 3) patient capable of judgment, i.e. able to understand information regarding the drug, the 
mode of administration and evaluation of efficacy and side effects; 4) signed informed consent.

Exclusion criteria were 1) limited life expectancy (investigator's judgment); 2) intrathecal chemotherapy; 3) known or suspected intracranial hypertension; 4) known liver or kidney disease, defined as serum transaminases, total bilirubin, alkaline phosphatase or creatinine >1.2 Upper Limit of Normal (ULN); 5) advanced cardio-pulmonary disease (investigator's judgment); 6) ongoing infection, whether systemically or locally in the lumbar area; 7) coagulopathy (including medication with warfarin, clopidogrel and heparin); 8) allergy to ziconotide or any of the excipients in the ziconotide vial; 9) history of psychiatric disorders which in the investigator's opinion would put the patient at risk; 10) pregnant or lactating woman (menstruating women had to use contraceptives during the trial period); 11) participation in another clinical trial during the last 30 days.

All patients had at least probable neuropathic pain according to the criteria published by Treede et al, see section 3.4.1 [239]. All patients but two had or had tried opioids; all patients but one were on or had tried amitriptyline and/or duloxetine; all patients but one were on or had tried gabapentinoids (gabapentin and/or pregabalin). Moreover, 18 patients also tried test-SCS. For further detailed characteristics, see Table 1 in appended Paper II.

\subsection{Healthy Controls}

For Paper III and IV, healthy controls were recruited by local advertisement at the Faculty of Health Sciences, Linköping University, Sweden, and by contacting healthy subjects from earlier studies. A structured in-depth interview was conducted to ensure the absence of any significant medical condition. See below section 3.4.7.

\subsection{Medical and Sampling Procedures}

\subsubsection{Body Fluid Sampling}

For every subject in Paper II, III and IV, a blood sample was taken before lumbar puncture. Then, a standard lumbar puncture was performed sitting or in the lateral recumbent position, preferably at level L3-L4 or L4-L5. A 27G pencil-point noncutting Whitacre needle (BD Medical, Franklin Lakes, New Jersey, USA) was used, and $10 \mathrm{ml}$ of CSF was aspirated in $2 \mathrm{ml}$ syringes. The CSF samples were immediately cooled on ice. The blood and CSF samples were transported to the Painomics ${ }^{\circledR}$ laboratory, Linköping University Hospital. The blood samples were centrifuged for $10 \mathrm{~min}$ at $1000 \mathrm{~g}$ within $30 \mathrm{~min}$ of blood collection, plasma was removed, aliquoted and stored at $-70^{\circ} \mathrm{C}$ until analysis. The CSF samples were 
checked for blood contamination and centrifuged for $10 \mathrm{~min}$ at $1000 \mathrm{~g}$ to discard any cellular debris. The supernatant was removed to a new tube and stored as $1 \mathrm{ml}$ aliquots at $-70^{\circ} \mathrm{C}$.

\subsubsection{Ziconotide Trialing Procedure}

The following data were registered: basic demographic data; pain diagnosis; pain duration; present and past medical history; concomitant medication. A physical examination was performed.

Before each ziconotide injection, a blood sample for Creatine Kinase (CK) was taken [215]. Commercially available ziconotide (Prialt ${ }^{\circ}$ ) was used. Apotek Produktion \& Laboratorier (APL), one of the leading contract manufacturers in Life Science in Scandinavia (www.apl.se), diluted Prialt@ according to the standards of the Swedish Medical Products Agency, and vials containing $2 \mathrm{ml}$ of Prialt ${ }^{\circledR} 5 \mu \mathrm{g} / \mathrm{ml}$ were delivered and stored in a refrigerator at $5^{\circ} \mathrm{C}$. Immediately prior to each injection, the investigator (EB) drew the appropriate volume of Prialt $5 \mu \mathrm{g} / \mathrm{ml}$ and diluted it with physiologic saline under aseptic conditions to a total volume of $2 \mathrm{ml}$. The appropriate dose of ziconotide was injected during one minute without barbotage. At 6 hours post-injection, the protocol stated that the patient could either stay in the hospital overnight or be discharged (investigator's judgment).

Each patient received up to three ziconotide bolus injections according to a comprehensive expert-based, agreed-upon algorithm. The first bolus dose was always $2.5 \mu \mathrm{g}$ of ziconotide. After this first injection, the way the patient progressed in the algorithm depended on the presence or absence of clinically meaningful percentage pain reduction (PPR, as calculated according to section 3.4.4) and on the presence or absence of a significant adverse event (AE, as defined in section 3.4.5). See Figure 2 in appended Paper II for a detailed algorithm. Briefly, if the patient experienced:

- no meaningful pain reduction and a significant $\mathrm{AE}$, no second injection was given

- no meaningful pain reduction and no significant AE: the dose of the second injection was increased to $3.75 \mu \mathrm{g}$

- meaningful pain reduction and no significant AE: a dose of $2.5 \mu \mathrm{g}$ was repeated for confirmatory purposes

- meaningful pain reduction and significant AE: the dose of the second injection was decreased to $1.25 \mu \mathrm{g}$

Following the same principles, a third injection could be given to patients who had received 1.25 or $3.75 \mu \mathrm{g}$ at second injection. One week \pm three days elapsed between each injection. 
A patient was considered a "responder" if experiencing meaningful pain reduction (PPR $\geq$ $30 \%$ ) and no significant AE on two consecutive occasions at the same dosage. All other cases were defined as "non-responder".

\subsubsection{Intrathecal Catheters and Pumps}

The placement of ITA-catheters (Paper I) was done under local anaesthesia with varying levels of sedation. A commercially available intrathecal catheter set was used (Celsite ST304-19, B. Braun Medical). The dura mater was punctured and a 19-gauge catheter was threaded into the cerebrospinal fluid. Fluoroscopy was used routinely to place the catheter tip at the segmental level corresponding to the most painful dermatome. Then, the catheter was tunnelled and connected to a subcutaneous port, which was placed in the midclavicular line a few centimetres cranial to the costal arch. Via an external pump (CADD-Legacy ${ }^{\circledR}$ PCA), a combination of morphine $(0.2 \mathrm{mg} / \mathrm{ml})$, bupivacaine $(1 \mathrm{mg} / \mathrm{ml})$, and in some cases clonidine (10 or $20 \mathrm{mcg} / \mathrm{ml}$ ) was infused intrathecally. The usual starting rate was $0.5 \mathrm{ml} / \mathrm{h}$ with patient-controlled boluses of $0.2 \mathrm{ml}$ available up to twice hourly as needed. ITAdosages were subsequently adjusted according to clinical response but were not registered prospectively. Patients were instructed to use the bolus function for BTP, including prophylactically for predictable movement-evoked pain.

\subsection{Assessments}

\subsubsection{Neuropathic Pain Assessment}

In Paper I, the presence of a neuropathic pain component was assessed clinically, taking into account neurological signs such as sensory and motor disturbances, tumour site, radiological findings, and pain characteristics such as a "burning pain", feeling "electric shocks", or feeling "pins and needles".

In Paper II-IV, the certainty of the presence of neuropathic pain was reported using the grading system adopted both by the neuropathic pain special interest group of IASP, and by the European Federation of Neurological Societies [165,239]. The four criteria are:

1) Pain with a distinct neuroanatomically plausible distribution. Due to referred pain or central sensitization, the distribution may extend outside the primary innervation territory, but it must still be plausible in terms of the underlying disorder.

2) A history of a relevant lesion or disease affecting the somatosensory system.

3) Confirmatory tests demonstrating presence of negative or positive sensory signs confined to innervation territory of the lesioned nervous structure (i.e. hypoesthesia, allodynia or hyperalgesia). 
4) Further diagnostic tests confirming lesion or disease entity underling the neuropathic pain.

Criteria 1+2 equals "possible" neuropathic pain. The addition of Criteria 3 or 4 equals "probable" neuropathic pain, whereas the addition of Criteria 3 and Criteria 4 equals "definite" neuropathic pain [165,239].

\subsubsection{Numerical Rating Scale and Global Level of Satisfaction}

At the time of ITA procedure (Paper I), the patients graded Spontaneous Resting Pain Intensity (SRPI) and Movement-Evoked Pain Intensity (MEPI) for the last 24 hours. A 010 Numerical Rating Scale (NRS) was used. Zero denoted "no pain" and 10 "worst imaginable pain". Using the same scale, SRPI and MEPI were also recorded one week \pm two days (T1w) and one month \pm one week (T1m) after the ITA procedure. We defined mild pain as NRS $\leq 3$ and severe pain as NRS $\geq 7$. When treatment ended, the patients also verbally graded their global level of satisfaction with the ITA-treatment: very satisfied; rather satisfied; neither satisfied nor dissatisfied; rather dissatisfied; and very dissatisfied. When ITA continued until death, the closest relatives were asked to grade their view of the patient's level of satisfaction.

\subsubsection{Concomitant Medicines}

In all patients and controls, concomitant medicines were registered. Opioids were converted to oral morphine equivalents as follows: $100 \mathrm{mg}$ oral morphine $=50 \mathrm{mg}$ oral oxycodone $=$ $20 \mathrm{mg}$ oral hydromorphone $=20 \mathrm{mg}$ oral methadone $=1 \mathrm{mg}$ transdermal fentanyl $[155,218]$. For morphine and hydromorphone, a mean oral bioavailability of $33 \%$ was used.

\subsubsection{VASPI, Percentage Pain Reduction, and PGIC}

The primary outcome variable in Paper II was patient-reported Visual Analogue Pain Intensity (VASPI). A horizontal, 0-100 mm, continuous, unmarked line was used, zero representing no pain and $100 \mathrm{~mm}$ worst pain imaginable. The patients were asked to draw a line perpendicular to the VASPI-line at the appropriate place [107]. Immediately before each ziconotide injection, VASPI was reported for three time frames: past week (VASPI7d); past 24 hrs (VASPI-24h); current (VASPI-now). After each ziconotide injection, patients reported VASPI-now hourly for 6 hours (separate sheets of paper were used for each hourly rating), and the mean of these 6 post-injection values was calculated (VASPImean). Ziconotide-induced PPR was calculated using pre-injection VASPI-now and postinjection VASPI-mean (i.e., the mean of the 6 post-injection values). PPR $\geq 30 \%$ was defined as clinically meaningful [74]. 
At 6 hours post-injection, Patient Global Impression of Change (PGIC) for the past 6 hours (PGIC-6h) was also recorded. PGIC is a 7-point scale that ranges from "very much improved" to "very much worse" with "no change" as the mid-point [74]. At 24 hours postinjection, the patient graded VASPI-24h, VASPI-now and PGIC for the past 24 hours (PGIC-24h).

\subsubsection{Adverse Events}

In Paper I, AEs were not prospectively recorded; however, if ITA was discontinued, the cause of discontinuation was registered prospectively. In Paper II, an AE was defined as any undesirable experience appearing within 24 hours after each injection, whether or not considered related to intrathecal ziconotide. All AEs reported spontaneously by the subject or observed by the investigators were recorded in a specific AE-form and in the medical record. The intensity was graded by the investigator on a 3-point scale: mild (discomfort but no disruption of normal daily activity); moderate (discomfort sufficient to reduce or affect normal daily activity); severe (inability to perform daily activity). An AE of moderate or severe intensity was considered to be significant, and only significant AEs influenced the way patients progressed in the study algorithm. For each adverse event the relation to the ziconotide bolus was rated as: probable; possible; unlikely; not assessable.

In accordance with the principles of Good Clinical Practice (GCP), the occurrence within 24 hours after each ziconotide injection of an AE that was fatal, life-threatening, disabling or required/ prolonged in-patient hospitalization or caused congenital anomaly was defined in the protocol as a Serious Adverse Event (SAE). Furthermore, if not listed in the Summary of Product Characteristics (SPC) or in the official Swedish medicines compendium (www.fass.se), a SAE was defined as a Suspected Unexpected Serious Adverse Reaction (SUSAR), prompting immediate report to the relevant authorities.

\subsubsection{Vital Signs}

During the first hour post-injection (Paper II), vital signs (heart rate, blood pressure and oxygen saturation) were recorded every 15 minutes. Thereafter, vital signs were recorded hourly for 5 hours. Mean arterial pressure (MAP) was calculated using systolic blood pressure $(\mathrm{SBP})$ and diastolic blood pressure $(\mathrm{DBP})$ as follows: $\mathrm{MAP}=(\mathrm{SBP}+(2 * \mathrm{DBP})) / 3$ [254].

\subsubsection{Healthy Controls Structured Interview}

A structured interview was conducted to ensure the absence of any significant medical condition. The following areas were specifically assessed in the interview: earlier major trauma; back, joints, muscles or skeletal disease; heart or vascular disease; lung or bronchial disease; psychiatric symptoms; neurological, ear or eye disease; digestive tract disease; 
kidney, urinary or genital disease; skin disease; tumour or cancer; endocrine disease; haematological disease; birth defects; other disease, disability or allergy. Moreover, the presence of a known bleeding disorder was specifically inquired for. The absence of a chronic pain condition was ensured by a structured questionnaire covering sociodemographic data, presence of pain now, location of pain now, generalization of pain, presence of intermittent pain, duration of persistent pain. The questionnaire also covered anxiety and depressive symptomatology using Hospital Anxiety and Depression Scale [276], coping aspects (i.e., catastrophizing) using Pain Catastrophizing Scale [235] and health-related quality of life aspects using Short Form-36 (SF-36) [234] in order to ensure that the controls were healthy. Subjects were also given the possibility to make a pain drawing about pain now, pain at worst and pain at best. Musculoskeletal pain was more deeply assessed by VASPI last month for 9 specific anatomical locations: neck; shoulders; arms; hands; upper back; lower back; hips; knees; feet. Concomitant medicines were registered. A medical examination was performed, including assessment for fibromyalgia tender points.

\subsection{Luminex Technology Kit}

In Paper III, SP and BE were quantified by using the MILLIPLEX® MAP Human Neuropeptide Magnetic Panel Kit, HNPMAG-35K (EMD Millipore Corporation, Billerica, MA, USA). This is a Luminex technology kit, which enables simultaneous quantification of SP and BE in the same assay and comprises all components necessary (buffers, standards and microplate) for the whole assay procedure. SP and BE from plasma samples were extracted by acetonitrile precipitation method according to the manufacturer's recommendations. $50 \mu 1$ of the extracted plasma samples and $50 \mu 1$ of CSF were analysed in the Luminex 200 instrument (Life Technologies, Invitrogen Stockholm, Sweden). The concentrations were calculated by reference to a seven-point five-parameter logistic standard curve for each substance using MasterPlex QT 2010 (MiraiBio Inc., San Diego, CA, USA).

\subsection{Gel-Based Proteomics}

For a detailed description of the gel-based proteomics method that was used, see appended Paper IV. Here, a broad, non-technical overview will be presented. The overall workflow is presented in Figure 11. 


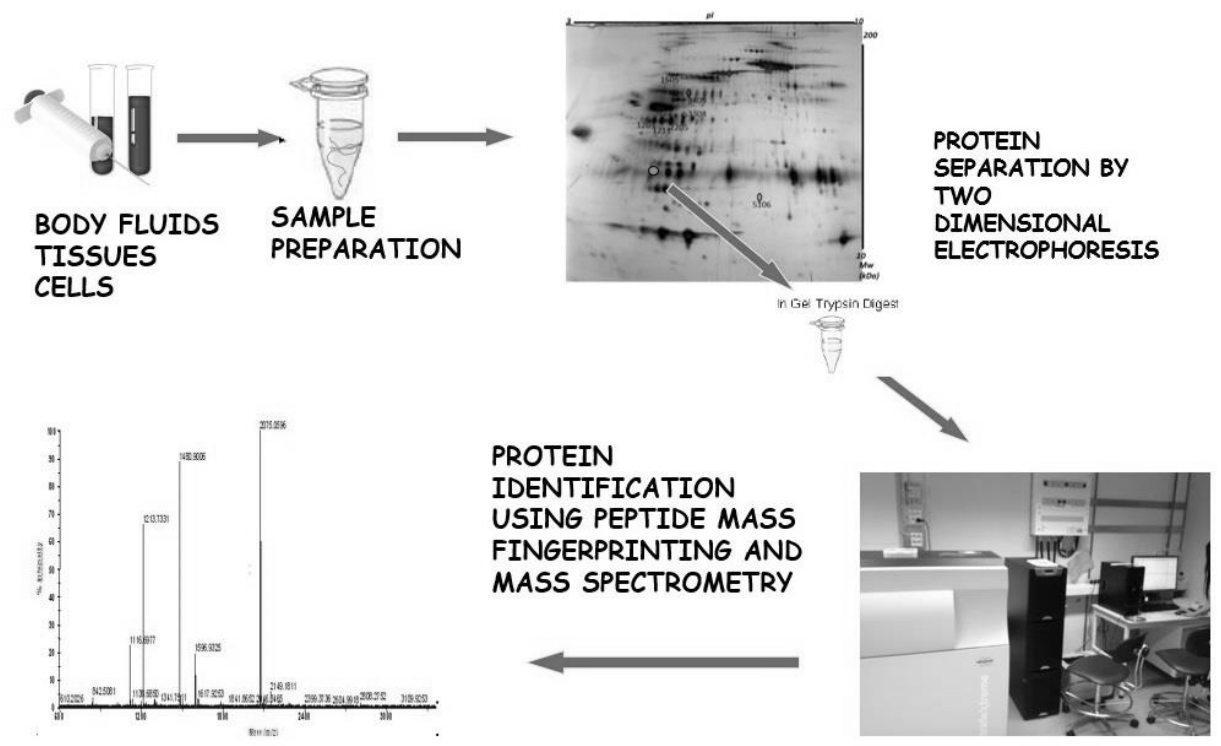

Figure 11 Schematic workflow of gel-based proteomics, from sampling of the relevant body fluid, tissue or cells (top left), to sample preparation and protein separation by twodimensional gel electrophoresis, to excision of a particular spot and protein identification by mass spectrometry.

The proteome is the total protein content in a specific cell, body fluid or tissue. Whereas the genome is constant, the proteome is constantly modulated by genome-environment interactions [169,170]. Post-translational modifications (PTMs) generate a tremendous protein diversity from the $\sim 20000$ protein-coding genes of the human genome, the complexity of the proteome being several orders of magnitude greater than the coding capacity of the genome $[50,115,122]$. The relationship between genome, transcriptome and proteome is depicted in Figure 12. After the genome, mapping different proteomes is next in turn [127].

PTMs modulate enzyme activity, protein turnover and localization, protein-protein interactions, various signalling cascades, DNA repair, and cell division [122]. It is becoming increasingly clear that PTMs are important in both health and disease. For instance, posttranslational glycosylation patterns are said to be an extremely sensitive indicator of intracellular conditions, and the fields of glycoproteomics is emerging as an important contributor in the search for biomarkers in different medical conditions [109]. The glycosylation form of a protein can be altered significantly because of diseases such as cancer, inflammatory conditions and neurodegenerative disorders [72,151,180]. For example, the role of glycosylation on alpha-1-antitrypsin has recently been reviewed [151]. Hence, PTM-patterns are probably important when trying to identify the molecular 
"fingerprints" of different pain conditions. Other important forms of PTMs include acetylation, deamidation, hydroxylation, nitration, palmitoylation, phosphorylation, sulfation and ubiquitination [122,205]. Hence, looking only at total levels of a particular protein is probably often too simplistic.

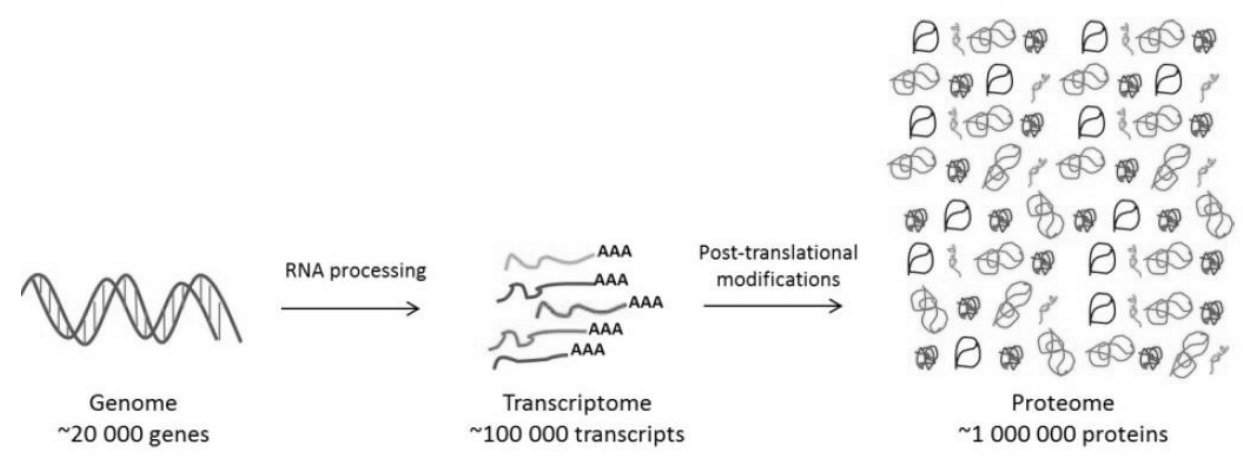

Figure 12 The DNA to RNA to protein complexity. Each gene can give rise to multiple mRNA transcripts by e.g. alternative splicing. The number of protein variants is further increased by post-translational modifications. Reproduced with permission from [110].

Two-dimensional gel-based proteomics is a well-known analytical method with high resolution and good quantitative analysis capability; it is particularly suited for mapping PTM patterns [193,194,205]. Two-dimensional maps of the proteome are generated by twodimensional gel electrophoresis, enabling the visualization and quantification of hundreds of proteins, each protein appearing as a spot (see proteome map in Figure 11) [169,170]. The Spot Optical Density (SOD) is a surrogate measure for relative quantity. Selected proteins are then excised and identified by mass spectrometry. The major limitations of twodimensional gel techniques have to do, on the one hand with the fact that only highly abundant proteins are detected and, on the other hand with the fact that "extreme proteins" (extremely basic or acidic, extremely small or big) fall outside the $\mathrm{pI} / \mathrm{Mw}$ range of detection (in this thesis 8-250 kDa for Mw and 3-10 for $\mathrm{pI}$ ) [193,194].

\subsection{Statistics}

\subsubsection{Traditional Statistics}

In Paper I, McNemar's test was used for comparing proportions, and Wilcoxon Signed Rank Test was used to compare non-ITA opioid doses. The IBM Statistical Package for the Social Sciences (SPSS, IBM Corporation, Somers, NY, USA) version 17.0 was used for all analyses. 
In Paper II, we used IBM® SPSS® Statistics Version 21. Patients were descriptively classified as responders or non-responders. Because of the complicated data structure generated from the study algorithm (each patient receiving one, two or three bolus injections), a summary measures approach was chosen for inferential statistics [150]. Hence, for patients who were injected twice or thrice, mean values were calculated at each time point for VASPI, pulse, blood pressure, PGIC and ziconotide dose, resulting in one set of outcome data for each patient. Repeated Measures Analysis of Variance (RM-ANOVA) and paired t-test were used to measure change over time. When the assumption of sphericity was not met for RM-ANOVA (i.e. when Mauchly's test $\leq 0.05$ ), Greenhouse-Geisser was chosen. Using a Bonferroni correction for post hoc analysis was judged to be far too conservative (high risk of Type II error); least significance difference was chosen instead in SPSS (equivalent to no correction). Moreover, Fisher's exact test or Wilcoxon signed ranks test were used when appropriate.

For traditional univariate statistics of Paper III, SPSS version 20.0 was used. For comparisons between groups, we performed the Mann Whitney U test or, for categorical data, the Chi-square test or Fisher's exact test. Spearman's non-parametric rank correlation coefficient $\left(\mathrm{r}_{\mathrm{s}}\right)$ was used for correlation analysis.

For traditional univariate statistics of Paper IV, all computations were made using IBM® SPSS® Statistics version 20. Mann-Whitney U test, Fisher's exact test, and Spearman's rho for correlation were used as appropriate. As many variables were analyzed, one should be aware the problem of multiple testing, i.e. a high risk of Type I errors (false positives). Changing the significance level, e.g. with a Bonferroni correction, was considered to be too conservative in this exploratory study, because of the corresponding risk increase of Type II errors (false negatives) [261].

For all papers, a p-value of $\leq 0.05$ was accepted as significant.

\subsubsection{Multivariate Data Analysis}

\section{Conceptual background}

Each proteomic sample can generate the quantification of hundreds or even thousands of potentially mutually interacting proteins. Traditional univariate statistical methods can quantify level changes of individual substances but disregard interrelationships between them and thereby ignore system-wide aspects. The development of Omics methods (meaning large-scale characterization and quantification of pools of biological molecules) has been paralleled by the development of statistical methods capable of handling such a high number of inter-correlated variables in few individuals - i.e., Multivariate Data 
Analysis by projection (MVDA) [80,261]. For MVDA computations in this thesis project (Paper III and IV), SIMCA (Umetrics AB, Umeå, Sweden) was used.

Conceptually, imagine a multidimensional space where each protein is a dimension (" $\mathrm{k}$ " dimensions). Each subject (patient or control) will be a point in this k-dimensional space. Due to a combination of technological development (rendering high " $k$ ") and practical/economic constraints (leading to a low number of subjects "n"), todays data tables in the Omics field often have a low subjects-to-variables ratio $(\mathrm{n}<<<\mathrm{k})$. Classical regression techniques like multiple linear regression (MLR) or logistic regression (LR), which were developed in the early days of the $20^{\text {th }}$ century, are not suited for such high-dimensional and multi-collinear data. Hence, todays data table often break one of the underlying assumption behind MLR and LR, namely that the predictor (X) variables are fairly independent. MLR and LR also assume that a high subject-to-variables ratio is present (e.g., >5), and they have difficulties coping with missing data. Due to the above-mentioned drawbacks of classical regression techniques (with regression coefficients becoming unstable and their interpretability breaking down), the modern MVDA method of Orthogonal Partial Least Squares (OPLS) regression was used instead. OPLS can handle subject-to-variables ratios $<1$, and copes well with both multi-collinearity and missing data. OPLS is a recent, easierto-interpret modification of Partial Least Squares (PLS). In OPLS-Discriminant Analysis (OPLS-DA), the outcome variable (Y) is nominal, e.g. patient or healthy control. The MVDA workflow of Paper IV and the reporting of parameters necessary for evaluating model quality were in accordance with the paper published by Wheelock \& Wheelock [261]. Before all MVDA analyses, data were log-transformed when needed (using the SIMCA function "auto transform selected variables as appropriate") and scaling to unit variance was applied [80,261,265].

\section{Statistical workflow}

First, the data was overviewed by unsupervised Principal Components Analysis (PCA), which is the foundation of all latent variable projection methods (Paper III and IV). PCA entails the definition of only a few latent variables that describe the underlying structure in the data. The latent variables (called principal components, PC) are uncorrelated to each other, and they summarize and simplify the data, separating information from noise and enabling to find relevant patterns in the data. Optimal model dimensionality (i.e. number of PCs) is determined by cross-validation, which is a practical and reliable way to test the significance of a PCA model. This is default in SIMCA. Hence, PCA can be viewed as a form of multivariate correlation analysis. PCA also enables the identification of outliers and deviant subgroups. A PC relates to each original variable by a loading (p), which has a value between -1 and +1 . Variables with high loadings (ignoring the sign) are considered to be of large or moderate importance for the PC under consideration. Variables that have high loadings (with positive or negative sign) on the same PC are inter-correlated. Two plots are generated from the PCA analysis: The score plot illustrates the relationships between the 
subjects, using PCs as axes in a two- or three-dimensional coordinate system and representing each subject by a dot. The complementary loading plot describes the relationships between variables $[80,261,265]$.

After data overview with PCA, OPLS-DA was used in Paper IV to regress (predict) group membership, i.e. to find which variables were responsible for class discrimination (patient or healthy control). Hence, the outcome variable (Y) was nominal (patient or healthy control), whereas the predictor variables (Xs) where numerical (relative quantification of each measured protein by SOD). In SIMCA, optimal model dimensionality (i.e. the number of latent variables) is by default determined by cross-validation, which is a practical and reliable way to test the significance of the model. The $\mathrm{R}^{2}$ value indicates how well the model explains the dataset, and cross-validated $\mathrm{Q}^{2}$ is a measure of the predictive power of the model. If $\mathrm{R}^{2}$ is substantially greater than $\mathrm{Q}^{2}$ (a difference $>0.3$ is mentioned in the literature [80]), the robustness of the model is poor, implying overfitting [261]. Moreover, Analysis of Variance of Cross-Validated predictive residuals (CV-ANOVA), which is a SIMCA diagnostic tool for assessing model reliability, was also computed. CV-ANOVA measures the significance of the observed group separation and provides a familiar $\mathrm{p}$-value metric for the model [261]. Group separation and dimensionality reduction are both metaphorically conceptualized Figure 13.
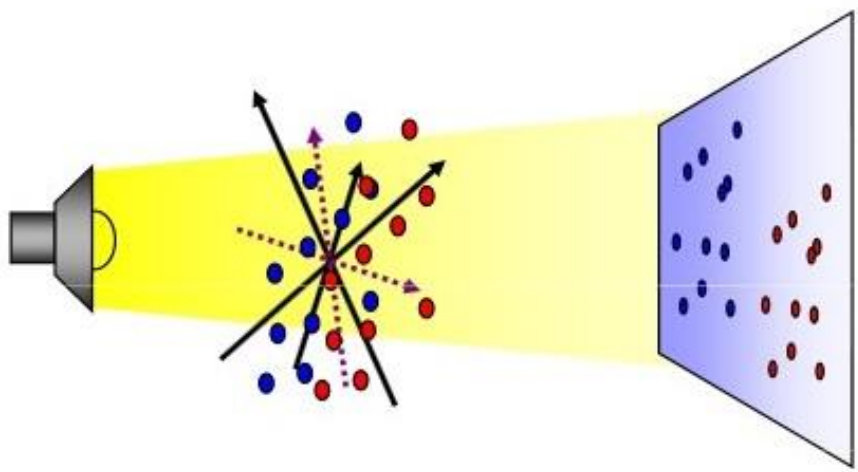

Figure 13 Metaphorical representation of the principle of dimensionality reduction (in this highly simplified case, from three to two dimensions) combined with group separation by OPLS-DA. Reproduced with permission from Umetrics AB. The "angle" of the flashlight is chosen to maximise group separation. In Paper IV, 260 dimensions are reduced to two or three dimensions, as exemplified by Figure 15 and Figure 16.

The importance of the variables can be measured as a Variable Influence on Projection (VIP) value. This indicates the relevance of each $\mathrm{X}$-variable pooled over all dimensions and Y-variables - the group of variables that best explain Y. Variables with VIP $\geq 1.0$ and having 
a 95\% confidence interval not including zero are usually considered significant, but in Paper IV, VIP $\geq 1.5$ was used for OPLS-DA. The direction of the relationship (positive or negative) was determined by sign of the corresponding loading. In addition to OPLS-DA, OPLS was also used in patients $(n=11)$ with age as outcome $(Y)$ variable, rendering an ageVIP. Age-VIP <1 or having a 95\% confidence interval including zero was taken to indicate a low risk of an association between protein and patient age. In Paper III, VIP-values were generated using PLS [80,261,265].

\subsection{Good Clinical Practice}

Ziconotide (Prialt $\left.{ }^{\circledR}\right)$ is approved for intrathecal continuous infusions, not intrathecal bolus injections. Hence, the relevant authorities in Sweden considered that the standards of ICHGCP (International Conference of Harmonization - Good Clinical Practice) had to be applied in Paper II. Accordingly, this EudraCT 2010-018920-21 study was conjointly approved by the Swedish Medical Products Agency and the Regional Ethics Committee in Linköping, Sweden. Study monitoring was effectuated by the Linköping Academic Research Centre, based at University Hospital, Linköping, Sweden. The study protocol was pre-published on-line on ClinicalTrials.gov (identifier NCT01373983), which is a registry database of publicly and privately supported clinical studies for human subjects. ClinicalTrials.gov is a service of the US National Institutes of Health. 


\section{4}

\section{Results}

WHAT DOES THE WORKER GAIN FROM HIS TOIL?

ECCLESIASTES 3:9

Referring back to the specific aims described in Chapter 2, the main findings of Papers IIV will be summarized in the present chapter. Instead of merely transcribing all results reported in the papers, I will focus on some of the main findings of Paper I-III and present the results of Paper IV in more detail. For supplementary information, the reader is referred to the Results section of Papers I-IV.

\subsection{Movement-Evoked Pain despite Intrathecal Analgesia}

The main results from Paper I are summarized in Table 1. For a quick overview, the reader is also referred to the figures in the paper itself. In brief, we showed that movement-evoked BTP remained a major clinical problem in patients with ITA throughout the study month: $44 \%$ still had severe MEPI after one week and $40 \%$ after a month.

Table 1 Spontaneous resting pain intensity (SRPI) and movement-evoked pain intensity (MEPI) graded by a 0-10 numerical rating scale (NRS), and non-intrathecal analgesia (nonITA) opioid doses at the time of ITA start (T0), after one week (T1w), and after one month (T1m). *Denotes statistical significance, $P \leq 0.05$. Opioid doses are oral morphine equivalents (mg/day).

\begin{tabular}{|c|c|c|c|c|c|}
\hline & $\begin{array}{l}\text { T0 } \\
(\%)\end{array}$ & $\begin{array}{l}\mathrm{T} 1 \mathrm{w} \\
(\%)\end{array}$ & $\begin{array}{l}\mathrm{T} 1 \mathrm{~m} \\
(\%)\end{array}$ & $\begin{array}{l}\text { Statistics T0 } \\
\text { vs. T1w }(P)\end{array}$ & $\begin{array}{l}\text { Statistics T1w } \\
\text { vs. T1m (P) }\end{array}$ \\
\hline \multicolumn{6}{|l|}{ SRPI $0-10$, NRS } \\
\hline $\mathrm{n}$ & 26 & 21 & 16 & & \\
\hline $\mathrm{SRPI} \leq 3$ & (27) & (76) & (69) & $0.002^{*}$ & 1.0 \\
\hline $\mathrm{SRPI} \geq 7$ & (31) & $(0)$ & (13) & $0.008^{*}$ & 1.0 \\
\hline \multicolumn{6}{|l|}{ MEPI $0-10$, NRS } \\
\hline $\mathrm{n}$ & 25 & 18 & 15 & & \\
\hline $\mathrm{MEPI} \leq 3$ & (12) & (44) & (33) & 0.07 & 1.0 \\
\hline $\mathrm{MEPI} \geq 7$ & (56) & $(44)$ & (40) & 0.453 & 0.25 \\
\hline \multicolumn{6}{|l|}{ Non-ITA opioids } \\
\hline $\mathrm{n}$ & 28 & 27 & 17 & & \\
\hline Median & 575 & 120 & 69 & $<0.001^{*}$ & 0.289 \\
\hline Min, max & $0-3680$ & $0-1500$ & $0-2340$ & & \\
\hline
\end{tabular}


However, no patient had severe SRPI after one week compared to $31 \%$ before ITA, and the proportion of patients with mild SRPI had increased from $27 \%$ to $76 \%$. Meanwhile, the median daily dose of non-ITA opioids decreased from 575 to $120 \mathrm{mg}$ of oral morphine equivalents. The positive effect on SRPI and on doses of non-ITA opioids remained essentially unchanged during the study month.

\subsection{Ziconotide Bolus Trialing Seems Feasible}

\subsubsection{Low Proportion of Responders}

In Paper II, a total of 36 injections were given to 23 patients. The results, expressed as PPR for each bolus injection, are summarized in Figure 14 and in the figures of appended Paper II. We found a low proportion of responders (13\%). However $30 \%$ of patients experienced $\geq 30 \%$ pain reduction on a least one injection, yielding a number needed to treat of $\sim 3$ for clinically significant pain relief. Pain intensity changed significantly over time $(0-6 \mathrm{~h})$ ( $\mathrm{p}=0.047$ ) after a mean ziconotide dose of $2.75 \mu \mathrm{g}$. Pairwise post hoc analysis showed that the only time point at which pain intensity significantly differed from any other time point was the pre-injection VASPI-now; it differed significantly from time points $1 \mathrm{~h}, 2 \mathrm{~h}, 4 \mathrm{~h}$ and 5h. Moreover, VASPI-mean was significantly lower than pre-injection VASPI-now $(\mathrm{p}=0.019)$. However, pre-injection VASPI-24h did not differ significantly from postinjection VASPI-24h ( $\mathrm{p}=0.078)$. The PGIC mode was "no change", both after 6 and 24 hours.

\subsubsection{Adverse Events}

Fifteen out of 23 patients experienced a total number of 33 AEs on 18 occasions. No SAE occurred. AEs occurring more than once were, in falling order of frequency: dizziness (9); tiredness (6); headache (5 - none of them being a classical post dural puncture headache); nausea and/or vomiting (3); itch (2). All AEs were consistent with the SPC, and all resolved. Seventeen out of 33 AEs were mild, 16 were moderate, and none was severe. The relation to the ziconotide bolus was rated as probable in 24 cases; possible in 7; unlikely in 2; not assessable in one. When the relation to ziconotide was assessed to be probable or possible, the number of days to AE stop date was 1 (0-6) day (median, range). 


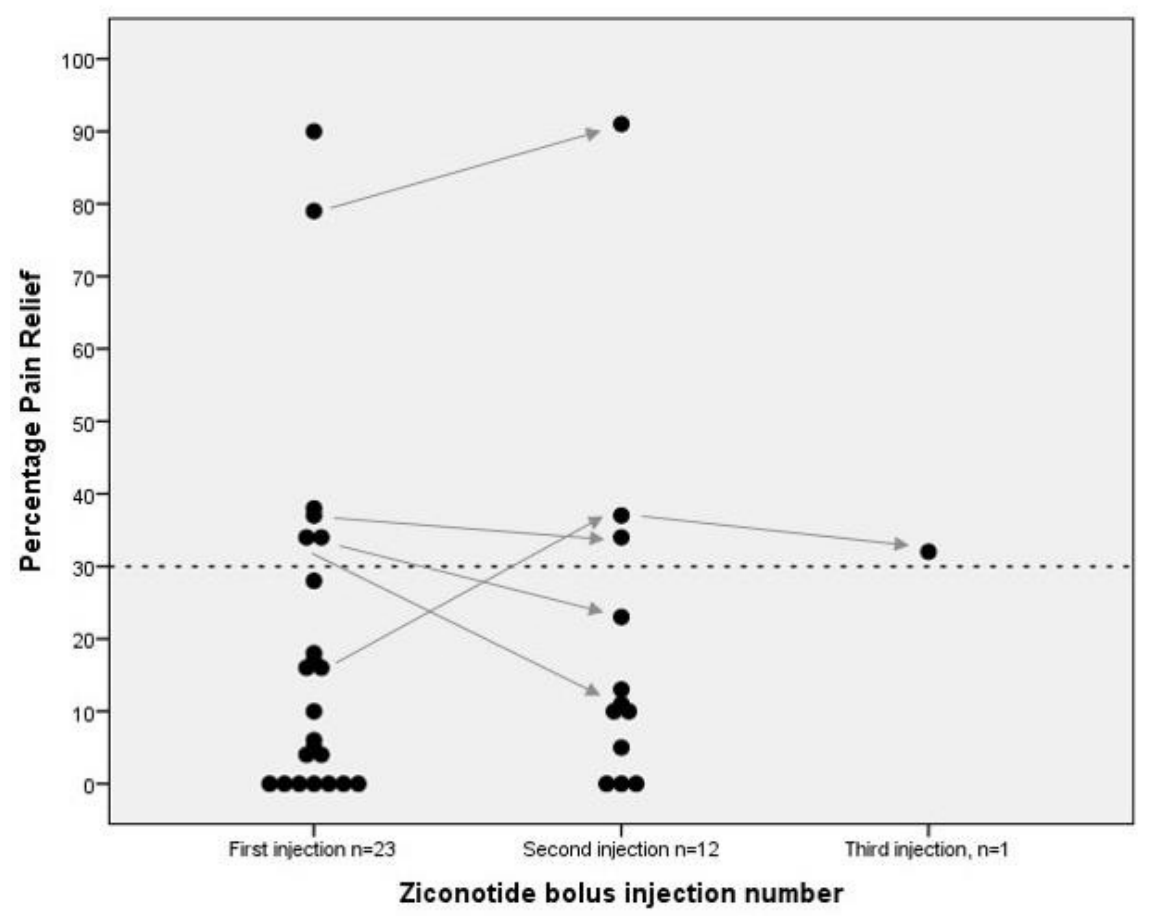

Figure 14 Percentage Pain Reduction of each bolus injection. Each dot represents one injection of ziconotide, and the dotted line represents $30 \%$ pain reduction. Negative values are depicted as zero. The first injection dose of ziconotide was always $2.5 \mu \mathrm{g}$. The second and third injection doses varied according to the study algorithm $(1.25,2.5$, or $3.75 \mu \mathrm{g})$. Only one patient completed three injections. Arrows indicate how patients experiencing more than $30 \%$ pain reduction on at least one occasion and receiving more than one injection progressed in the study.

\subsection{Low CSF Beta-Endorphins in Neuropathic Pain}

In Paper III, we found low levels of BE in the CSF of neuropathic pain patients $(66 \pm 11$ $\mathrm{pcg} / \mathrm{ml})$ compared to healthy controls $(115 \pm 14 \mathrm{pcg} / \mathrm{ml})(\mathrm{p}=0.017)$. SP levels in the CSF did not differ $(20 \pm 2 \mathrm{pcg} / \mathrm{ml}, 26 \pm 2, \mathrm{p}=0.08)$. However, MVDA showed that belonging to the patient group was associated with low levels of both substances in the CSF. A higher correlation between the levels of BE and SP in CSF was found in healthy controls than in patients $\left(r_{s}=0.725, p<0.001\right.$ vs $\left.r_{s}=0.574, p=0.032\right)$. For a quick overview, the reader is referred to the figures and tables of appended Paper III. 


\subsection{A Neuropathic Pain Proteomic Fingerprint?}

\subsubsection{Data Overview and Quality Control}

Initially (data not presented in Paper IV), our data consisted of 28 individuals. The data table was overviewed and quality-controlled by unsupervised PCA. The PCA model (3 PCs, $\mathrm{R}^{2}=0.39, \mathrm{Q}^{2}=0.14$ ) revealed a cluster of sex deviant individuals (Figure 15). Retrospective checking confirmed that these six individuals had indeed been analysed together, and that the gel separation process of this group had been biased with an abnormally long duration (six hours vs usually four hours). These six individuals were therefore excluded from further analysis.

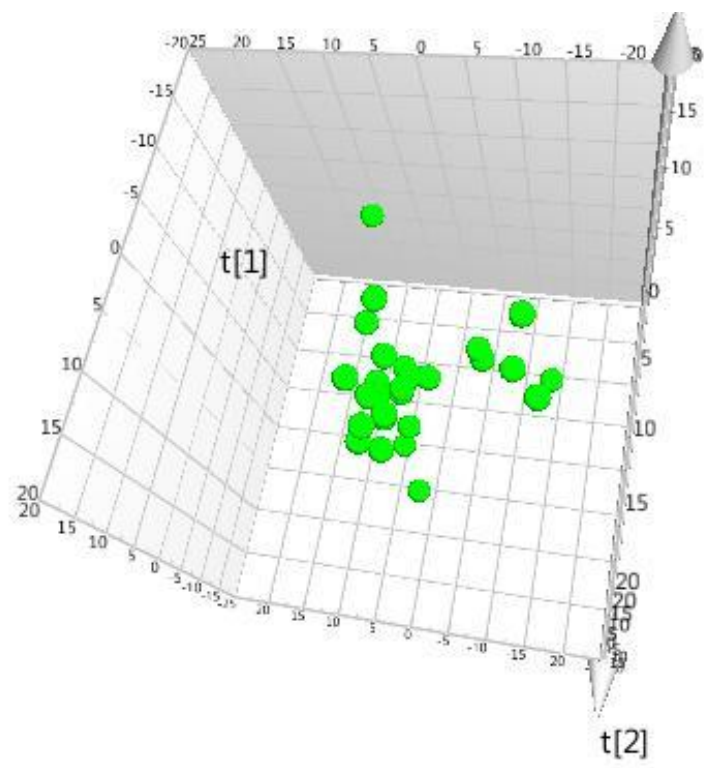

Figure 15 Three-dimensional score plot of initial PCA overview of proteomic data $(n=28)$. Each dot represents an individual (patient or healthy control). The three dimensions of the plot $(\mathrm{t}[1], \mathrm{t}[2], \mathrm{t}[3])$ correspond to the three principal components of the model. On the righthand side, a cluster of six individuals can be identified. These six individuals were excluded from further analysis, see text.

In the remaining 22 individuals, a new PCA model was computed ( 2 PCs, $\mathrm{R}^{2}=0.29$, $\mathrm{Q}^{2}=0.06$ ) to check for multivariate outliers. No strong outlier was found by Hotelling's $\mathrm{T}^{2}$ $\left(\mathrm{T}^{2} \mathrm{Crit} 99 \%\right)$. Distance to model in X-space (DModX) identified two non-serious borderline moderate outliers, which hence were not excluded from further analysis) to check for 
multivariate outliers. Thus, the results of Paper IV are based on 22 individuals: 11 patients and 11 healthy controls. Details about patients and healthy controls are given in appended Paper IV.

\subsubsection{Regression of Class Discriminating Proteins}

In order to identify proteins discriminating between patients and healthy controls, an OPLSDA regression model with three latent variables (one predictive inter-class and two orthogonal intra-class) was computed. The model had an excellent fit $\left(\mathrm{R}^{2}=0.99\right)$ and a good predictivity $\left(\mathrm{Q}^{2}=0.70\right)$. Hence, clear class separation was achieved (as illustrated in Figure 16) and, using CV-ANOVA, the model was shown to be highly significant ( $\mathrm{p}=0.005$ ).

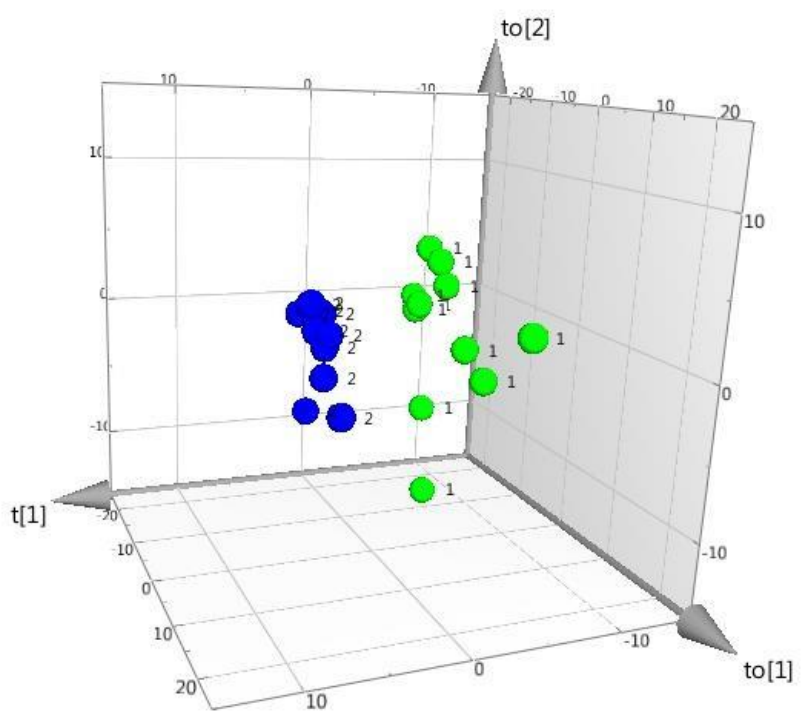

Figure 16 Three-dimensional score plot of group membership OPLS-DA. Class separation between patients ( $n=11$, green dots (1) on the right-hand side of the plot) and healthy controls ( $n=11$, blue dots (2) on the left-hand side of the plot) occurs along the $t[1]$ axis (inter-class variation), whereas the other two axes (to[1] and to[2]) represent intra-class variation. 
VIP computations led to the identification of 36 proteins highly associated with class discrimination (VIP $\geq 1.5$ ), i.e. discriminating between patients and healthy controls. Due to the possible confounding effect of age, a three latent variables OPLS regression model was computed for patients $(n=11)$, with age as outcome $(Y)$ variable $\left(R^{2}=0.99\right.$ and $\left.Q^{2}=0.78\right)$. Out of 36 class discriminating proteins, four were excluded due to a possible confounding effect of age (haptoglobin alpha chain, Ig gamma-1, plasminogen isoform, and unknown protein). Hence, 32 proteins were finally selected as being potential biomarkers. The proteins are listed in a table in appended Paper IV.

\subsubsection{The Seven Most Discriminating Proteins}

The OPLS-DA analysis showed that 7 protein spots had VIP $\geq 2$ and no missing values. The 7 proteins were (in falling order according to VIP): one isoform of angiotensinogen, two isoforms of alpha-1-antitrypsin, three isoforms of haptoglobin, and one isoform of pigment epithelium-derived factor (PEDF) (Figure 17).

Angiotensinogen (spot 3409): The isoform spot 3409 of angiotensinogen was significantly up-regulated in patients, and had the highest discriminatory power between patients and healthy controls. In total, five angiotensinogen isoforms were identified, and total angiotensinogen (ie, the sum of the five isoforms) did not differ between groups ( $\mathrm{p}=0.533$ ). Isoform spot 3409 represented $46 \%$ (median value) of total angiotensinogen in patients, compared to $12 \%$ in controls $(\mathrm{p}=0.001)$, indicating a shift in the balance between angiotensinogen isoforms.

To investigate a possible confounding effect of hypertension, a new OPLS-DA was computed after exclusion of the three patients having a hypertension diagnosis. Even then, angiotensinogen isoform spot 3409 had the highest VIP of all, and it was of the same magnitude ( $\mathrm{VIP}=2.6$ ). Moreover, with hypertension patients excluded, a significant group difference still existed according to traditional statistics $(\mathrm{p}=0.002)$.

To investigate a possible confounding effect of opioid medication, a new OPLS-DA was computed after exclusion of patients taking opioids. Even then, angiotensinogen isoform spot 3409 had the highest VIP of all (VIP=2.97). Moreover, with patients on opioids excluded, both groups still differed by traditional statistics $(\mathrm{p}<0.001)$. No correlation between age and spot 3409 was found in patients $(n=11$, Spearman's rho=0.05, $p=0.884$ ). 

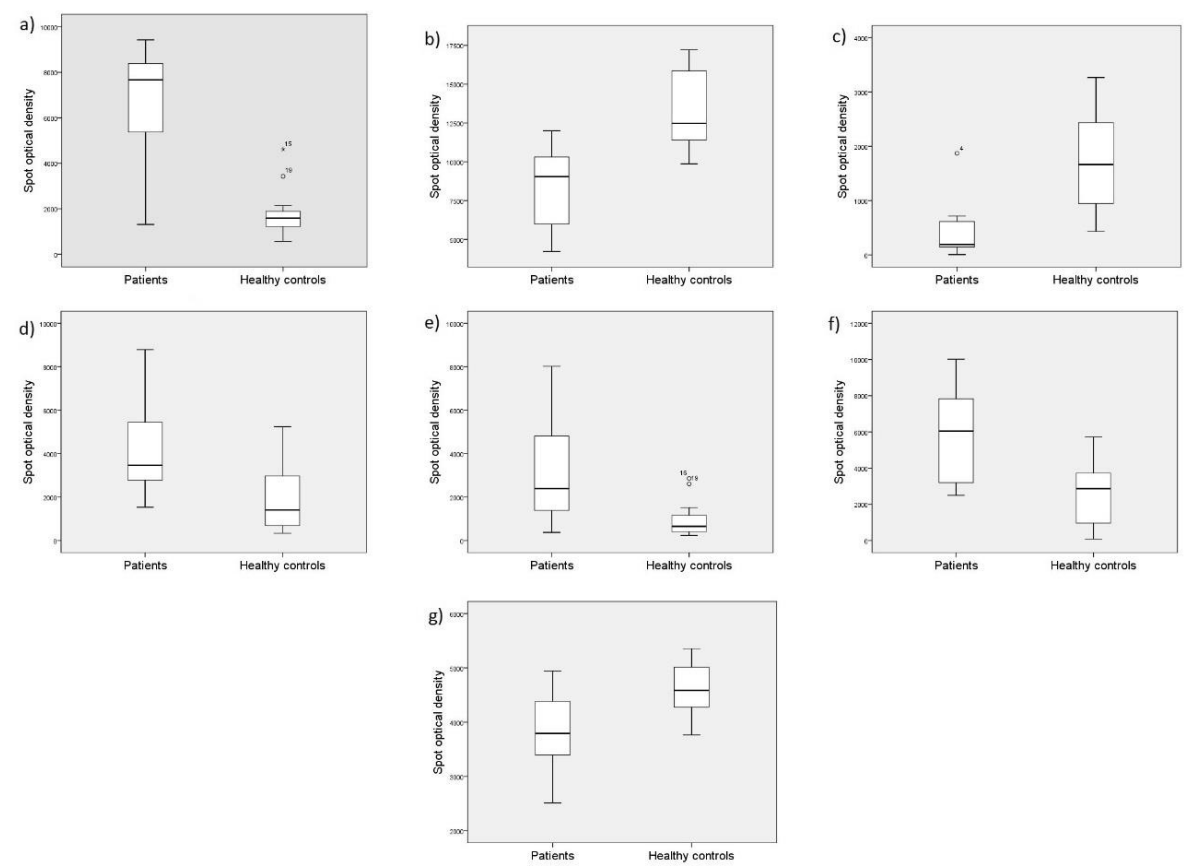

Figure 17 Spot optical densities in parts per million (ppm) for the seven most discriminating protein spots (on each panel, patients are on the left side and healthy controls on the right side). Median values are represented by horizontal lines and the interquartile ranges by boxes. In the absence of points (representing outliers) and asterisks (representing extremes), the ends of the whiskers represent minimum and maximum values. P-values refer to group differences (patients vs. controls). a) Angiotensinogen isoform, spot 3409, p<0.001; b) alpha-1-antitrypsin isoform, spot 5106, $\mathrm{p}=0.001$; c) alpha-1-antitrypsin isoform, spot 1505 , $\mathrm{p}=0.002$; d) haptoglobin isoform, spot 1211, $\mathrm{p}=0.008$; e) haptoglobin isoform, spot 1203, $\mathrm{p}=0.013$; f) haptoglobin isoform, spot 2205, $\mathrm{p}=0.013$; $\mathrm{g}$ ) pigment epithelium-derived factor (PEDF) isoform, spot 3308, $\mathrm{p}=0.013$.

Alpha-1-antitrypsin (spots 5106 and 1505): Two out of 20 identified isoforms of this protein had VIP $\geq 2$, and these two were down-regulated in patients. According to the location on the gels, five subgroups of alpha-1-antitrypsin were identified. Spot 1505 belonged to a subgroup of four isoforms, and it represented 10\% (median value) of these four isoforms in patients, compared to 55\% in controls ( $\mathrm{p}<0.001)$. Total alpha-1-antitrypsin of this subgroup did no differ between patients and healthy controls $(\mathrm{p}=0.2)$. Spot 5106, probably a degradation fragment, did not belong to any subgroup.

Haptoglobin (spots 1211, 1203, 2205): Three out of five identified isoforms of haptoglobin had VIP $\geq 2$, and they were up-regulated in patients. These three isoforms together 
represented $68 \%$ (median value) of total haptoglobin in patients, compared to $48 \%$ in controls $(\mathrm{p}=0.019)$. Total haptoglobin differed between patients and healthy controls $(\mathrm{p}=0.006)$.

PEDF (spot 3308): One out of five identified isoforms of this protein had VIP $\geq 2$; spot 3308 was down-regulated in patients. Spot 3308 represented $31 \%$ (median value) of total PEDF in patients, compared to $35 \%$ in controls $(\mathrm{p}=0.053)$. Total PEDF did not differ between patients and healthy controls $(\mathrm{p}=0.309)$.

\subsubsection{Final Statistical Model Based on the Seven Proteins}

A final OPLS-DA model was computed on the above-mentioned seven proteins. The model had one intra-class latent variable, had a god fit $\left(\mathrm{R}^{2}=0.83\right)$ and a high predictivity $\left(\mathrm{Q}^{2}=0.78\right)$. Hence, clear class separation was achieved with these seven variables, and the model was shown to be highly significant by CV-ANOVA $(\mathrm{p}<0.001)$.

A typical two-dimensional gel highlighting these seven proteins is shown in Figure 18.

\subsubsection{Pain Networks Interaction Analysis}

In order to analyse our results from a systems biology perspective, the names of the four genes coding for the above mentioned seven proteins were retrieved from www.uniprot.org and entered into an online human Pain Networks search [7,184]. Using "AGT SERPINA1 HP SERPINF1" as entry for query genes and using the "physical" filtering option (i.e., only including interactions with evidence of the proteins physically touching), an interaction map was generated (Figure 19). The map features two known pain-related genes (highlighted in grey): 1) MME codes for neprilysin, which is important for the destruction of opioid peptides [190], and MME interacts with AGT (codes for angiotensinogen); 2) APOE codes for apolipoprotein E, an isoform of which (spot 3107) has VIP=1.53 (see protein table in appended Paper IV) and interacts with haptoglobin. 


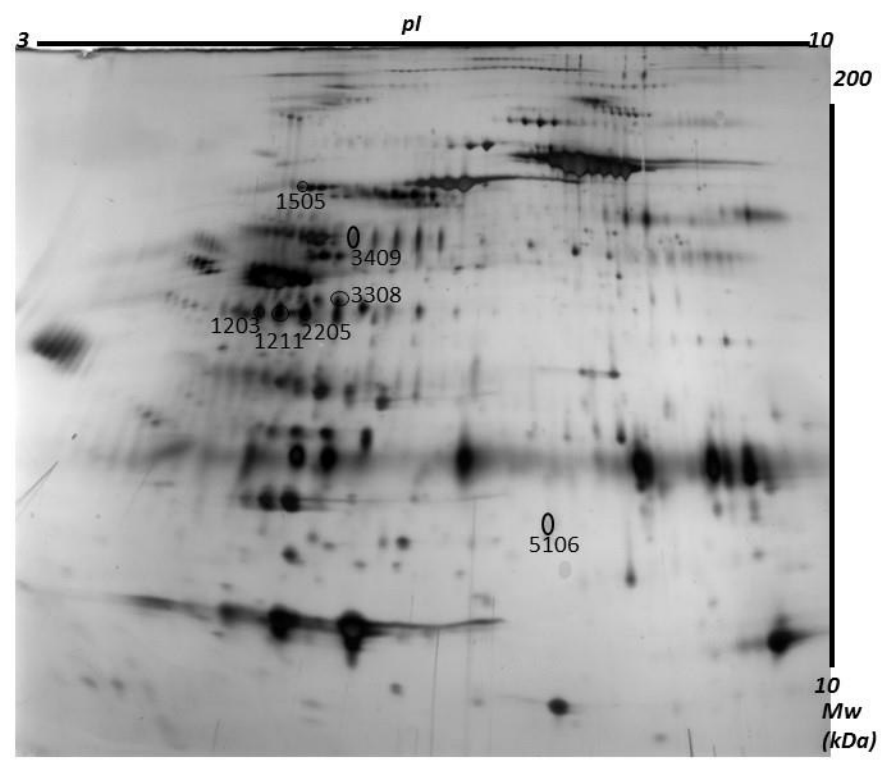

Figure 18 Typical two-dimensional gel electrophoresis map. The seven protein spots having the highest discriminatory power between patients and healthy controls have been encircled and annotated: spot 3409 is an isoform of angiotensinogen; 5106 and 1505 are isoforms of alpha-1-antitrypsin; 1203, 1211 and 2205 are isoforms of haptoglobin; 3308 is an isoform of pigment epithelium-derived factor. 


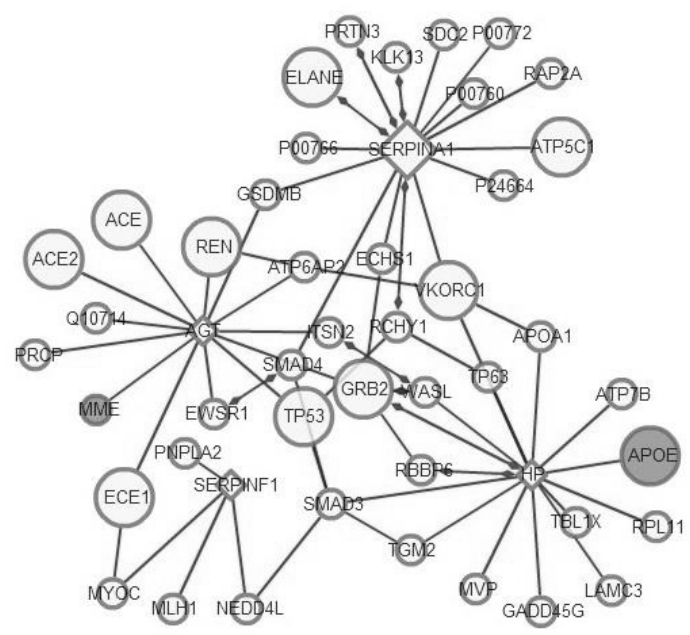

Figure 19 Interaction map for the four genes coding for the seven proteins having the highest discriminatory power between patients and healthy controls. AGT codes for angiotensinogen, HP for haptoglobin, SERPINA1 for alpha-1-antitrypsin, and SERPINF1 for pigment epithelium-derived factor. The on-line tool Pain Networks was used, accessed June 9, 2015, and the "physical" filtering option was chosen, i.e. the map displays only interactions with evidence of the proteins physically touching. Known pain-related genes are highlighted in grey (see text). 


\section{5}

\section{Discussion}

\section{WHAT IS TWISTED CANNOT BE STRAIGHTENED.}

\section{ECCLESIASTES 1:15}

As stated in Chapter 2, the overall aim of the thesis was to conduct translational pain research at the interface between clinical pain medicine and the growing field of human proteomics. Bridging the gap between basic and clinical research is generally acknowledged to be an important task for contemporary researchers [125,147]. As illustrated in Figure 20, the number of PubMed articles related to the world "translational" has increased dramatically during the past two decades.

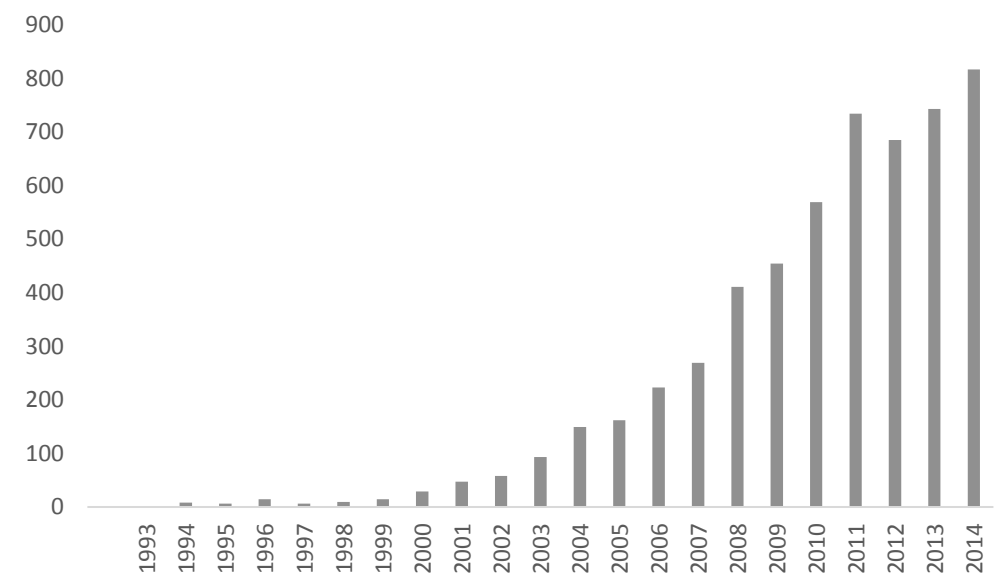

Figure 20 Number of PubMed counts per year using the search strategy "translational research" [Title/Abstract] OR "translational medicine" [Title/Abstract] OR "translational medical research" [Title/Abstract]). 
Translational pain research is all the more important because of the therapeutic shortcomings of pain medicine. The present dissertation illustrates two domains of unmet medical needs: the treatment of cancer BTP and the treatment of neuropathic pain.

\subsection{Improving the Treatment of Cancer Breakthrough Pain}

Paper I, which discusses the issue of cancer BTP in the ITA setting, was published four years ago. Recent developments in the field of cancer BTP have been reviewed by Davies in 2014 [63]. Depending on the subgroup of cancer patients studied, the prevalence of BTP was 40-80\%, excluding "end-of-dose failure" as this (according do Davies) "is no longer considered a subtype of breakthrough pain" [63]. The cornerstone of cancer BTP treatment remains rescue medication with short-acting opioids. Traditionally, oral short-acting opioids are used, but their pharmacodynamic and pharmacokinetic profiles match the temporal characteristics of cancer BTP very poorly; modern transmucosal opioids provide quicker analgesia than oral opioids [63]. In what is claimed to be the hitherto largest study of the clinical features of cancer BTP, almost one out of four patients "had found nothing that relieved their breakthrough pain" [63]. Hence, cancer BTP remains a significant unmet medical need.

Concerning cancer BTP and ITA, Brogan et al very recently published a prospective case series of implanted pumps with patients having the possibility of administrating bolus doses via a remote-control device [34]. They concluded that such patient-controlled ITA provided superior analgesia and a 3-fold faster onset of action compared with conventional BTP regimens. However, it is important to stress that this was not a controlled study, and it is difficult to disentangle the effect of the newly started ITA-infusion per se from the effect of ITA bolus doses. Moreover, $35 \%$ of patients still reported a "worst pain" intensity of $\geq 7$ on NRS, which is similar to the $40 \%$ found to have MEPI $\geq 7$ in Paper I. Despite these caveats, the Brogan study is an important contribution to the on-going discussion concerning how to treat cancer BTP.

A major drawback of the WHO analgesic ladder is that it is not mechanism-based. The same is true about a lot of research concerning the management of cancer BTP; often, such research projects focus on e.g. improving the dynamics and kinetics of opioids (e.g., transmucosal opioids), or on interventional techniques (sometimes called "the fourth step" of the WHO ladder) [46,63]. That an interventional technique like ITA is not a guarantee for adequate BTP control was amply demonstrated in Paper I. Arguably, in addition to improving currently available treatment options, a very important area of research ought to be investigations into the pathophysiological mechanisms of cancer BTP in humans.

In Paper I, it was reported that almost all patients with severe MEPI despite ITA had breast or lung cancer. As these two cancer types are among the cancers most frequently giving rise 
to bone metastases [121], and as bone metastases are acknowledged to be an important cause of cancer BTP, research into the mechanisms of metastatic bone pain due to breast cancer and lung cancer seems to be an important area for future studies [119]. This would entail biomarker studies in human, in analogy with the biomarker studies for neuropathic pain described in Papers III and IV. Ideally, instead of treating BTP when it arises, one can conceptually imagine disease-modifying drugs acting on nociception-related processes in bone metastases (see below), perhaps combining a halting/cure of the metastatic disease itself with mechanism-based pain relief.

There are, however, theoretical difficulties in the vision described in the paragraph above. For instance, compared to research on non-cancer neuropathic pain conditions, biomarker studies on cancer-related pain are arguably more complicated. This is due to the fact that, in chronic non-cancer pain, the pain is itself often the disease, whereas in cancer-related pain there is a conceptually blurred boundary between, on the one hand, biomarkers for the presence of the cancer itself and, on the other hand, biomarkers related to the pain caused by the cancer. These difficulties notwithstanding, the vision of being able to treat bone cancer pain with mechanism-specific drugs is appealing. This is a huge unmet medical need, as cancer-induced bone pain is acknowledged to be one of the most difficult pain conditions to treat, and as current improvements in cancer treatments mean that many patients live with metastatic cancer for years [121]. The fact that bisphosphonates, who are osteoclast inhibitors, can be used to treat cancer bone pain (especially in metastatic breast cancer) shows that mechanism-specific analgesia is conceptually possible [121]. Potential future targets have recently been reviewed [270] and include, among many others, NGF and receptor activator of nuclear factor kappa-B ligand (RANKL) [270]. The novel RANKLinhibitor denosumab is interesting in this respect $[121,270]$.

\subsection{Improving the Use of Ziconotide}

As was shown in Paper I, ITA is a method that needs to be developed further. As described in section 1.5.3, a major development in the field of ITA in recent years has been the advent of ziconotide. Paper II aimed at evaluating the feasibility of trialing this analgesic by high dose bolus injections. Many patients were non-responders, and this raises questions about the trialing method itself (given the slow tissue penetrance profile of the drug - see discussion in appended Paper II), but also, more fundamentally, about the mechanisms of neuropathic pain in this cohort of patients.

Ziconotide is a blocker of N-type voltage-gated calcium channels, and a schematic representation of the putative structure of the channel is shown in Figure 21. These channels seem to be up-regulated in neuropathic pain, at least in animal models [47]. But is this true in humans? And in this particular neuropathic pain condition? Indeed, although our cohort of patients is rather homogenous (e.g., compared to the Mohammed study [161]), it may 
very well be that there might be different degrees of up-regulation of voltage-gated calcium channels in different subgroups. We simply don't know. This is an important reminder of the importance of research into the mechanisms of different pain conditions. One should not assume that blocking the calcium channel is the right thing to do in each and every one of these patients. Once again, this highlights the importance of biomarkers studies - i.e., what if in the future it was possible to prescribe analgesics based on a precise understanding of the pathophysiological pain type of the individual patient? As of today, this kind of "tailormade prescription" might seem more like science fiction than science, but it is arguably an appealing vision for pain medicine.

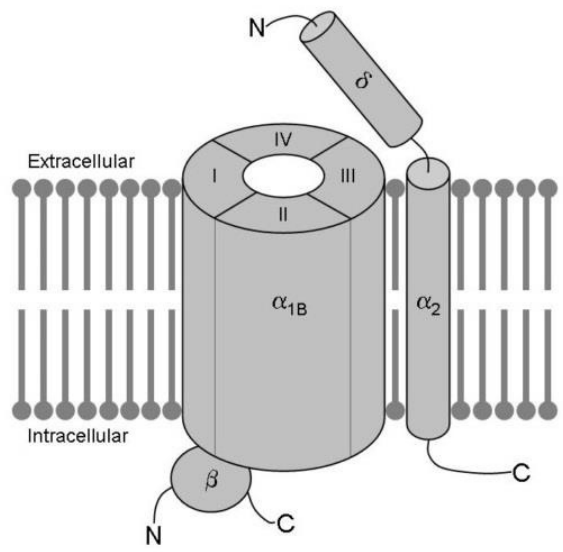

Figure 21 Schematic representation of the putative structure of the voltage-gated N-type calcium channel. Reproduced from [152] with permission.

Speaking of pain mechanisms and the balance between analgesia and side-effects (a balance illustrated by the narrow pharmacological window of ziconotide), it might be argued that an ideal analgesic ought to have a multi-facetted mechanism of action (as opposed to a single effect). One modern example of such a drug is tapentadol (Palexia $\left.{ }^{\circledR}\right)$, which is a molecule with a dual mechanism of action (it acts both as an opioid agonist and as a norepinephrine reuptake inhibitor). Conceptually, this may increase the tolerability of the drug (provided the targets are reasonably nociception-specific).

Hence, improving the use of ziconotide (or of any other analgesic) entails improving our understanding of different pain mechanisms. Human biomarker studies are crucial in this respect. Papers III and IV pertain to such a search for human biomarkers in pain conditions. First, two classical potential markers (SP and BE) were revisited (Paper III). We now therefore turn to a discussion of Paper III, which actualizes the importance of endogenous pain modulation systems. 


\subsection{Improving the Understanding of Top-Down Control}

Even though BE is an "old" biomarker candidate, recent developments in the understanding of brain neurophysiology imply that there is a possible link between release of BE in the CSF and the PAG-RVM system, and this for obvious neuroanatomical reasons: BE released in the ventricles soon reaches the PAG [259]. As described in section 1.3.3, endogenous pain modulation ("top-down control", of which the PAG-RVM system is a part) is a very important area of research. The nociceptive system is not only about "bottom-up" factors; "top-down" control is also of paramount importance. Therefore, investigations into the mechanisms of chronic pain entail studying endogenous pain modulation. Three particular points are important in relation to top-down control when interpreting and placing the results of Paper III in a larger context: 1) the distinction between psychophysical tests and biomarkers; 2) the issue of confounding factors; 3 ) the temporal variation of CSF-BE during the course of the development of peripheral neuropathic pain (a "chicken and egg" problem). These three topics will now be discussed.

\subsubsection{Psychophysical Tests vs Biomarkers}

The most common way of investigating endogenous pain modulation is by studying the DNIC system by performing CPM experiments. CPM has been called an "advanced psychophysical" method [192]. Generally speaking, psychophysics entails asking individuals to make quantitative reports about their perception of a stimulus while systematically varying the properties of the stimulus [200]. As a psychophysical test, CPM is therefore influenced both by physiology and psychology. This is both the strength of the method (it is anti-dualistic and looks at the psychophysical "whole") and its limitation (it may be difficult or perhaps even impossible to disentangle the importance of the different components). For instance, the possible influence of distraction, expectation, suggestion, and placebo on CPM results have been discussed [272]. Even so, it has been convincingly argued that psychophysical studies will remain an important tool in human neuroscience [200].

Psychophysical tests like CPM are sometimes described as being biomarkers [10], but as a biomarker by definition is a biological marker, the extension of the concept to psychophysical tests may not be entirely appropriate. It is perhaps better to view biomarkers and psychophysical tests as two different ways of studying the complex phenomenon of pain. Viewed from that perspective, the findings of Paper III are an important complement to the numerous studies of CPM available in the literature. As is stated in the paper, we speculate that low CSF-BE might indicate (i.e., be a biomarker of) defective top-down modulation in patients compared to healthy controls. CSF-BE might perhaps be considered a candidate biomarker for defective top-down modulation of this particular type of neuropathic pain, and might therefore perhaps in the future be part of a panel of proteins 
used in clinical pain medicine. All in all, the present state of play concerning CSF-BE is characterized by a significant level of doubt, as the findings of Paper III might conceivably be due to a number of confounding factors.

\subsubsection{Possible Confounding Factors}

Age, comorbidities, concomitant analgesics, and circadian variations are four important potential confounding factors in Paper III.

Age

In Paper III patients were much olders than controls, and one study in 20 healthy individuals has described that CSF-BE decreases with age [81]. However, other studies of adults have failed to confirm this age-effect on CSF-BE $[4,8,167]$. All in all, the balance of evidence does not favour a simple confounding effect of age on CSF-BE. However, this has to be confirmed in an aged-matched study.

\section{Comorbidities}

The possibility of concomitant diseases acting as confounding factors must be acknowledged, i.e. the difference between patients and controls would be attributable to the comorbidities of the patients group. This hypothesis can be scrutinized by post-hoc subgrouping the pain patients into two groups: patients with comorbidities and patients without comorbidities (see Table 2 in appended Paper II for a list of comorbidities). A graphic depiction of these two subgroups of patients compared to healthy controls is shown in Figure 22.

The difference between the two patients subgroups is not statistically significant (the sample sizes of the subgroups are very small), but descriptively pain patients without comorbidities seem to have lower CSF-BE levels than pain patients with comorbidities. Hence, there is no outright evidence for a confounding effect of comorbidities, although this of course remains a possibility.

\section{Concomitant analgesics}

As described in appended Paper III, no relationship was found between concomitant analgesics and CSF-BE in the patients group. As BE is an endogenous opioid, the relationship to opioid treatment is of particular interest. Descriptively, subgrouping patients according to the presence or absence of opioid treatment and depicting the results in a similar manner to that shown in Figure 22 does not reveal any trend of differences between patients on opioids and patients not on opioids (data not shown). Interestingly, CSF-BE levels in patients taking the opioid methadone have been shown to be higher than in controls [131]. Hence, we concluded that there is no outright evidence for a confounding effect of opioids. 


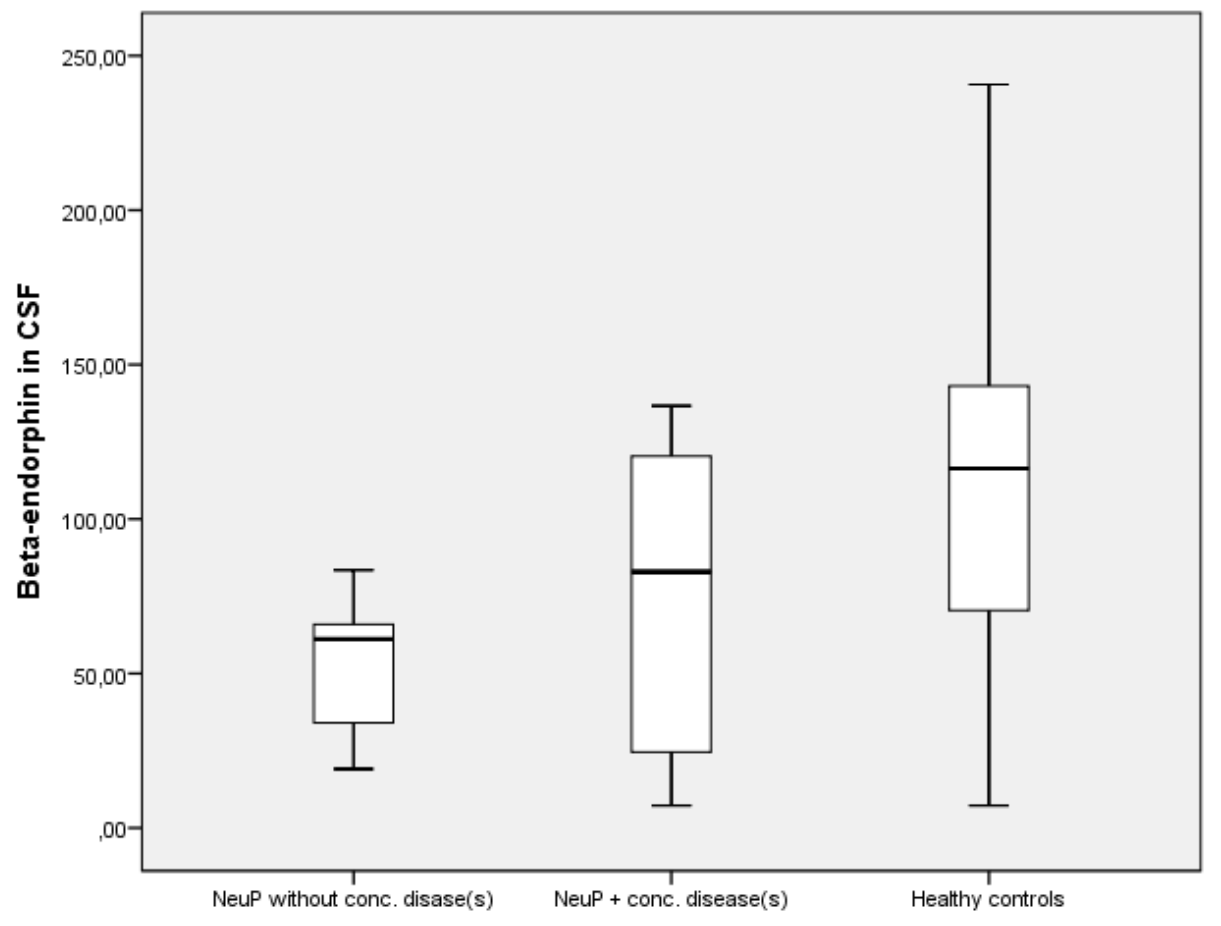

Figure 22 Levels of Beta-endorphin (pcg/mL) in the cerebrospinal fluid (CSF) with subgrouping of patients according to the presence or absence of co-morbidities. The three boxes represent healthy controls $(n=19)$, neuropathic pain patients with concomitant disease(s) $(n=8)$, and neuropathic pain patients without concomitant disease(s) $(n=6)$. NeuP $=$ Neuropathic pain patients. Conc.$=$ Concomitant.

\section{Circadian variations}

An important consideration not discussed in Paper III is the issue of circadian variations in CSF-BE levels. According to the literature, CSF-BE levels are highest early in the morning, between 6 and 9 a.m. [13,103]. In the present thesis, all lumbar puncture on patients were done between 8 and 9 a.m., whereas the timing of lumbar puncture in healthy controls ranged from early morning to very early afternoon. Hence, the finding of low levels of CSF$\mathrm{BE}$ in patients is all the more interesting, as the CSF of patients was collected during the period of peak CSF-BE levels. If the CSF of healthy controls had been collected between 8 and 9 a.m., the difference between the two groups might possibly have been even greater. 


\subsubsection{The Temporal Variation of CSF-BE}

If it were to turn out that the findings of Paper III do indeed point to a defective pain modulation system in this group of patients, there would still be a plethora of unanswered questions. Importantly, there is an important and ongoing "chicken and egg" discussion concerning CPM [272], and this discussion also applies to the findings of Paper III, namely: Is defective endogenous pain modulation a risk factor for the development of pathological pain (I call this the vulnerability hypothesis), or is it a consequence of the pathological pain state (the consequence hypothesis)? In other words: What is the temporal variation of CSF-BE during the course of the development of peripheral neuropathic pain?

In a recent review not restricted to neuropathic pain, Yarnitsky favours the vulnerability hypothesis (which seems to have some empirical support) but also states that these findings do not rule out the possibility that CPM itself can change during, and possibly due to, the presence of chronic pain [272]. Indeed, this may not be an either-or issue. It is conceivable that both hypotheses are true, perhaps to different degrees in different pain conditions. For example, in patients with painful osteoarthritis, Kosek \& Ordeberg found evidence of the DNIC dysfunction being maintained by chronic nociceptive pain [130], favouring the consequence hypothesis in that cohort of patients. Interestingly, Leong and co-worker showed that peripheral nerve injury in rats induced death of anti-nociceptive RVM neurons [136], also favouring the consequence hypothesis in neuropathic pain (albeit in an animal model).

Going back to the vulnerability hypothesis, it is interesting to ponder whether this putative vulnerability might be mediated purely by "lower" brainstem processes, or if it might (at least in part) be mediated by top-down influence from higher brain centres. Is there perhaps a causal association between anxiety/catastrophizing (a well-known risk factor for chronic postoperative pain [124,249]) and defective top-down modulation of pain?

Concerning CSF-BE, longitudinal studies before and after an invasive intervention have yielded inconclusive results, and/or results that are difficult to interpret due to the nature of the intervention [87,238]. In one of these studies [87], mean CSF-BE decreased by $56 \%$ in 9 patients 12-17 days after successful treatment with Dorsal Root Entry Zone Lesions. However, there was no control group at baseline, and the neuro-destructive nature of the intervention makes interpretation difficult. Hence, longitudinal studies are warranted in order to better understand the temporal variations (if any) of CSF-BE during the course of the development of peripheral neuropathic pain. The same is true concerning CSF-SP, which although being mainly a "negative" finding in this cohort of patients should not be ruled out as a potential biomarker in pain medicine (see below section 5.4.2), not least when taking the temporal dimension into account (the findings of the present thesis pertain to established chronic neuropathic pain, not to the development of chronic pain). It also has to be remembered that high levels of CSF-SP have been found in patients with fibromyalgia [208,245]. 


\subsection{Improving the Chances of Finding Biomarkers}

\subsubsection{Animal Models vs Research on Humans}

As should be clear by now, I contend that research into pain mechanisms is essential and that biomarker studies are central to this endeavour. I have elsewhere in a concept paper discussed the need for mechanism-based pain diagnoses [10]. The reader is also referred to section 1.4.1 in the present thesis for a review of the rationale for biomarker research. Most importantly, the significance of studying pain mechanisms in humans must be underlined. Although animal models are essential, there will always be a translational gap between animals and humans, especially concerning such a multi-facetted phenomenon as pain. This is far from trivial [147]. The failure of SP antagonists to translate from animal models to humans is an important example of this [139]. It is also of interest to underline that findings in humans might be reverse-translated to animals for refined experiments and controlled studies. Hence, there should be a back-and-forth movement between human and animal models, the one illuminating the other.

\subsubsection{Candidate Proteins vs Proteomics}

Biomarker studies in pain conditions usually follow a candidate protein approach: based on e.g. animal data, a small number of candidate proteins are hypothesized to be up- or downregulated in humans, and a hypothesis-testing study is then conducted. Biomarker CSF candidates in earlier studies have included Cystatin C [75,146], nociceptin [35,195], and different neurotrophins [40,143]. SP and BE are also classical candidates, and on the basis of Paper III and other studies [3,4,138,208,238,244,245], one might perhaps hypothesize that peripheral neuropathic pain and fibromyalgia are characterized by different combined patterns of CSF-BE and CSF-SP: the former would be associated with a tendency to low CSF-BE and normal/low CSF-SP, whereas the latter would be associated with a tendency to normal CSF-BE and high CSF-SP. Hence, CSF-BE and CSF-SP may perhaps in the future be part of a panel of proteins used to discriminate between different pain conditions.

However, given the complexity of the processes involved, with multiple protein systems interacting in manifold ways, an alternative research strategy to the "candidate protein approach" is to explore the entire protein content (i.e., the proteome) of the CSF without any prior assumptions of biological relevance. Recent technological advances have made such high-throughput, hypothesis-generating studies feasible, and broad hypothesisgenerating studies are nowadays seen as an important complement to classical hypothesistesting research [19]. This kind of broad research has sometimes pejoratively been referred to as data fishing or data dredging [112,222]. If high-throughput studies are done without discernment or pathophysiological thought, they surely deserve such pejorative appellations. But used wisely, I contend that there is indeed a place for hypothesis- 
generating research. In fact, making an absolute dichotomy between hypothesis-testing and hypothesis-generating research might perhaps be too simplistic. The difference between the former and the latter might be viewed not as the presence or absence of a hypothesis, but in how precise the hypothesis is. It is a matter of degree, not an either-or. For instance, underlying Paper IV is a broad hypothesis, namely that the CSF can be used to "mirror" the pathophysiological changes in the spinal cord. Admittedly, this is a very imprecise hypothesis that is difficult to falsify, and one should be aware of the associated risks of multiple testing and false positive results. But if the preliminary nature of such studies is underlined (and using the label "hypothesis-generating" is very helpful in this regard), it does not seem sensible to dogmatically disparage such efforts outright. I think that Paper IV illustrates the potential fruitfullness of this approach, especially when combined with MVDA methods. Indeed, the power of MVDA is illustrated by the fact that we rectrospectively were able to identify a methodological bias (see section 4.4.1). PCA is suited for this kind of control of the quality and homogeneity of the dataset (through identification of outliers and unexpected strong subgroups) [261].

\subsubsection{Age- and Sex-Matched Controls}

Improving the chances of finding biomarkers entails considering sampling issues carefully. A major limitation of Paper IV is that it is not an age-matched study. It is generally acknowledged that there is an increase in CSF protein concentrations with age (especially for plasma-derived proteins), and this is interpreted to be due to either a decline of the integrity of the blood-brain barrier or to a decreased CSF turnover [45]. However, it is very important to remember that this study quantifies protein levels in a relative (not absolute) manner, the same amount of protein being used for each gel. Moreover, in a study by Zhang et al, less than $10 \%$ out of more than 300 identified CSF proteins were more than $20 \%$ upor down-regulated in older individuals (66-85 years) compared to younger (22-36 years) [275]. Hence, we do not think our results can be dismissed outright as a confounding effect of age, although this of course remains as a possibility. When planning future similar studies, age- and sex-matching patients and controls will be important.

While we do not claim that it is possible to statistically adjust for the potential confounding effect of age (in the sense of classical linear regression), MVDA still entails some possibilities to take age into account and mitigate its effect. In addition to a model based on group as outcome variable (patient or control), a model with age as outcome variable was constructed for patients, leading to the exclusion of four age-related proteins. A graphical representation of this combination of two models can be obtained by constructing a Shared and Unique Structures plot (SUS-plot) in SIMCA, plotting the predictive loadings of each model against each other, as shown in Figure 23. 


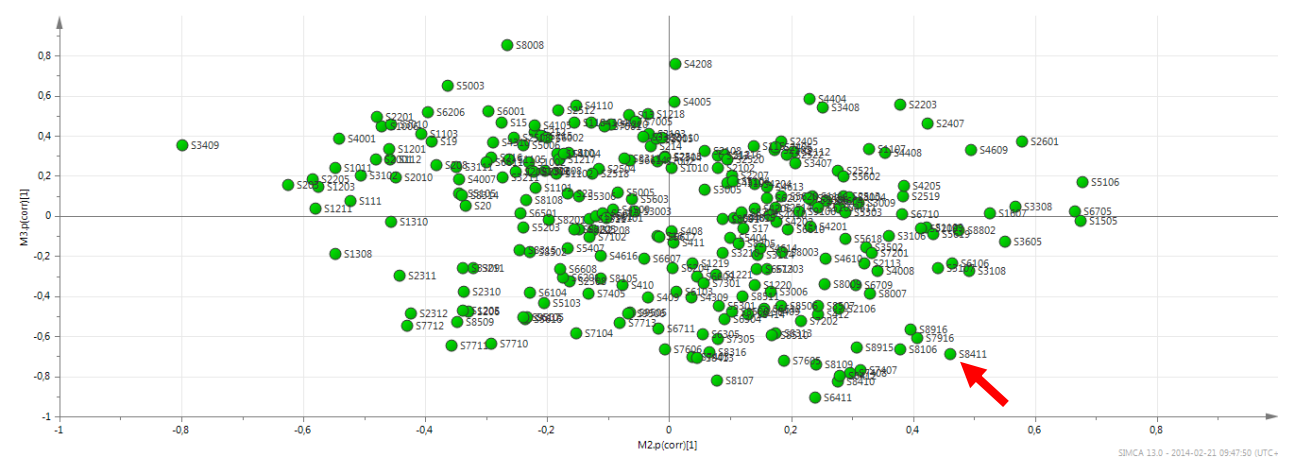

Figure 23 Shared and Unique Structures plot (SUS-plot) with contribution of proteins for group membership (patients vs controls) on the x-axis, and contribution of proteins for prediction of patient age on the y-axis. Each dot represents a protein. Proteins with a high absolute value on the $\mathrm{x}$-axis are important for class discrimination, and proteins that are ageindependent are close to zero on the y-axis. For further explanation, e.g. concerning the red arrow, see text.

How is the SUS-plot to be interpreted? The p(corr) is a loading scaled as a correlation coefficient (ranging from -1.0 to 1.0 ) between the model and original data [261]; the loading has been re-expressed as a correlation coefficient between the variable itself and $t 1$ ( $\mathrm{t} 1$ being the score of the predictive component) [80]. Proteins having high absolute $\mathrm{p}$ (corr) (often defined as $\mid \mathrm{p}$ (corr) $\mid \geq 0.5$ ) for group membership (x-axis) and at the same time having a $\mathrm{p}$ (corr) for age near zero (y-axis) predict group membership in an age-independent manner. As can be seen on the plot, few proteins have high absolute $\mathrm{p}$ (corr) on both axes, i.e. few of the proteins that discriminate between groups are at the same time correlated with patient age. Protein 8411 (red arrow) is one example of a protein with high absolute values on both axes, i.e. age is a possible confounding factor for that protein.

\subsubsection{Other Sampling Issues}

Looking more broadly on sampling issues, the risk of a selection bias due to nonprobability sampling must be taken into account. Nonprobability sampling means that the selection process is not completely random. Concerning the patients, the consecutive sampling process ensured that only patients with severe neuropathic pain were selected. But of course not all patients were included, due to inclusion and exclusion criteria (see Figure 1 in appended Paper II). Both neurobiological and psychological confounders could therefore be involved. Concerning the healthy controls, the convenience sampling we used was not random, but this is arguably rather unproblematic. It seems reasonable to assume that our healthy controls have the potential of being representative of the healthy general population, although of course the small number of individuals is problematic in itself. Another sampling issue relates to the fact that, for reasons of convenience, the position of the 
patient/healthy control during lumbar puncture (sitting or recumbent) was not standardized. Although a confounding effect seems unlikely, routinely placing individuals in a standardized position is advisable in future similar studies. (However, from a pragmatic point of view, a CSF biomarker that would be strongly position-dependent would be far from ideal.)

\subsubsection{Reliability Issues}

We now turn to measurement issues, and begin with reliability. Handling of the CSF is an important matter, and the procedure described in section 3.3.1 probably ensures that biochemical stability is not a problem. Two-dimensional gel-based proteomics is a wellknown analytical method which is considered to have high resolution and good quantitative analysis capability [193,194], but due to the complex multistep nature of the experimental procedure, reproducibility is still a challenge. A median coefficient of variation of approximately $20 \%$ has been reported in a multi laboratory study on its feasibility [16]. Continuously improving the reliability of analytical methods is of course very important in order to improve the chances to find valid biomarkers. It is also important to use MVDA as quality control, see section 4.4.1.

\subsubsection{Validity Issues}

In measurement theory, validity is "the degree to which an instrument measures what it is supposed to measure" [188]. This is related to interpretation: one cannot assume a priori that findings measure what they are intended to measure. At least the following four interpretational issues are important to keep in mind.

First, it is not certain that the CSF is a good enough "mirror" for the pathophysiological processes we intend to study. Maybe the "protein leak" into the CSF is too small to be detectable in any meaningful way (as opposed to e.g. the massive effects of Alzheimer's disease on the brain)? Second, it is not certain that our findings are specific for activity in the nociceptive system. There are other co-morbidities or processes that could be mirrored in the CSF, e.g., psychological co-morbidities or pharmacological effects of analgesics and other drugs. This is a very important interpretational point to be aware of. Third, it is not certain that our findings are specific for the spinal cord; supraspinal processes could be involved (see Paper III) and, notwithstanding the blood-brain barrier, systemic changes could perhaps be observed in the CSF.

Finally, blood contamination of the CSF is worth discussing, as this is an important potential confounder [273]. Even minor contamination may dramatically alter the protein profile of the CSF. To minimize this risk, the first millilitre of CSF was not analysed and the samples were ocularly scrutinized for blood contamination (both before and after centrifugation). 
Improving the reliability of CSF markers in this respect could entail using "blood contamination markers" [273]. However, this was not done in this study. Two additional factors concur with blood contamination not being an issue in this study. First, if a sample is contaminated by blood, haemoglobin spots are usually visible on the basic $15 \mathrm{kDa}$ area of the gel; no such contamination was observed. Second, it is probable that blood contamination of a CSF sample would lead to that individual being an outlier in unsupervised PCA (see section 4.4.1); hence, MVDA has a role to play not only concerning the discrimination of patients and healthy controls, but also (on a more fundamental level) in quality control and data validity.

The points mentioned above are about internal validity. External validity, on the other hand, has to do with questions of generalizability, which in turn are intrinsically linked to the sampling issues discussed in 5.4.3 and 5.4.4.

\subsubsection{Avoiding Statistical Overfitting}

When using MVDA to build statistical models, it is important to avoid overfitting. This relates to the number of latent variables in the model. Increasing the number of latent variables will increase the goodness of fit $\left(\mathrm{R}^{2}\right)$ and, with sufficiently many latent variables, $\mathrm{R}^{2}$ will approach 1 (i.e., the model will explain almost $100 \%$ of the variation in the data set). However, increasing the number of latent variables above a certain point will lead to a markedly reduced goodness of prediction $\left(\mathrm{Q}^{2}\right)$. This is illustrated in Figure 24 . Hence, there is a trade-off between $\mathrm{R}^{2}$ and $\mathrm{Q}^{2}$, and the difference between these two should not be $>0.3$ [80]. Otherwise, the model will be overfitted, i.e. it will only mirror the present data set without being able to predict new data. It is therefore important to choose the right amount of latent variables (optimal model dimensionality). In SIMCA (Umetrics AB, Umeå, Sweden), this is done by cross-validation. Cross-validation "is a practical and reliable way to test the significance of a PCA- or a PLS model", and it "has become standard in multivariate analysis, and is incorporated in one form or another in most commercial software" [80]. Hence, looking at $\mathrm{R}^{2}$ is not in itself enough to judge a model; assessing $\mathrm{Q}^{2}$ and the difference between $\mathrm{R}^{2}$ and $\mathrm{Q}^{2}$ is of paramount importance. In Paper IV, the OPLS and OPLS-DA models had a very high $\mathrm{R}^{2}$, but not at the expense of a low $\mathrm{Q}^{2}$. Nonetheless, one should be aware of the fact that overfitting is an inherent risk in OPLS [261].

Of course, making a statistical model is not an end in itself; the purpose is to move from the model back to biology. We now therefore turn to a discussion of the protein findings of Paper IV. What might the biological relevance of these findings be? 


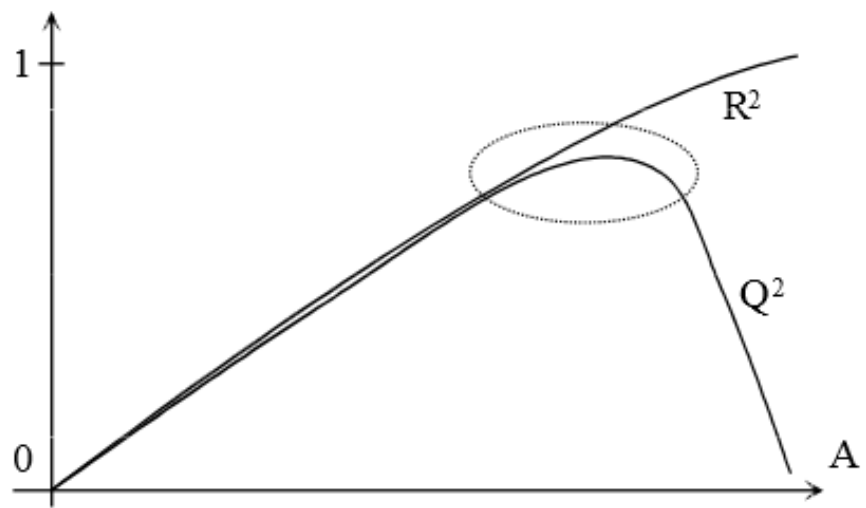

Figure 24 Trade-off between the goodness of fit $\left(\mathrm{R}^{2}\right)$ and the goodness of prediction $\left(\mathrm{Q}^{2}\right)$. The horizontal axis (A) depicts the number of latent variables, and the vertical axis the amount of explained $\left(\mathrm{R}^{2}\right)$ or predicted $\left(\mathrm{Q}^{2}\right)$ variation (range $\left.0-100 \%\right)$. For further details, see text. Reproduced from [80] with permission from Umetrics AB.

\subsubsection{From Statistical Models to Biological Hypotheses}

The possible biological relevance of the proteins described in section 4.4 .3 will now be discussed. Using MVDA, seven highly up- and down-regulated proteins in the CSF of patients with peripheral neuropathic pain were identified. The protein having the highest discriminatory power was an isoform of angiotensinogen, which was up-regulated in patients.

The CNS has a local renin-angiotensin system (RAS), astrocytes synthesizing angiotensinogen [182]. The RAS has recently been convincingly linked to the pathophysiology of neuropathic pain [5,84,148,168,202,225], and investigation of the $\mathrm{CSF} /$ plasma ratio of angiotensinogen has confirmed local production in the CNS [29]. In this context, it is noteworthy that when searching for neuropathic pain biomarkers with a purely explorative methodology, it was indeed a RAS-protein that had the highest discriminatory power between patients and controls. Hence, our results are in agreement with several other recent lines of evidence, suggesting a role for the RAS in the pathophysiology of neuropathic pain. Given that angiotensinogen is synthesized by astrocytes, one might speculate that our findings perhaps indicate glial activation in human neuropathic pain [157,236]. Although many animal studies have shown glial activation in neuropathic pain models, direct evidence for glial involvement in humans has hitherto been almost non-existent [236].

It was a specific isoform of angiotensinogen that was elevated in patients, not total angiotensinogen. Indeed, this study highlights the importance of taking PTMs into account 
in biomarker studies. Further research is needed to elucidate the mechanisms behind the increase of this particular isoform of angiotensinogen.

Both alpha-1-antitrypsin and haptoglobin are well-known plasma acute phase proteins $[43,151]$, but there is also evidence that they can be synthesized in the CNS $[43,94,118,135,183]$. Interestingly, under certain circumstances, astrocytes may synthesize haptoglobin [135] and perhaps alpha-1-antitrypsin [94], as well as other proteins discriminating between groups in this study, e.g. clusterin [52], and apolipoprotein E [163] (see Table 3 in appended Paper IV). More research is needed to elucidate the source of different isoforms of alpha-1-antitrypsin and haptoglobin, as well as the complex interplay between different PTMs. Concerning PEDF, this protein has been described as having (among other things) a neuroprotective effect from degeneration due to overexcitation (exitotoxicity) by glutamate [57].

Network analysis graphs such as the one in Figure 19 are an important systems biology tool. Based on that interaction map, one might hypothesize a network of interacting pathophysiological events in the spinal cord, perhaps centred around astrocytes and involving:

- The RAS-system of the CNS (angiotensinogen)

- Inflammation (alpha-1-antitrypsin and haptoglobin)

- Neuroprotective compensatory reactions (PEDF)

- Repair attempts (modulating apolipoprotein E, which is secreted from astrocytes and microglia, has been claimed to potentially provide therapeutic approaches for several neurological disorders [83]; apolipoprotein E is a CSF-enriched protein, see section 1.6.2)

- Dysfunctional endogenous opioid function (protecting enkephalins by inhibiting neprilysin has recently been called an "innovative approach for acute and neuropathic pain alleviation" [190]; this is of course also a potentially interesting link to the findings of Paper III concerning BE)

This is of course, to say the least, highly speculative but it is nonetheless arguably a plausible broad picture. It is here that neurobiologists need to step in and turn such hypothesisgenerating ideas into carefully designed hypothesis-driven neurobiological research. These two modes of research should be viewed as complementary, not antithetical. 


\subsection{Conclusion}

Referring back to the specific aims described in chapter 2, I conclude that:

1. Although SRPI was well controlled, movement-evoked BTP remained a major clinical problem in cancer patients with ITA throughout the study month. Further cancer BTP research is of paramount importance.

2. Although many patients were non-responders in our study, ziconotide bolus trialing seems feasible. However, it is too early to recommend this simple single-shot trialing method over the more tedious method of trialing by continuous infusion with an external pump.

3. Low CSF-BE in neuropathic pain patients might indicate defective top-down modulation. Both CSF-BE and CSF-SP should be considered candidates for a future biomarker panel used to discriminate between different pain conditions.

4. Proteomics in combination with MVDA revealed a number of interesting CSF proteins discriminating between neuropathic pain patients and healthy controls. The protein with the highest discriminatory power between the groups was an isoform of angiotensinogen. The preliminary and hypothesis-generating nature of these findings must be emphasized. 


\section{Future Prospects}

\section{THE END OF A MATTER IS BETTER THAN ITS BEGINNING.}

\section{ECCLESIASTES 7:8}

This PhD thesis demonstrates the fruitfulness of studying the CSF, both as a target for infusing analgesics (Papers I and II) and as a potential mirror of the neurobiological processes involved in pathological pain conditions (Papers III and IV). Even the clinically oriented papers of the dissertation (Papers I and II) point to the need for mechanism-based pain diagnoses: we know too little about the mechanisms of metastatic bone pain and cancer BTP (Paper I), and we know too little about the mechanisms of different peripheral neuropathic pain conditions (Paper II). Too often, therefore, pain medicine is a matter of "trial and error". We prescribe very much "in the dark". But might it be possible that in the future, pain physicians may prescribe drugs on the basis of precise pathophysiological information generated by a panel of biomarkers? This dissertation may perhaps be seen as a small step in that direction. Needless to say, many more studies will be required before achieving the vision of mechanism-specific pain diagnoses and treatments.

Broadly speaking, two interrelated areas of biomarker research are illustrated in this dissertation. First, there is the growing field of endogenous pain modulation research ("topdown"). This is anatomically very much of a "brainstem thing", but how neural pathways originating from higher brain centres may influence the brainstem (PAG-RVM, locus coeruleus, SRD) is also an important topic of research. Indeed, endogenous pain modulation is an important theoretical link between neurobiological factors and psychosocial factors. Although the focus of this thesis has been on the former, the centrality of the latter must underlined.

Then, there is the field of biomarker research into spinal mechanisms of pathological pain ("bottom-up"). Obviously, these two areas are intertwined, but it seems nonetheless conceptually fruitful to distinguish them. Metaphorically speaking, it is important to investigate both the gas pedal and the brake pedal. (Indeed, sometimes the brake pedal seems to turn into a gas pedal, i.e., top-down pain facilitation.) 
This $\mathrm{PhD}$ thesis illustrates the importance of what has been called "diagnostic research" and, using the terminology of Sackett \& Haynes, the kind of diagnostic research described in this dissertation belongs to "phase 1" (not to be confused with the well-known phases of clinical trials) [209]. According to this terminology, phase 1 diagnostic studies try to answer the question: Do test results in affected patients differ from those in normal individuals? As should be clear by now, I find it unlikely that it will be possible to answer this question by a univariate diagnostic test. Another important and sobering topic has to do with how to combine a putative future panel of biomarkers with other pre-test information provided by e.g. medical history, physical examination, sensory phenotyping, etc. Traditional concepts like sensitivity and specificity merely quantify the characteristics of the test rather than the test's contribution to estimate the diagnostic probability of disease presence or absence; this has been called "test research" as opposed to multivariable "diagnostic research" (the latter refer to studies that aim to quantify a test's added contribution beyond information available before to the physician) [162]. Hence, finding panels of biomarkers for different pain conditions will not in itself suffice; the integration of such coming panels into everyday medical practice will also need to be investigated during the coming decades, this being paralleled by the development of new analgesics. Disentangling these intricacies will be a difficult challenge. The task is immense. So is the need. 


\title{
Summary in Swedish
}

\author{
NOW ALL HAS BEEN HEARD.
}

ECCLESIASTES 12:13

\section{Populärvetenskaplig sammanfattning på svenska}

Behandlingen av både cancersmärta och kronisk smärta är fortfarande suboptimal. Det övergripande syftet med avhandlingen var att bedriva smärtforskning i gränsområdet mellan klinisk smärtvård och moderna proteinanalytiska metoder (proteomik). Utgångspunkten var vår kliniska verksamhet med intrathekal analgesi (ITA), en avancerad form av smärtlindring som innebär att en tunn kateter förs in i cerebrospinalvätskan (CSV) för att möjliggöra tillförsel av smärthämmande läkemedel så nära ryggmärgen som möjligt. Följaktligen står CSV i centrum för avhandlingen. I Studie I rapporterades 28 fall av ITA hos cancerpatienter med svår smärta. Behandlingen var framgångsrik såtillvida att god lindring av vilosmärtan uppnåddes (samtidigt som doserna morfin minskade), men rörelseorsakad genombrottssmärta förblev ett stort kliniskt problem. Denna studie belyser därför vikten av att beakta om genombrottssmärta föreligger, även när god kontroll över vilosmärtan har erhållits med ITA.

I Studie II utvärderades en algoritm för testning av det relativt nya ITA-läkemedlet zikonotid (Prialtß) genom engångsinjektioner hos en grupp patienter med kronisk "nervsmärta" efter operation/trauma. Totalt gavs 36 injektioner till 23 patienter (1-3 injektioner per patient $\mathrm{i}$ enlighet med algoritmen). Enligt studies strikta kriterier erhöll endast $13 \%$ betydande smärtlindring utan samtidiga påtagliga biverkningar, men var tredje patient upplevde påtaglig smärtlindring vid åtminstone någon av injektionerna. Huruvida denna testmetod kan predicera vilka patienter som har effekt av kontinuerlig tillförsel av zikonotid via pump är fortfarande en öppen fråga.

I Studie III fann vi låga nivåer av beta-endorfin i CSV hos 15 patienter med kronisk "nervsmärta" jämfört med 19 friska kontroller. Möjligen kan detta tyda på att dessa patienters smärthämmande bansystem inte fungerar tillfredsställande. I Studie IV jämfördes 
det övergripande proteinmönstret hos 11 patienter med kronisk "nervsmärta" med 11 friska kontroller. För detta ändamål kombinerades gel-baserade proteomik med multivariat dataanalys. Av 260 proteiner var de följande sju viktigast för åtskillnaden mellan friska och sjuka individer: en isoform av angiotensinogen, två isoformer av alfa-1-antitrypsin, tre isoformer av haptoglobin, och en isoform av pigment epithelium-derived factor. Studien illustrerar de inneboende möjligheterna i kombinationen av proteomisk vetenskap och multivariat dataanalys avseende biomarkörforskning vid svåra smärttillstånd.

Avhandlingen visar CSV:s potential i modern avancerad smärtforskning/vård, både som "måltavla" för tillförsel av smärtläkemedel (Studie I och II) och som möjlig "spegel" för de neurobiologiska processer som pågår i ryggmärgen vid svåra smärttillstånd (Studie III och IV). I förlängningen ligger frågan om man måhända i framtiden kommer att kunna skräddarsy valet att smärtlindring baserat på en analys av ryggmärgsvätskan. Avhandlingen kan ses som ett litet steg i den riktningen. Det är viktigt att det även fortsättningsvis bedrivs studier syftande till att kartlägga de bakomliggande mekanismerna för olika smärttillstånd. 


\title{
Acknowledgements
}

\author{
IF ONE FALLS DOWN, HIS FRIEND CAN HELP HIM UP.
}

ECCLESIASTES 4:10

I am privileged to be surrounded by many relatives and friends who together constitute the social fabric of my life. You are all deeply appreciated. Here, I would like to express my gratitude to those who have been specifically involved in making this $\mathrm{PhD}$ thesis possible.

Björn Gerdle, main supervisor, professor and head of the Pain and Rehabilitation Centre: I want to thank you especially for your empowering way of letting me grow as a researcher. You have made me feel free and respected, and at the same time I have never felt alone.

Jan Sörensen, co-supervisor and former head of the Pain and Rehabilitation Centre: Thank you especially for sharing with me your competence in the field of "pharmacological pain analysis", as well as your vast knowledge of the practicalities of clinical trials. Your critical mind has been an inspiration to me.

Britt Larsson, co-supervisor and associate professor: Thank you especially for sharpening my paper writing skills, and for introducing me into the mysteries of how to organize data files and use SPSS.

Bijar Ghafouri, co-supervisor and associate professor, head of the Painomics® laboratory at the Pain and Rehabilitation Centre: Thank you for guiding a simple clinician like me through the world of proteins and proteomics.

Patrik Olausson, medical biologist, PhD candidate, and co-author: Thank you for introducing me into the world of proteomics, for patiently explaining and correcting my misunderstandings, and for diligently fetching the CSF samples whenever it was needed.

Anders Carlsson, research engineer at the Painomics ${ }^{\circledR}$ laboratory and co-author: Thank you for your excellent laboratory workmanship.

Jan Lindquist, senior consultant in pain management and former chief physician of the Pain Units of Region Östergötland: Thank you for teaching me clinical pain medicine, for 
trusting and mentoring me, and for sharing your skills as an interventional pain physician. Without you, I wouldn't be the clinician I am today.

Among the other colleagues at the Pain and Rehabilitation Centre, I especially want to mention Lena Fagerström: Since my first on-call night as an anaesthesiology registrar almost 15 years ago, when you were my "backup colleague" at the ICU, I have always enjoyed working with you. The width of your clinical competence in pain medicine (from psychotherapy to spinal cord stimulation!) is an inspiration.

Anne Schaller, head nurse and $\mathrm{PhD}$ candidate: It is a pleasure collaborating with you in our common task of leading the Pain Units of Region Östergötland. I always enjoy working with you. Thanks for your support and kind encouragement during the years.

Nurses Marie Berggården, Anna Peterson and Eva-Britt Lind: Thank you for your thoroughness, competence, trustworthiness, and positive attitude during the whole project.

All other nurses, physicians, and secretaries at the Pain Unit in Linköping from 2007 and onwards: Thanks for your contribution to the daily clinical work at our Pain Unit. A wellfunctioning clinical department is the basis for effective clinical research!

Gunn Johansson and Lotta Lindh-Åstrand, Linköping Academic Research Centre: Thanks for excellent assistance in the planning of the ziconotide bolus study, and for helping me to implement the principles of Good Clinical Practice in my research. All the paperwork would have been a lot more incomprehensible without your help (thinking about the EudraCT form still sends shivers down my spine).

Statisticians Mats Fredriksson and Karl Wahlin: Thanks for help with Paper II.

Folke Sjöberg and Karl-Fredrik Sjölund: Thanks for valuable comments during the halftime seminar.

Martin Golster, head of the Department of Intensive Care: Thank you for kindly allowing me to send the ziconotide patients to the post-operative ward overnight.

Finally, and most of all, to Rebecka Domeij Bäckryd: As we walk the Path of life together, experiencing our own fair amount of both joys and sorrows, I feel extremely privileged to have you at my side. For me, you are the embodiment of faithfulness. Love you.

Elna, Alvin, and Vera, my three little whirlwinds: Får jag säga ordet "artikel" nu? Hugs and laughter!

This work is dedicated to the memory of Vilgot. Small and beautiful. Painfully lost but not beyond hope. "Arise! Shine! Your new day is dawning." (Isaiah 60:1) 


\section{References}

\section{MUCH STUDY WEARIES THE BODY.}

\section{ECCLESIASTES 12:12}

[1] Ahmed S, Martin N, Chang Y. Patient selection and trial methods for intraspinal drug delivery for chronic pain: a national survey. Neuromodulation 2005;8:112-120.

[2] Alicino I, Giglio M, Manca F, Bruno F, Puntillo F. Intrathecal combination of ziconotide and morphine for refractory cancer pain: A rapidly acting and effective choice. Pain 2012; 153:245-249.

[3] Almay BG, Johansson F, Von Knorring L, Le Greves P, Terenius L. Substance P in CSF of patients with chronic pain syndromes. Pain 1988;33:3-9.

[4] Almay BG, Johansson F, Von Knorring L, Terenius L, Wahlstrom A. Endorphins in chronic pain. I. Differences in CSF endorphin levels between organic and psychogenic pain syndromes. Pain 1978;5:153-162.

[5] Anand U, Facer P, Yiangou Y, Sinisi M, Fox M, McCarthy T, Bountra C, Korchev YE, Anand P. Angiotensin II type 2 receptor (AT2 R) localization and antagonistmediated inhibition of capsaicin responses and neurite outgrowth in human and rat sensory neurons. Eur J Pain 2013;17:1012-1026.

[6] Anderson V, Burchiel K, Cooke B. A prospective, randomized trial of intrathecal injection vs. epidural infusion in the selection of patients for continuous intrathecal opioid therapy. Neuromodulation 2003;6:142-152.

[7] Antunes-Martins A, Perkins JR, Lees J, Hildebrandt T, Orengo C, Bennett DL. Systems biology approaches to finding novel pain mediators. Wiley Interdiscip Rev Syst Biol Med 2013;5:11-35.

[8] Bach FW, Schmidt JF, Faber T. Radioimmunoassay of beta-endorphin in ventricular and lumbar cerebrospinal fluid. Clin Chem 1992;38:847-852.

[9] Backryd E. Smärtan och medvetandet gäckar filosofer och forskare. Läkartidningen 2012;109:1039-1040.

[10] Backryd E. Pain in the Blood? Envisioning Mechanism-Based Diagnoses and Biomarkers in Clinical Pain Medicine. Diagnostics 2015;5:84-95. 
[11] Ballantyne JC, Carwood CM. Comparative efficacy of epidural, subarachnoid, and intracerebroventricular opioids in patients with pain due to cancer. Cochrane Database of Syst Rev 2005;CD005178.

[12] Baron R, Binder A, Wasner G. Neuropathic pain: diagnosis, pathophysiological mechanisms, and treatment. Lancet Neurol 2010;9:807-819.

[13] Barreca T, Siani C, Franceschini R, Francaviglia N, Messina V, Perria C, Rolandi E. Diurnal beta-endorphin changes in human cerebrospinal fluid. Life Sci 1986;38:2263-2267.

[14] BBC. Millions denied end-of-life drugs. Available from www.bbc.com/news/health27661462 (6 August 2014).

[15] Beaudry H, Dubois D, Gendron L. Activation of spinal mu- and delta-opioid receptors potently inhibits substance $\mathrm{P}$ release induced by peripheral noxious stimuli. J Neurosci 2011;31:13068-13077.

[16] Bech-Serra JJ, Borthwick A, Colome N, ProteoRed C, Albar JP, Wells M, Sanchez del Pino M, Canals F. A multi-laboratory study assessing reproducibility of a 2D-DIGE differential proteomic experiment. J Biomol Tech 2009;20:293-296.

[17] Beggs S, Trang T, Salter MW. P2X4R+ microglia drive neuropathic pain. Nat Neurosci 2012;15:1068-1073.

[18] Bennett MI, Rayment C, Hjermstad M, Aass N, Caraceni A, Kaasa S. Prevalence and aetiology of neuropathic pain in cancer patients: a systematic review. Pain 2012;153:359-365.

[19] Biesecker LG. Hypothesis-generating research and predictive medicine. Genome Res 2013;23:1051-1053.

[20] Biomarkers Definitions Working Group. Biomarkers and surrogate endpoints: preferred definitions and conceptual framework. Clin Pharmacol Ther 2001;69:8995.

[21] Blennow K, Zetterberg H, Fagan AM. Fluid biomarkers in Alzheimer disease. Cold Spring Harb Perspect Med 2012;2:a006221.

[22] Bonica JJ. The need of a taxonomy. Pain 1979;6:247-248.

[23] Borrell-Carrio F, Suchman AL, Epstein RM. The biopsychosocial model 25 years later: principles, practice, and scientific inquiry. Ann Fam Med 2004;2:576-582.

[24] Borsook D, Becerra L, Hargreaves R. Biomarkers for chronic pain and analgesia. Part 1: the need, reality, challenges, and solutions. Discov Med 2011;11:197-207.

[25] Bouhassira D, Lanteri-Minet M, Attal N, Laurent B, Touboul C. Prevalence of chronic pain with neuropathic characteristics in the general population. Pain 2008;136:380387.

[26] Brand PW, Yancey P. The Gift of Pain. Grand Rapids, MI: Zondervan, 1997. 
[27] Breivik H, Cherny N, Collett B, de Conno F, Filbet M, Foubert AJ, Cohen R, Dow L. Cancer-related pain: a pan-European survey of prevalence, treatment, and patient attitudes. Ann Oncol 2009;20:1420-1433.

[28] Breivik H, Collett B, Ventafridda V, Cohen R, Gallacher D. Survey of chronic pain in Europe: prevalence, impact on daily life, and treatment. Eur J Pain 2006;10:287333.

[29] Brettschneider J, Hartmann N, Lehmensiek V, Mogel H, Ludolph AC, Tumani H. Cerebrospinal fluid markers of idiopathic intracranial hypertension: is the reninangiotensinogen system involved? Cephalalgia 2011;31:116-121.

[30] Brisby H, Olmarker K, Larsson K, Nutu M, Rydevik B. Proinflammatory cytokines in cerebrospinal fluid and serum in patients with disc herniation and sciatica. Eur Spine J 2002;11:62-66.

[31] Brisby H, Olmarker K, Rosengren L, Cederlund CG, Rydevik B. Markers of nerve tissue injury in the cerebrospinal fluid in patients with lumbar disc herniation and sciatica. Spine (Phila Pa 1976) 1999;24:742-746.

[32] Brodal P. Neurotransmitters and their receptors. In: The Central Nervous System : Structure and Function. New York: Oxford University Press USA, 2010. pp. 53-71.

[33] Brodal P. Pain. In: The Central Nervous System : Structure and Function. New York: Oxford University Press USA, 2010. pp. 204-214.

[34] Brogan SE, Winter NB, Okifuji A. Prospective Observational Study of PatientControlled Intrathecal Analgesia: Impact on Cancer-Associated Symptoms, Breakthrough Pain Control, and Patient Satisfaction. Reg Anesth Pain Med 2015;40:369-375.

[35] Brooks H, Elton CD, Smart D, Rowbotham DJ, McKnight AT, Lambert DG. Identification of nociceptin in human cerebrospinal fluid: comparison of levels in pain and non-pain states. Pain 1998;78:71-73.

[36] Bulat M, Klarica M. Recent insights into a new hydrodynamics of the cerebrospinal fluid. Brain Res Rev 2011;65:99-112.

[37] Burton AW, Deer TR, Wallace MS, Rauck RL, Grigsby E. Considerations and methodology for trialing ziconotide. Pain Physician 2010;13:23-33.

[38] Burton AW, Rajagopal A, Shah HN, Mendoza T, Cleeland C, Hassenbusch SJ, 3rd, Arens JF. Epidural and intrathecal analgesia is effective in treating refractory cancer pain. Pain Med 2004;5:239-247.

[39] Buvanendran A, Kroin JS, Della Valle CJ, Moric M, Tuman KJ. Cerebrospinal fluid neurotransmitter changes during the perioperative period in patients undergoing total knee replacement: a randomized trial. Anesth Analg 2012;114:434-441.

[40] Capelle HH, Weigel R, Schmelz M, Krauss JK. Neurotrophins in the cerebrospinal fluid of patient cohorts with neuropathic pain, nociceptive pain, or normal pressure hydrocephalus. Clin J Pain 2009;25:729-733. 
[41] Centers for Disease Control. CDC grand rounds: prescription drug overdoses - a U.S. epidemic. MMWR Morb Mortal Wkly Rep 2012;61:10-13.

[42] Chalmers DJ. The puzzle of conscious experience. Sci Am 1995;273:80-86.

[43] Chang KH, Tseng MY, Ro LS, Lyu RK, Tai YH, Chang HS, Wu YR, Huang CC, Hsu WC, Kuo HC, Chu CC, Chen CM. Analyses of haptoglobin level in the cerebrospinal fluid and serum of patients with neuromyelitis optica and multiple sclerosis. Clin Chim Acta 2013;417:26-30.

[44] Chang L. Altered glutamatergic metabolism and activated glia: biomarkers for neuropathic pain? Pain 2013;154:181-182.

[45] Chen CP, Chen RL, Preston JE. The influence of ageing in the cerebrospinal fluid concentrations of proteins that are derived from the choroid plexus, brain, and plasma. Exp Gerontol 2012;47:323-328.

[46] Christo PJ, Mazloomdoost D. Interventional pain treatments for cancer pain. Ann N Y Acad Sci 2008;1138:299-328.

[47] Cizkova D, Marsala J, Lukacova N, Marsala M, Jergova S, Orendacova J, Yaksh TL. Localization of $\mathrm{N}$-type $\mathrm{Ca} 2+$ channels in the rat spinal cord following chronic constrictive nerve injury. Exp Brain Res 2002;147:456-463.

[48] Clauw DJ. Fibromyalgia: a clinical review. JAMA 2014;311:1547-1555.

[49] Compton AK, Shah B, Hayek SM. Spinal cord stimulation: a review. Curr Pain Headache Rep 2012;16:35-42.

[50] Consortium IHGS. Finishing the euchromatic sequence of the human genome. Nature 2004;431:931-945.

[51] Coombs DW, Maurer LH, Saunders RL, Gaylor M. Outcomes and complications of continuous intraspinal narcotic analgesia for cancer pain control. J Clin Oncol 1984;2:1414-1420.

[52] Cordero-Llana O, Scott SA, Maslen SL, Anderson JM, Boyle J, Chowhdury RR, Tyers P, Barker RA, Kelly CM, Rosser AE, Stephens E, Chandran S, Caldwell MA. Clusterin secreted by astrocytes enhances neuronal differentiation from human neural precursor cells. Cell Death Differ 2011;18:907-913.

[53] Cortese I. The Blood-brain and Blood-Cerebrospinal Fluid Barriers. In: DN Irani, editor. The Cerebrospinal Fluid in Clinical Practice. Philadelphia, PA: Saunders, 2009. pp. 33-43.

[54] Cortese I, Calabresi PA. Inflammatory and Demyelinating Disorders. In: DN Irani, editor. Cerebrospinal fluid in Clinical Practice. Philadelphia, PA: Saunders, 2009. pp. 209-223.

[55] Craig AD. Interoception: the sense of the physiological condition of the body. Curr Opin Neurobiol 2003;13:500-505.

[56] Craig AD. A new view of pain as a homeostatic emotion. Trends Neurosci 2003;26:303-307. 
[57] Craword SE, Fitchev P, Veliceasa D, Volpert OV. The many facets of PEDF in drug discovery and disease: a diamond in the rough or split personality disorder? Expert Opin Drug Discov 2013;8:769-792.

[58] Cruccu G, Truini A. Tools for assessing neuropathic pain. PLoS Med 2009;6:e1000045.

[59] Cserr HF, Cooper DN, Suri PK, Patlak CS. Efflux of radiolabeled polyethylene glycols and albumin from rat brain. Am J Physiol 1981;240:F319-328.

[60] D'Mello R, Dickenson AH. Spinal cord mechanisms of pain. Br J Anaesth 2008;101:816.

[61] Dahm P, Lundborg C, Janson M, Olegard C, Nitescu P. Comparison of 0.5\% intrathecal bupivacaine with $0.5 \%$ intrathecal ropivacaine in the treatment of refractory cancer and noncancer pain conditions: results from a prospective, crossover, double-blind, randomized study. Reg Anesth Pain Med 2000;25:480-487.

[62] Dahm P, Nitescu P, Appelgren L, Curelaru I. Efficacy and technical complications of long-term continuous intraspinal infusions of opioid and/or bupivacaine in refractory nonmalignant pain: a comparison between the epidural and the intrathecal approach with externalized or implanted catheters and infusion pumps. Clin J Pain 1998;14:4-16.

[63] Davies AN. Breakthrough cancer pain. Curr Pain Headache Rep 2014;18:420.

[64] De Felice M, Sanoja R, Wang R, Vera-Portocarrero L, Oyarzo J, King T, Ossipov MH, Vanderah TW, Lai J, Dussor GO, Fields HL, Price TJ, Porreca F. Engagement of descending inhibition from the rostral ventromedial medulla protects against chronic neuropathic pain. Pain 2011;152:2701-2709.

[65] de Leon-Casasola O. New developments in the treatment algorithm for peripheral neuropathic pain. Pain Med 2011;12 Suppl 3:S100-108.

[66] Deer T, Krames E, Hassenbusch S, Burton A, Caraway D, Dupen S, Eisenach J, Erdek M, Grigsby E, Kim P. Polyanalgesic Consensus Conference 2007: recommendations for the management of pain by intrathecal (intraspinal) drug delivery: report of an interdisciplinary expert panel. Neuromodulation 2007;10:300-328.

[67] Deer T, Serafini M, Buchser E, Ferrante F, Hassenbusch S. Intrathecal bupivacaine for chronic pain: A review of current knowledge. Neuromodulation 2002;5:196-207.

[68] Deer TR, Kim C, Bowman R, Tolentino D, Stewart C, Tolentino W. Intrathecal ziconotide and opioid combination therapy for noncancer pain: an observational study. Pain Physician 2009;12:E291-296.

[69] Deer TR, Prager J, Levy R, Burton A, Buchser E, Caraway D, Cousins M, De Andres J, Diwan S, Erdek M, Grigsby E, Huntoon M, Jacobs M, Kim P, Kumar K, Leong M, Liem L, McDowell G, Panchal SJ, Rauck R, Saulino M, Staats P, Stanton-Hicks M, Stearns L, Sitzman BT, Wallace M, Willis KD, Witt W, Yaksh T, Mekhail N. Polyanalgesic Consensus Conference--2012: recommendations on trialing for intrathecal (intraspinal) drug delivery: report of an interdisciplinary expert panel. Neuromodulation 2012;15:420-435; discussion 435. 
[70] Deer TR, Prager J, Levy R, Rathmell J, Buchser E, Burton A, Caraway D, Cousins M, De Andres J, Diwan S, Erdek M, Grigsby E, Huntoon M, Jacobs MS, Kim P, Kumar K, Leong M, Liem L, McDowell GC, 2nd, Panchal S, Rauck R, Saulino M, Sitzman BT, Staats P, Stanton-Hicks M, Stearns L, Wallace M, Willis KD, Witt W, Yaksh T, Mekhail N. Polyanalgesic Consensus Conference 2012: recommendations for the management of pain by intrathecal (intraspinal) drug delivery: report of an interdisciplinary expert panel. Neuromodulation 2012;15:436-464; discussion 464436.

[71] Dickinson BD, Head CA, Gitlow S, Osbahr AJ, 3rd. Maldynia: pathophysiology and management of neuropathic and maladaptive pain--a report of the AMA Council on Science and Public Health. Pain Med 2010;11:1635-1653.

[72] Drake PM, Cho W, Li B, Prakobphol A, Johansen E, Anderson NL, Regnier FE, Gibson BW, Fisher SJ. Sweetening the pot: adding glycosylation to the biomarker discovery equation. Clin Chem 2010;56:223-236.

[73] Dupoiron D, Bore F, Lefebvre-Kuntz D, Brenet O, Debourmont S, Dixmerias F, Buisset N, Lebrec N, Monnin D. Ziconotide adverse events in patients with cancer pain: a multicenter observational study of a slow titration, multidrug protocol. Pain Physician 2012;15:395-403.

[74] Dworkin RH, Turk DC, Farrar JT, Haythornthwaite JA, Jensen MP, Katz NP, Kerns RD, Stucki G, Allen RR, Bellamy N, Carr DB, Chandler J, Cowan P, Dionne R, Galer BS, Hertz S, Jadad AR, Kramer LD, Manning DC, Martin S, McCormick CG, McDermott MP, McGrath P, Quessy S, Rappaport BA, Robbins W, Robinson JP, Rothman M, Royal MA, Simon L, Stauffer JW, Stein W, Tollett J, Wernicke J, Witter J. Core outcome measures for chronic pain clinical trials: IMMPACT recommendations. Pain 2005;113:9-19.

[75] Eisenach JC, Thomas JA, Rauck RL, Curry R, Li X. Cystatin C in cerebrospinal fluid is not a diagnostic test for pain in humans. Pain 2004;107:207-212.

[76] Ellis A, Bennett DL. Neuroinflammation and the generation of neuropathic pain. Br J Anaesth 2013;111:26-37.

[77] Ellis DJ, Dissanayake S, McGuire D, Charapata SG, Staats PS, Wallace MS, Grove GW, Vercruysse P. Continuous Intrathecal Infusion of Ziconotide for Treatment of Chronic Malignant and Nonmalignant Pain Over 12 Months: A Prospective, Open label Study. Neuromodulation 2008;11:40-49.

[78] Engel GL. The need for a new medical model: a challenge for biomedicine. Science 1977; 196:129-136.

[79] Erdine S, De Andres J. Drug delivery systems. Pain Pract 2006;6:51-57.

[80] Eriksson L, Byrne T, Johansson E, Trygg J, Vikström C. Multi- and Megavariate Data Analysis: Basic Principles and Applications. Malmö: MKS Umetrics AB, 2013.

[81] Facchinetti F, Nappi G, Martignoni E, Antoni G, Parrini D, Genazzani AR. Different patterns of central and peripheral beta EP, beta LPH and ACTH throughout life. Peptides 1983;4:469-474. 
[82] Falco FJ, Patel VB, Hayek SM, Deer TR, Geffert S, Zhu J, Onyewu O, Coubarous S, Smith HS, Manchikanti L. Intrathecal infusion systems for long-term management of chronic non-cancer pain: an update of assessment of evidence. Pain Physician 2013;16:SE185-216.

[83] Fan J, Shimizu Y, Chan J, Wilkinson A, Ito A, Tontonoz P, Dullaghan E, Galea LA, Pfeifer T, Wellington CL. Hormonal modulators of glial ABCA1 and apoE levels. J Lipid Res 2013;54:3139-3150.

[84] Finnerup NB, Baastrup C. Angiotensin II: from blood pressure to pain control. Lancet 2014;383:1613-1614.

[85] Fitzgibbon DR, Chapman CR. Cancer Pain: Assessment and Diagnosis. . In: JD Loeser, editor. Bonica's management of pain. Philadelphia, PA: Lippincott Williams \& Wilkins, 2001.

[86] Follett KA, Hitchon PW, Piper J, Kumar V, Clamon G, Jones MP. Response of intractable pain to continuous intrathecal morphine: a retrospective study. Pain 1992;49:21-25.

[87] Fujiwara N, Shimoji K, Kumagai Y, Endoh H, Fukuda S. Effects of dorsal root entry zone lesions on CSF and plasma neuropeptides and catecholamines. Acta Neurochir (Wien) 1992;117:38-43.

[88] Gatchel RJ, Peng YB, Peters ML, Fuchs PN, Turk DC. The biopsychosocial approach to chronic pain: scientific advances and future directions. Psychol Bull 2007;133:581.

[89] Gebert E, Sarubin J, Yoeung KA. Morphin intrathekal - zur Bekämpfung von tumorbedingten und postoperativen Schmerzen. Anaesthesist 1980;29:653-655.

[90] Gerdle B, Bjork J, Henriksson C, Bengtsson A. Prevalence of current and chronic pain and their influences upon work and healthcare-seeking: a population study. J Rheumatol 2004;31:1399-1406.

[91] Gestin Y, Vainio A, Pegurier AM. Long-term intrathecal infusion of morphine in the home care of patients with advanced cancer. Acta Anaesthesiol Scand 1997;41:1217.

[92] Ghidoni R, Benussi L, Paterlini A, Albertini V, Binetti G, Emanuele E. Cerebrospinal fluid biomarkers for Alzheimer's disease: the present and the future. Neurodegener Dis 2011;8:413-420.

[93] Glanz K, Rimer BK, Viswanath K. Health Behavior and Health Education - Theory, Research, and Practice. San Francisco: John Wiley \& Sons, 2008.

[94] Gollin PA, Kalaria RN, Eikelenboom P, Rozemuller A, Perry G. Alpha 1-antitrypsin and alpha 1-antichymotrypsin are in the lesions of Alzheimer's disease. Neuroreport 1992;3:201-203.

[95] Gosselin RD, Suter MR, Ji RR, Decosterd I. Glial cells and chronic pain. Neuroscientist 2010;16:519-531. 
[96] Grace PM, Hutchinson MR, Maier SF, Watkins LR. Pathological pain and the neuroimmune interface. Nat Rev Immunol 2014;14:217-231.

[97] Grady K. Intrathecal Drug Delivery for the Management of Pain and Spasticity in Adults: Recommendations for best clinical practice. London: The British Pain Society, 2008.

[98] Grigsby E, McGlothlen G. Single-shot Bolus Trialing to Assess Patient Response to Intrathecal Ziconotide. Available from http://asracom/display_fall_2010php?id=14 2010 (7 december 2012).

[99] Grünenthal Group. Available from http://www.change-pain.se/grt-change-painportal/285200237.jsp (31 January 2015).

[100] Guindon J, Hohmann AG. The endocannabinoid system and pain. CNS Neurol Disord Drug Targets 2009;8:403-421.

[101] Guo SL, Han CT, Jung JL, Chen WJ, Mei JJ, Lee HC, Cheng YC. Cystatin C in cerebrospinal fluid is upregulated in elderly patients with chronic osteoarthritis pain and modulated through matrix metalloproteinase 9-specific pathway. Clin J Pain 2014;30:331-339.

[102] Gustavsson A, Bjorkman J, Ljungcrantz C, Rhodin A, Rivano-Fischer M, Sjolund KF, Mannheimer C. Socio-economic burden of patients with a diagnosis related to chronic pain--register data of 840,000 Swedish patients. Eur J Pain 2012;16:289299.

[103] Hamel E. CSF-endorphines in acute and chronic brain lesions. Neurosurg Rev 1988;11:193-199.

[104] Hansson P. Translational aspects of central sensitization induced by primary afferent activity: what it is and what it is not. Pain 2014;155:1932-1934.

[105] Hartman AL. Normal Anatomy of the Cerebrospinal Fluid Compartment. In: DN Irani, editor. Cerebrospinal Fluid in Clinical Practice. Philadelphia, PA: Saunders, 2009. pp. 5-10.

[106] Haugen DF, Hjermstad MJ, Hagen N, Caraceni A, Kaasa S. Assessment and classification of cancer breakthrough pain: a systematic literature review. Pain 2010;149:476-482.

[107] Hawker GA, Mian S, Kendzerska T, French M. Measures of adult pain: Visual Analog Scale for Pain (VAS Pain), Numeric Rating Scale for Pain (NRS Pain), McGill Pain Questionnaire (MPQ), Short-Form McGill Pain Questionnaire (SF-MPQ), Chronic Pain Grade Scale (CPGS), Short Form-36 Bodily Pain Scale (SF-36 BPS), and Measure of Intermittent and Constant Osteoarthritis Pain (ICOAP). Arthritis Care Res (Hoboken) 2011;63 Suppl 11:S240-252.

[108] Heinricher MM, Tavares I, Leith JL, Lumb BM. Descending control of nociception: Specificity, recruitment and plasticity. Brain Res Rev 2009;60:214-225.

[109] Hua S, An HJ. Glycoscience aids in biomarker discovery. BMB Rep 2012;45:323330. 
[110] Hultin-Rosenberg L. Multivariate analysis of cancer proteomics data - towards a biological systems view and understanding (PhD thesis). Stockholm: Karolinska institutet, 2013.

[111] Indo Y. Nerve growth factor, pain, itch and inflammation: lessons from congenital insensitivity to pain with anhidrosis. Expert Rev Neurother 2010;10:1707-1724.

[112] Ingvar M. Vad är vetenskap och 100 andra jätteviktiga frågor. Langenskiöld, 2012.

[113] Irani DN. Properties and Composition of Normal Cerebrospinal Fluid. In: DN Irani, editor. Cerebrospinal Fluid in Clinical Practice. Philadelphia, PA: Saunders, 2009. pp. 67-89.

[114] Jakobsson U. The epidemiology of chronic pain in a general population: results of a survey in southern Sweden. Scand J Rheumatol 2010; 39:421-9.

[115] Jensen ON. Modification-specific proteomics: characterization of post-translational modifications by mass spectrometry. Curr Opin Chem Biol 2004;8:33-41.

[116] Jensen TS, Baron R, Haanpaa M, Kalso E, Loeser JD, Rice AS, Treede RD. A new definition of neuropathic pain. Pain 2011;152:2204-2205.

[117] Jeon Y, Huh BK. Spinal cord stimulation for chronic pain. Ann Acad Med Singapore 2009;38:998-1003.

[118] Jesse S, Lehnert S, Jahn O, Parnetti L, Soininen H, Herukka SK, Steinacker P, Tawfik S, Tumani H, von Arnim CA, Neumann M, Kretzschmar HA, Kulaksiz H, Lenter M, Wiltfang J, Ferger B, Hengerer B, Otto M. Differential sialylation of serpin A1 in the early diagnosis of Parkinson's disease dementia. PLoS One 2012;7:e48783.

[119] Jimenez-Andrade JM, Mantyh WG, Bloom AP, Ferng AS, Geffre CP, Mantyh PW. Bone cancer pain. Ann N Y Acad Sci 2010;1198:173-181.

[120] Kalso E. Biomarkers for pain. Pain 2004;107:199-201.

[121] Kane CM, Hoskin P, Bennett MI. Cancer induced bone pain. BMJ 2015;350:h315.

[122] Karve TM, Cheema AK. Small changes huge impact: the role of protein posttranslational modifications in cellular homeostasis and disease. J Amino Acids 2011;2011:207691.

[123] Kedlaya D, Reynolds L, Waldman S. Epidural and intrathecal analgesia for cancer pain. Best Pract Res Clin Anaesthesiol 2002;16:651-665.

[124] Kehlet H, Jensen TS, Woolf CJ. Persistent postsurgical pain: risk factors and prevention. Lancet 2006;367:1618-1625.

[125] Keramaris NC, Kanakaris NK, Tzioupis C, Kontakis G, Giannoudis PV. Translational research: from benchside to bedside. Injury 2008;39:643-650.

[126] Khasabov SG, Rogers SD, Ghilardi JR, Peters CM, Mantyh PW, Simone DA. Spinal neurons that possess the substance $\mathrm{P}$ receptor are required for the development of central sensitization. J Neurosci 2002;22:9086-9098.

[127] Kim MS, Pinto SM, Getnet D, Nirujogi RS, Manda SS, Chaerkady R, Madugundu AK, Kelkar DS, Isserlin R, Jain S, Thomas JK, Muthusamy B, Leal-Rojas P, Kumar 
P, Sahasrabuddhe NA, Balakrishnan L, Advani J, George B, Renuse S, Selvan LD, Patil AH, Nanjappa V, Radhakrishnan A, Prasad S, Subbannayya T, Raju R, Kumar M, Sreenivasamurthy SK, Marimuthu A, Sathe GJ, Chavan S, Datta KK, Subbannayya Y, Sahu A, Yelamanchi SD, Jayaram S, Rajagopalan P, Sharma J, Murthy KR, Syed N, Goel R, Khan AA, Ahmad S, Dey G, Mudgal K, Chatterjee A, Huang TC, Zhong J, Wu X, Shaw PG, Freed D, Zahari MS, Mukherjee KK, Shankar S, Mahadevan A, Lam H, Mitchell CJ, Shankar SK, Satishchandra P, Schroeder JT, Sirdeshmukh R, Maitra A, Leach SD, Drake CG, Halushka MK, Prasad TS, Hruban RH, Kerr CL, Bader GD, Iacobuzio-Donahue CA, Gowda H, Pandey A. A draft map of the human proteome. Nature 2014;509:575-581.

[128] Kleggetveit IP, Namer B, Schmidt R, Helas T, Ruckel M, Orstavik K, Schmelz M, Jorum E. High spontaneous activity of C-nociceptors in painful polyneuropathy. Pain 2012;153:2040-2047.

[129] Koneru A, Satyanarayana S, Rizwan S. Endogenous opioids: their physiological role and receptors. Global J Pharmacol 2009;3:149-153.

[130] Kosek E, Ordeberg G. Lack of pressure pain modulation by heterotopic noxious conditioning stimulation in patients with painful osteoarthritis before, but not following, surgical pain relief. Pain 2000;88:69-78.

[131] Kosten TR, Kreek MJ, Swift C, Carney MK, Ferdinands L. Beta endorphin levels in CSF during methadone maintenance. Life Sci 1987;41:1071-1076.

[132] Kress HG, Simpson KH, Marchettini P, Ver Donck A, Varrassi G. Intrathecal therapy: what has changed with the introduction of ziconotide. Pain Pract 2009;9:338-347.

[133] Lambert DG, Bird MF, Rowbotham DJ. Cebranopadol: a first in-class example of a nociceptin/orphanin FQ receptor and opioid receptor agonist. Br J Anaesth 2015; 114:364-6.

[134] Leavens ME, Hill CS, Jr., Cech DA, Weyland JB, Weston JS. Intrathecal and intraventricular morphine for pain in cancer patients: initial study. J Neurosurg 1982;56:241-245.

[135] Lee MY, Kim SY, Choi JS, Lee IH, Choi YS, Jin JY, Park SJ, Sung KW, Chun MH, Kim IS. Upregulation of haptoglobin in reactive astrocytes after transient forebrain ischemia in rats. J Cereb Blood Flow Metab 2002;22:1176-1180.

[136] Leong ML, Gu M, Speltz-Paiz R, Stahura EI, Mottey N, Steer CJ, Wessendorf M. Neuronal loss in the rostral ventromedial medulla in a rat model of neuropathic pain. J Neurosci 2011;31:17028-17039.

[137] Lewis GN, Heales L, Rice DA, Rome K, McNair PJ. Reliability of the conditioned pain modulation paradigm to assess endogenous inhibitory pain pathways. Pain Res Manag 2012;17:98-102.

[138] Lindh C, Liu Z, Lyrenas S, Ordeberg G, Nyberg F. Elevated cerebrospinal fluid substance P-like immunoreactivity in patients with painful osteoarthritis, but not in patients with rhizopatic pain from a herniated lumbar disc. Scand J Rheumatol 1997;26:468-472. 
[139] Linnman C. New pieces for the substance P puzzle. Pain 2013;154:966-967.

[140] Linton SJ, Bergbom S. Understanding the link between depression and pain. Scand J Pain 2011;2:47-54.

[141] Loeser JD, Treede RD. The Kyoto protocol of IASP Basic Pain Terminology. Pain 2008;137:473-477.

[142] Lundborg C, Dahm P, Nitescu P, Biber B. High intrathecal bupivacaine for severe pain in the head and neck. Acta Anaesthesiol Scand 2009;53:908-913.

[143] Lundborg C, Hahn-Zoric M, Biber B, Hansson E. Glial cell line-derived neurotrophic factor is increased in cerebrospinal fluid but decreased in blood during long-term pain. J Neuroimmunol 2010;220:108-113.

[144] Maier C, Gockel HH, Gruhn K, Krumova EK, Edel MA. Increased risk of suicide under intrathecal ziconotide treatment? - a warning. Pain 2011;152:235-237.

[145] Manchikanti L, Helm S, 2nd, Fellows B, Janata JW, Pampati V, Grider JS, Boswell MV. Opioid epidemic in the United States. Pain Physician 2012;15:ES9-38.

[146] Mannes AJ, Martin BM, Yang HY, Keller JM, Lewin S, Gaiser RR, Iadarola MJ. Cystatin $\mathrm{C}$ as a cerebrospinal fluid biomarker for pain in humans. Pain 2003; 102:251-256.

[147] Mao J. Translational pain research: achievements and challenges. J Pain 2009;10:1001-1011.

[148] Marion E, Song OR, Christophe T, Babonneau J, Fenistein D, Eyer J, Letournel F, Henrion D, Clere N, Paille V, Guerineau NC, Saint Andre JP, Gersbach P, Altmann KH, Stinear TP, Comoglio Y, Sandoz G, Preisser L, Delneste Y, Yeramian E, Marsollier L, Brodin P. Mycobacterial toxin induces analgesia in buruli ulcer by targeting the Angiotensin pathways. Cell 2014;157:1565-1576.

[149] Marvizon JC, Ma Y-Y, Charles AC, Walwyn W, Evans JE. Pharmacology of the Opioid System. In: P Beaulieu, D Lussier, F Porreca, AH Dickenson, editors. Pharmacology of Pain. Seattle: IASP Press, 2010. pp. 87-110.

[150] Matthews JN, Altman DG, Campbell MJ, Royston P. Analysis of serial measurements in medical research. BMJ 1990;300:230-235.

[151] McCarthy C, Saldova R, Wormald MR, Rudd PM, McElvaney NG, Reeves EP. The role and importance of glycosylation of acute phase proteins with focus on alpha-1 antitrypsin in acute and chronic inflammatory conditions. J Proteome Res 2014;13:3131-3143.

[152] McGivern JG. Ziconotide: a review of its pharmacology and use in the treatment of pain. Neuropsychiatr Dis Treat 2007;3:69-85.

[153] Melzack R. From the gate to the neuromatrix. Pain 1999;Suppl 6:S121-126.

[154] Melzack R, Wall PD. Pain mechanisms: a new theory. Science 1965;150:971-979. 
[155] Mercadante S, Intravaia G, Villari P, Ferrera P, Riina S, David F, Mangione S. Intrathecal treatment in cancer patients unresponsive to multiple trials of systemic opioids. Clin J Pain 2007;23:793-798.

[156] Merskey H. The taxonomy of pain. Med Clin North Am 2007;91:13-20, vii.

[157] Mika J, Zychowska M, Popiolek-Barczyk K, Rojewska E, Przewlocka B. Importance of glial activation in neuropathic pain. Eur J Pharmacol 2013;716:106-119.

[158] Miljanich GP. Ziconotide: neuronal calcium channel blocker for treating severe chronic pain. Curr Med Chem 2004;11:3029-3040.

[159] Miller RJ, Jung H, Bhangoo SK, White FA. Cytokine and chemokine regulation of sensory neuron function. Handb Exp Pharmacol 2009:417-449.

[160] Minde J. Norrbottnian congenital insensitivity to pain ( $\mathrm{PhD}$ thesis). Umeå: Umeå University, 2006.

[161] Mohammed SI, Eldabe S, Simpson KH, Brookes M, Madzinga G, Gulve A, Baranidharan G, Radford H, Crowther T, Buchser E, Perruchoud C, Batterham AM. Bolus intrathecal injection of ziconotide (Prialt(R)) to evaluate the option of continuous administration via an implanted intrathecal drug delivery (ITDD) system: a pilot study. Neuromodulation 2013;16:576-581; discussion 582.

[162] Moons KG, Biesheuvel CJ, Grobbee DE. Test research versus diagnostic research. Clin Chem 2004;50:473-476.

[163] Morikawa M, Fryer JD, Sullivan PM, Christopher EA, Wahrle SE, DeMattos RB, O'Dell MA, Fagan AM, Lashuel HA, Walz T, Asai K, Holtzman DM. Production and characterization of astrocyte-derived human apolipoprotein $\mathrm{E}$ isoforms from immortalized astrocytes and their interactions with amyloid-beta. Neurobiol Dis 2005; 19:66-76.

[164] Morrison BM. Physiology of cerebrospinal fluid secretion, recirculation and resorption. In: DN Irani, editor. Cerebrospinal fluid in Clinical practice. Philadelphia: Saunders, 2009. pp. 11-17.

[165] Mulvey MR, Rolke R, Klepstad P, Caraceni A, Fallon M, Colvin L, Laird B, Bennett MI; IASP Cancer Pain SIG and the EAPC Research Network. Confirming neuropathic pain in cancer patients: applying the NeuPSIG grading system in clinical practice and clinical research. Pain 2014;155:859-863.

[166] Myers J, Chan V, Jarvis V, Walker-Dilks C. Intraspinal techniques for pain management in cancer patients: a systematic review. Support Care Cancer 2010;18:137-149.

[167] Nagamitsu S, Matsuishi T, Komori H, Yamashita Y, Eguchi H, Ichikawa K, Fujimoto T, Kato H. Age-related changes in the cerebrospinal fluid level of beta-endorphin and substance P. Short communication. J Neural Transm 1998;105:53-58.

[168] Nemoto W, Nakagawasai O, Yaoita F, Kanno S, Yomogida S, Ishikawa M, Tadano T, Tan-No K. Angiotensin II produces nociceptive behavior through spinal AT1 receptor-mediated p38 mitogen-activated protein kinase activation in mice. Mol Pain 2013;9:38. 
[169] Niederberger E, Geisslinger G. Proteomics in neuropathic pain research. Anesthesiology 2008;108:314-323.

[170] Niederberger E, Kuhlein H, Geisslinger G. Update on the pathobiology of neuropathic pain. Expert Rev Proteomics 2008;5:799-818.

[171] Nitescu P, Dahm P, Appelgren L, Curelaru I. Continuous infusion of opioid and bupivacaine by externalized intrathecal catheters in long-term treatment of "refractory" nonmalignant pain. Clin J Pain 1998;14:17-28.

[172] Nitescu P, Sjoberg M, Appelgren L, Curelaru I. Complications of intrathecal opioids and bupivacaine in the treatment of "refractory" cancer pain. Clin J Pain 1995;11:4562.

[173] Niv D, Devor M. Chronic pain as a disease in its own right. Pain Pract 2004;4:179181.

[174] Obafemi A, Roth B. Prolonged delirium with psychotic features from omega conotoxin toxicity. Pain Med 2013;14:447-448.

[175] Okano D. Single-Shot Intrathecal Ziconotide to Predict Its Pump Infusion Effect. Available from http://aapmconfexcom/aapm/2008am/techprogram/P2851HTM 2008 (7 december 2012).

[176] Onofrio BM, Yaksh TL. Long-term pain relief produced by intrathecal morphine infusion in 53 patients. J Neurosurg 1990;72:200-209.

[177] Onofrio BM, Yaksh TL, Arnold PG. Continuous low-dose intrathecal morphine administration in the treatment of chronic pain of malignant origin. Mayo Clin Proc 1981;56:516-520.

[178] Oreskovic D, Klarica M. The formation of cerebrospinal fluid: nearly a hundred years of interpretations and misinterpretations. Brain Res Rev 2010;64:241-262.

[179] Ossipov MH, Dussor GO, Porreca F. Central modulation of pain. J Clin Invest 2010;120:3779-3787.

[180] Pan S, Chen R, Aebersold R, Brentnall TA. Mass spectrometry based glycoproteomics--from a proteomics perspective. Mol Cell Proteomics 2011;10:R110 003251.

[181] Pathan H, Williams J. Basic opioid pharmacology: an update. British Journal of Pain 2012;6:11-16.

[182] Paul M, Poyan Mehr A, Kreutz R. Physiology of local renin-angiotensin systems. Physiol Rev 2006;86:747-803.

[183] Pendyala G, Trauger SA, Kalisiak E, Ellis RJ, Siuzdak G, Fox HS. Cerebrospinal fluid proteomics reveals potential pathogenic changes in the brains of SIV-infected monkeys. J Proteome Res 2009;8:2253-2260.

[184] Perkins JR, Lees J, Antunes-Martins A, Diboun I, McMahon SB, Bennett DL, Orengo C. PainNetworks: A web-based resource for the visualisation of pain-related genes in the context of their network associations. Pain 2013;154:2586.e2581-2512. 
[185] Pert CB, Snyder SH. Opiate receptor: demonstration in nervous tissue. Science 1973;179:1011-1014.

[186] Pertovaara A. Noradrenergic pain modulation. Prog Neurobiol 2006;80:53-83.

[187] Peterson M, Svardsudd K, Appel L, Engler H, Aarnio M, Gordh T, Langstrom B, Sorensen J. PET-scan shows peripherally increased neurokinin 1 receptor availability in chronic tennis elbow: visualizing neurogenic inflammation? PLoS One 2013;8:e75859.

[188] Polit FD, Beck CT. Nursing Research. Philadelphia, PA: Lippincott Williams \& Wilkins, 2012.

[189] Pope JE, Deer TR. Ziconotide: a clinical update and pharmacologic review. Expert Opin Pharmacother 2013;14:957-966.

[190] Poras H, Bonnard E, Dange E, Fournie-Zaluski MC, Roques BP. New orally active dual enkephalinase inhibitors (DENKIs) for central and peripheral pain treatment. $\mathrm{J}$ Med Chem 2014;57:5748-5763.

[191] Portenoy RK, Hagen NA. Breakthrough pain: definition, prevalence and characteristics. Pain 1990;41:273-281.

[192] Pud D, Granovsky Y, Yarnitsky D. The methodology of experimentally induced diffuse noxious inhibitory control (DNIC)-like effect in humans. Pain 2009;144:1619.

[193] Rabilloud T. Two-dimensional gel electrophoresis in proteomics: old, old fashioned, but it still climbs up the mountains. Proteomics 2002;2:3-10.

[194] Rabilloud T, Lelong C. Two-dimensional gel electrophoresis in proteomics: a tutorial. J Proteomics 2011;74:1829-1841.

[195] Raffaeli W, Samolsky Dekel BG, Landuzzi D, Caminiti A, Righetti D, Balestri M, Montanari F, Romualdi P, Candeletti S. Nociceptin levels in the cerebrospinal fluid of chronic pain patients with or without intrathecal administration of morphine. $\mathrm{J}$ Pain Symptom Manage 2006;32:372-377.

[196] Raffaeli W, Sarti D, Demartini L, Sotgiu A, Bonezzi C. Italian registry on long-term intrathecal ziconotide treatment. Pain Physician 2011;14:15-24.

[197] Raphael J, Ahmedzai S, Hester J, Urch C, Barrie J, Williams J, Farquhar-Smith P, Fallon M, Hoskin P, Robb K, Bennett MI, Haines R, Johnson M, Bhaskar A, Chong S, Duarte R, Sparkes E. Cancer pain: part 1: Pathophysiology; oncological, pharmacological, and psychological treatments: a perspective from the British Pain Society endorsed by the UK Association of Palliative Medicine and the Royal College of General Practitioners. Pain Med 2010;11:742-764.

[198] Rauck RL, Cherry D, Boyer MF, Kosek P, Dunn J, Alo K. Long-term intrathecal opioid therapy with a patient-activated, implanted delivery system for the treatment of refractory cancer pain. J Pain 2003;4:441-447.

[199] Rauck RL, Wallace MS, Leong MS, Minehart M, Webster LR, Charapata SG, Abraham JE, Buffington DE, Ellis D, Kartzinel R. A randomized, double-blind, 
placebo-controlled study of intrathecal ziconotide in adults with severe chronic pain. J Pain Symptom Manage 2006;31:393-406.

[200] Read JC. The place of human psychophysics in modern neuroscience. Neuroscience 2015; 296: 116-29.

[201] Rhodin A. The rise of opiophobia: is history a barrier to prescribing? J Pain Palliat Care Pharmacother 2006;20:31-32.

[202] Rice AS, Dworkin RH, McCarthy TD, Anand P, Bountra C, McCloud PI, Hill J, Cutter G, Kitson G, Desem N, Raff M; EMA study group. EMA401, an orally administered highly selective angiotensin II type 2 receptor antagonist, as a novel treatment for postherpetic neuralgia: a randomised, double-blind, placebo-controlled phase 2 clinical trial. Lancet 2014;383:1637-1647.

[203] Rico RC, Hobika GH, Avellanosa AM, Trudnowski RJ, Rempel J, West CR. Use of intrathecal and epidural morphine for pain relief in patients with malignant diseases: a preliminary report. J Med 1982;13:223-231.

[204] Roche S, Gabelle A, Lehmann S. Clinical proteomics of the cerebrospinal fluid: Towards the discovery of new biomarkers. Proteomics Clinical Applications 2008;2:428-436.

[205] Rogowska-Wrzesinska A, Le Bihan MC, Thaysen-Andersen M, Roepstorff P. 2D gels still have a niche in proteomics. J Proteomics 2013;88:4-13.

[206] Romeo MJ, Espina V, Lowenthal M, Espina BH, Petricoin EF, 3rd, Liotta LA. CSF proteome: a protein repository for potential biomarker identification. Expert Rev Proteomics 2005;2:57-70.

[207] Rosenblum S. Intrathecal Bolus Injection of Ziconotide for Severe Chronic Pain: Evaluation of Analgesic Response. Anesthesiology 2008;109:A1566.

[208] Russell IJ, Orr MD, Littman B, Vipraio GA, Alboukrek D, Michalek JE, Lopez Y, MacKillip F. Elevated cerebrospinal fluid levels of substance $\mathrm{P}$ in patients with the fibromyalgia syndrome. Arthritis Rheum 1994;37:1593-1601.

[209] Sackett DL, Haynes RB. The architecture of diagnostic research. BMJ 2002;324:539541.

[210] Sakka L, Coll G, Chazal J. Anatomy and physiology of cerebrospinal fluid. Eur Ann Otorhinolaryngol Head Neck Dis 2011;128:309-316.

[211] Salter MW. Dorsal Horn Plasticity and Neuron-Microgila Interactions. In: I Tracey, editor. Pain 2012 Refresher Courses, 14ht World Congress On Pain. Seattle: IASP Press, 2012. pp. 15-25.

[212] Samuelsson H, Ekman R, Hedner T. CSF neuropeptides in cancer pain: effects of spinal opioid therapy. Acta Anaesthesiol Scand 1993;37:502-508.

[213] Sanford M. Intrathecal Ziconotide: A Review of Its Use in Patients with Chronic Pain Refractory to Other Systemic or Intrathecal Analgesics. CNS Drugs 2013;27:9891002. 
[214] Saulino M, Burton AW, Danyo DA, Frost S, Glanzer J, Solanki DR. Intrathecal ziconotide and baclofen provide pain relief in seven patients with neuropathic pain and spasticity: case reports. Eur J Phys Rehabil Med 2009;45:61-67.

[215] Schmidtko A, Lotsch J, Freynhagen R, Geisslinger G. Ziconotide for treatment of severe chronic pain. Lancet 2010;375:1569-1577.

[216] Schug SA, Zech D, Dorr U. Cancer pain management according to WHO analgesic guidelines. J Pain Symptom Manage 1990;5:27-32.

[217] Serra J. Microneurography: Towards a biomarker of spontaneous pain. Pain 2012;153:1989-1990.

[218] Shaheen PE, Walsh D, Lasheen W, Davis MP, Lagman RL. Opioid equianalgesic tables: are they all equally dangerous? J Pain Symptom Manage 2009;38:409-417.

[219] Sjoberg M, Appelgren L, Einarsson S, Hultman E, Linder LE, Nitescu P, Curelaru I. Long-term intrathecal morphine and bupivacaine in "refractory" cancer pain. I. Results from the first series of 52 patients. Acta Anaesthesiol Scand 1991;35:30-43.

[220] Sjoberg M, Nitescu P, Appelgren L, Curelaru I. Long-term intrathecal morphine and bupivacaine in patients with refractory cancer pain. Results from a morphine:bupivacaine dose regimen of $0.5: 4.75 \mathrm{mg} / \mathrm{ml}$. Anesthesiology 1994;80:284-297.

[221] Sjogren P, Ekholm O, Peuckmann V, Gronbaek M. Epidemiology of chronic pain in Denmark: an update. Eur J Pain 2009;13:287-292.

[222] Smith GD, Ebrahim S. Data dredging, bias, or confounding. BMJ 2002;325:14371438.

[223] Smith HS, Deer TR. Safety and efficacy of intrathecal ziconotide in the management of severe chronic pain. Ther Clin Risk Manag 2009;5:521-534.

[224] Smith HS, Deer TR, Staats PS, Singh V, Sehgal N, Cordner H. Intrathecal drug delivery. Pain Physician 2008;11:S89-S104.

[225] Smith MT, Lau T, Wallace VC, Wyse BD, Rice AS. Analgesic efficacy of smallmolecule angiotensin II type 2 receptor antagonists in a rat model of antiretroviral toxic polyneuropathy. Behav Pharmacol 2014;25:137-146.

[226] Smith TJ, Coyne PJ. Implantable drug delivery systems (IDDS) after failure of comprehensive medical management (CMM) can palliate symptoms in the most refractory cancer pain patients. J Palliat Med 2005;8:736-742.

[227] Smith TJ, Coyne PJ, Staats PS, Deer T, Stearns LJ, Rauck RL, Boortz-Marx RL, Buchser E, Catala E, Bryce DA, Cousins M, Pool GE. An implantable drug delivery system (IDDS) for refractory cancer pain provides sustained pain control, less drugrelated toxicity, and possibly better survival compared with comprehensive medical management (CMM). Ann Oncol 2005;16:825-833.

[228] Smith TJ, Staats PS, Deer T, Stearns LJ, Rauck RL, Boortz-Marx RL, Buchser E, Catala E, Bryce DA, Coyne PJ, Pool GE. Randomized clinical trial of an implantable drug delivery system compared with comprehensive medical management for 
refractory cancer pain: impact on pain, drug-related toxicity, and survival. J Clin Oncol 2002;20:4040-4049.

[229] Staats PS, Yearwood T, Charapata SG, Presley RW, Wallace MS, Byas-Smith M, Fisher R, Bryce DA, Mangieri EA, Luther RR, Mayo M, McGuire D, Ellis D. Intrathecal ziconotide in the treatment of refractory pain in patients with cancer or AIDS: a randomized controlled trial. JAMA 2004;291:63-70.

[230] Staniland AA, Walczak J-S, McMahon SB. Neurotrophic Factors, Neuropeptides, and Nitric Oxide: Therapeutic Targets in Chronic Pain Mechanisms. In: P Beaulieu, P Lussier, F Porreca, AH Dickenson, editors. Pharmacology of Pain. Seattle: IASP Press, 2010. pp. 253-278.

[231] Staud R. Abnormal endogenous pain modulation is a shared characteristic of many chronic pain conditions. Expert Rev Neurother 2012;12:577-585.

[232] Stephenson DT, Arneric SP. Neuroimaging of pain: advances and future prospects. J Pain 2008;9:567-579.

[233] Stålnacke B, Bäckryd E, Roeck Hansen E, Novo M, Gerdle B. Smärtanalys och Diagnossättning vid Kroniska Smärtor inom Specialiserad Smärtvård - Rapport 2014:3. Available from http://www.ucr.uu.se/nrs/index.php/arsrapporter (20 December 2014).

[234] Sullivan M, Karlsson J, Ware Jr JE. The Swedish SF-36 Health Survey-I. Evaluation of data quality, scaling assumptions, reliability and construct validity across general populations in Sweden. Social science \& medicine 1995;41:1349-1358.

[235] Sullivan MJ, Bishop SR, Pivik J. The pain catastrophizing scale: development and validation. Psychological assessment 1995;7:524-532.

[236] Tiwari V, Guan Y, Raja SN. Modulating the delicate glial-neuronal interactions in neuropathic pain: Promises and potential caveats. Neurosci Biobehav Rev 2014;45C:19-27.

[237] Todd AJ. Neuronal Circuits and Receptors Involved in Spinal Cord Pain Processing. In: J Castro-Lopes, editor. Current Topics in Pain - 12th World Congress on Pain. Seattle: IASP Press, 2009. pp. 25-51.

[238] Tonelli L, Setti T, Falasca A, Martignoni E, Torcia E, Calcaterra FM, Merli GA, Facchinetti F. Investigation on cerebrospinal fluid opioids and neurotransmitters related to spinal cord stimulation. Appl Neurophysiol 1988;51:324-332.

[239] Treede RD, Jensen TS, Campbell JN, Cruccu G, Dostrovsky JO, Griffin JW, Hansson P, Hughes R, Nurmikko T, Serra J. Neuropathic pain: redefinition and a grading system for clinical and research purposes. Neurology 2008;70:1630-1635.

[240] Treede RD, Rief W, Barke A, Aziz Q, Bennett MI, Benoliel R, Cohen M, Evers S, Finnerup NB, First MB, Giamberardino MA, Kaasa S, Kosek E, Lavand'homme P, Nicholas M, Perrot S, Scholz J, Schug S, Smith BH, Svensson P, Vlaeyen JW, Wang SJ. A classification of chronic pain for ICD-11. Pain 2015; 156:1003-7. 
[241] Turk DC, Okifuji A. Pain Terms and Taxonomies of Pain. In: JD Loeser, editor. Bonica's Management of Pain. Philadelphia, PA, USA: Lippincott Williams \& Wilkins, 2001. pp. 17-25.

[242] Turner JA, Sears JM, Loeser JD. Programmable intrathecal opioid delivery systems for chronic noncancer pain: a systematic review of effectiveness and complications. Clin J Pain 2007;23:180-195.

[243] Wadensten B, Frojd C, Swenne CL, Gordh T, Gunningberg L. Why is pain still not being assessed adequately? Results of a pain prevalence study in a university hospital in Sweden. J Clin Nurs 2011;20:624-634.

[244] Vaeroy H, Helle R, Forre O, Kass E, Terenius L. Cerebrospinal fluid levels of betaendorphin in patients with fibromyalgia (fibrositis syndrome). J Rheumatol 1988;15:1804-1806.

[245] Vaeroy H, Helle R, Forre O, Kass E, Terenius L. Elevated CSF levels of substance P and high incidence of Raynaud phenomenon in patients with fibromyalgia: new features for diagnosis. Pain 1988;32:21-26.

[246] Wallace M, Charapata S, Fisher R, Byas-Smith M, Staats P, Mayo M, McGuire D, Ellis D. Intrathecal ziconotide in the treatment of chronic nonmalignant pain: a randomized, double-blind, placebo-controlled clinical trial. Neuromodulation 2006;9:75-86.

[247] Wallace MS, Rauck R, Fisher R, Charapata SG, Ellis D, Dissanayake S. Intrathecal ziconotide for severe chronic pain: safety and tolerability results of an open-label, long-term trial. Anesth Analg 2008;106:628-637.

[248] Vallejo R, Tilley DM, Vogel L, Benyamin R. The role of glia and the immune system in the development and maintenance of neuropathic pain. Pain Pract 2010;10:167184.

[249] Van de Ven TJ, John Hsia HL. Causes and prevention of chronic postsurgical pain. Curr Opin Crit Care 2012;18:366-371.

[250] van den Beuken-van Everdingen MH, de Rijke JM, Kessels AG, Schouten HC, van Kleef M, Patijn J. Prevalence of pain in patients with cancer: a systematic review of the past 40 years. Ann Oncol 2007;18:1437-1449.

[251] van Dongen RT, Crul BJ, van Egmond J. Intrathecal coadministration of bupivacaine diminishes morphine dose progression during long-term intrathecal infusion in cancer patients. Clin J Pain 1999;15:166-172.

[252] van Wijk G, Veldhuijzen DS. Perspective on diffuse noxious inhibitory controls as a model of endogenous pain modulation in clinical pain syndromes. J Pain 2010;11:408-419.

[253] Wang JK, Nauss LA, Thomas JE. Pain relief by intrathecally applied morphine in man. Anesthesiology 1979;50:149-151.

[254] Ward M, Langton JA. Blood pressure measurement. Contin Educ Anaesth Crit Care Pain 2007;7:122-126. 
[255] Vargas-Schaffer G. Is the WHO analgesic ladder still valid? Twenty-four years of experience. Can Fam Physician 2010;56:514-517, e202-515.

[256] Watkins LR, Milligan ED, Maier SF. Mechanisms of Glial Activation after Nerve Injury. In: AI Basbaum, MC Bushnell, editors. Science of Pain. Oxford, UK \& San Diego, CA, USA: Elsevier, 2009. pp. 429-433.

[257] Webster LR. The Relationship Between the Mechanisms of Action and Safety Profiles of Intrathecal Morphine and Ziconotide: A Review of the Literature. Pain Med 2015; 16:1265-1277.

[258] Webster LR, Fisher R, Charapata S, Wallace MS. Long-term intrathecal ziconotide for chronic pain: an open-label study. J Pain Symptom Manage 2009;37:363-372.

[259] Veening JG, Gerrits PO, Barendregt HP. Volume transmission of beta-endorphin via the cerebrospinal fluid; a review. Fluids Barriers CNS 2012;9:16.

[260] Ver Donck A, Collins R, Rauck R, Nitescu P. An open-label, multicenter study of the safety and efficacy of intrathecal ziconotide for severe chronic pain when delivered via an external pump. Neuromodulation 2008;11:103-111.

[261] Wheelock AM, Wheelock CE. Trials and tribulations of 'omics data analysis: assessing quality of SIMCA-based multivariate models using examples from pulmonary medicine. Mol Biosyst 2013;9:2589-2596.

[262] WHO. Cancer Pain Relief: with a guide to opioid availability. Geneva: World Health Organization, 1996.

[263] Wise TN, Fishbain DA, Holder-Perkins V. Painful physical symptoms in depression: a clinical challenge. Pain Med 2007;8 Suppl 2:S75-82.

[264] Vlaeyen JW, Linton SJ. Fear-avoidance model of chronic musculoskeletal pain: 12 years on. Pain 2012;153:1144-1147.

[265] Wold S, Sjöström M, Eriksson L. PLS-regression: a basic tool of chemometrics. Chemometrics and intelligent laboratory systems 2001;58:109-130.

[266] Woolf CJ. Evidence for a central component of post-injury pain hypersensitivity. Nature 1983;306:686-688.

[267] Woolf CJ. Pain: moving from symptom control toward mechanism-specific pharmacologic management. Ann Intern Med 2004;140:441-451.

[268] Woolf CJ. Central sensitization: implications for the diagnosis and treatment of pain. Pain 2011;152:S2-15.

[269] Woolf CJ, Bennett GJ, Doherty M, Dubner R, Kidd B, Koltzenburg M, Lipton R, Loeser JD, Payne R, Torebjork E. Towards a mechanism-based classification of pain? Pain 1998;77:227-229.

[270] Wu J, Wei Y, Shi J, Chen F, Huang G, Chen J, Xia J. The potential therapeutic targets to bone pain induced by cancer metastasis. J Cancer Res Ther 2013;9 Suppl:S135141. 
[271] Yaksh TL, Rudy TA. Analgesia mediated by a direct spinal action of narcotics. Science 1976;192:1357-1358.

[272] Yarnitsky D. Role of endogenous pain modulation in chronic pain mechanisms and treatment. Pain 2015;156 Suppl 1:S24-31.

[273] You JS, Gelfanova V, Knierman MD, Witzmann FA, Wang M, Hale JE. The impact of blood contamination on the proteome of cerebrospinal fluid. Proteomics 2005;5:290-296.

[274] Zech DF, Grond S, Lynch J, Hertel D, Lehmann KA. Validation of World Health Organization Guidelines for cancer pain relief: a 10-year prospective study. Pain 1995;63:65-76.

[275] Zhang J, Goodlett DR, Peskind ER, Quinn JF, Zhou Y, Wang Q, Pan C, Yi E, Eng J, Aebersold RH, Montine TJ. Quantitative proteomic analysis of age-related changes in human cerebrospinal fluid. Neurobiol Aging 2005;26:207-227.

[276] Zigmond AS, Snaith RP. The hospital anxiety and depression scale. Acta Psychiatr Scand 1983;67:361-370. 
Part II

Appended Papers I-IV 



\section{Included Papers}

The articles associated with this thesis have been removed for copyright reasons. For more details about these see:

http://urn.kb.se/resolve?urn=urn:nbn:se:liu:diva-121494 